Igor Palmieri

\title{
Modelagem de sinais neuronais utilizando filtros lineares de tempo discreto
}


Igor Palmieri

\section{Modelagem de sinais neuronais utilizando filtros lineares de tempo discreto}

Dissertação apresentada à Escola Politécnica da Universidade de São Paulo para obtenção do Título de Mestre em Ciências. 
Igor Palmieri

\section{Modelagem de sinais neuronais utilizando filtros lineares de tempo discreto}

Dissertação apresentada à Escola Politécnica da Universidade de São Paulo para obtenção do Título de Mestre em Ciências.

Área de concentração:

Engenharia de Sistemas

Orientadora:

Profa. Dra. Maria D. Miranda 
Este exemplar foi revisado e corrigido em relação à versão original, sob responsabilidade única do autor e com a anuência de seu orientador.

São Paulo, de de

Assinatura do autor:

Assinatura do orientador:

Catalogação-na-publicação

Palmieri, Igor

Modelagem de sinais neuronais utilizando filtros lineares de tempo discreto / I. Palmieri -- versão corr. -- São Paulo, 2015.

$127 \mathrm{p}$.

Dissertação (Mestrado) - Escola Politécnica da Universidade de São Paulo. Departamento de Engenharia de Telecomunicações e Controle.

1.Identificação de sistemas 2.Processamento digital de sinais 3.Modelagem de sinais neuronais I.Universidade de São Paulo. Escola Politécnica. Departamento de Engenharia de Telecomunicações e Controle II.t. 


\section{Agradecimentos}

Este trabalho, e todo o aprendizado ao longo do programa de mestrado, não teriam sido possíveis sem a ajuda de algumas pessoas.

Agradeço à minha esposa, Tania Esther, minha maior inspiração para superar as dificuldades. Pela companhia e compreensão durante meus estudos.

À professora Maria D. Miranda pela paciência em discutir os rumos do trabalho e em compartilhar seu conhecimento. Pelo incontável tempo dedicado, e pela flexibilidade ao orientar o trabalho.

Ao professor Luiz H. A. Monteiro, pela ajuda no início da pós-graduação, e pelas contribuições sempre muito relevantes, especialmente na área de modelos neuronais.

À minha mãe, Tania Regina, pelos conselhos e pelo constante suporte. E a toda minha família, com quem os estudos concorreram pelo tempo disponível.

Aos amigos que estiveram próximos durante o desenvolvimento deste trabalho.

À Escola Politécnica da Universidade de São Paulo, que me possibilitou acesso a educação de ponta por muitos anos, desde a graduação. Reconheço o grande investimento realizado na minha formação acadêmica. 
This world is but a canvas to our imagination.

Henry David Thoreau 


\section{Resumo}

A aquisição experimental de sinais neuronais é um dos principais avanços da neurociência. Por meio de observações da corrente e do potencial elétricos em uma região cerebral, é possível entender os processos fisiológicos envolvidos na geração do potencial de ação, e produzir modelos matemáticos capazes de simular o comportamento de uma célula neuronal. Uma prática comum nesse tipo de experimento é obter leituras a partir de um arranjo de eletrodos posicionado em um meio compartilhado por diversos neurônios, o que resulta em uma mistura de sinais neuronais em uma mesma série temporal. Este trabalho propõe um modelo linear de tempo discreto para o sinal produzido durante o disparo do neurônio. Os coeficientes desse modelo são calculados utilizando-se amostras reais dos sinais neuronais obtidas in vivo. O processo de modelagem concebido emprega técnicas de identificação de sistemas e processamento de sinais, e é dissociado de considerações sobre o funcionamento biofísico da célula, fornecendo uma alternativa de baixa complexidade para a modelagem do disparo neuronal. Além disso, a representação por meio de sistemas lineares permite idealizar um sistema inverso, cuja função é recuperar o sinal original de cada neurônio ativo em uma mistura extracelular. Nesse contexto, são discutidas algumas soluções baseadas em filtros adaptativos para a simulação do sistema inverso, introduzindo uma nova abordagem para o problema de separação de spikes neuronais.

Palavras-chave: Identificação de sistemas. Modelagem de sinais neuronais. Parametrização de sinais. Spike sorting. 


\section{Abstract}

The experimental acquisition of neuronal signals is a major advance in neuroscience. Through observations of electric current and potential in a brain region, it is possible to understand the physiological processes involved in the action potential generation, and create mathematical models capable of simulating the behavior of the neuronal cell. A common practice in this kind of experiment is to obtain readings from an array of electrodes positioned in a medium shared by several neurons, which results in a mixture of neuronal signals in the same time series. This work proposes a discrete-time linear model of the neuronal signal during the firing of the cell. The coefficients of this model are estimated using real samples of the neuronal signals obtained in vivo. The conceived modeling process employs system identification and signal processing concepts, and is dissociated from any considerations about the biophysical function of the neuronal cell, providing a low-complexity alternative to model the neuronal spike. In addition, the use of a linear representation allows the idealization of an inverse system, whose main purpose is to recover the original signal of each active neuron in a given extracellular mixture. In this context, some solutions based on adaptive filters are discussed for the inverse model simulation, introducing a new approach to the problem of neuronal spike separation.

Keywords: System identification. Neuronal signal modeling. Signal parametrization. Spike sorting. 


\section{Lista de Figuras}

1.1 Etapas do processo de spike sorting . . . . . . . . . . . . . . . . . 17

1.2 Modelo idealizado . . . . . . . . . . . . . . . . . . . . 18

1.3 Modelo inverso utilizado como separador de impulsos . . . . . . . . . . . . 19

1.4 Posicionamento dos eletrodos para leitura simultânea . . . . . . . . . . . . 20

2.1 Principais fases do potencial de ação . . . . . . . . . . . . . . . . . . 25

2.2 Leitura intracelular vs. leitura extracelular. . . . . . . . . . . . . . 26

2.3 Modelo Hodgkin-Huxley . . . . . . . . . . . . . . . . . . . . . . . . . . . . 29

2.4 Resultados obtidos por Hodgkin e Huxley . . . . . . . . . . . . . . . . . . 29

2.5 Esquema básico do neurônio de McCulloch-Pitts . . . . . . . . . . . . . . . 34

2.6 Diagrama de bifurcação do modelo de Rulkov . . . . . . . . . . . . . 36

3.1 Etapas do processo de identificação de sistemas . . . . . . . . . . . . . . 41

3.2 Estrutura do modelo ARMA . . . . . . . . . . . . . . . . . 45

3.3 Diagrama de blocos do modelo Box-Jenkins . . . . . . . . . . . . . . 46

3.4 Diagrama de blocos do método de Shanks . . . . . . . . . . . . . . . . 49

4.1 Esquema do modelo para um neurônio isolado . . . . . . . . . . . . . 56

4.2 Modelo intracelular estendido . . . . . . . . . . . . . . . . . . . . 59

4.3 Estrutura do modelo SIMO f . . . . . . . . . . . . . . . . . 63

4.4 Estrutura do modelo MISO . . . . . . . . . . . . . . . . . . . 65

4.5 Estrutura do modelo MIMO . . . . . . . . . . . . . . . . . . 66

5.1 Efeito da filtragem do sinal extracelular . . . . . . . . . . . . . . . . 71

5.2 Efeito da filtragem do sinal intracelular . . . . . . . . . . . . . . . . . 72

5.3 Relação entre os sinais intracelular e extracelular . . . . . . . . . . . . . 72 
5.4 Valor médio do potencial de ação . . . . . . . . . . . . . . . . . . . 73

5.5 Valor médio do spike . . . . . . . . . . . . . . . . . . 73

5.6 Leitura do spike por mais de um eletrodo simultaneamente . . . . . . . . . 74

5.7 Função de autocorrelação parcial para o sinal intracelular . . . . . . . . . . . 75

5.8 Energia do erro de estimação vs. ordem do modelo $\quad$. . . . . . . . . . . . . 76

5.9 Resultado do modelo só-polo intracelular . . . . . . . . . . . . . . . . . 77

5.10 Sinais de saída dos diferentes modelos intracelulares . . . . . . . . . . . . . 78

5.11 Resultado do modelo média móvel extracelular . . . . . . . . . . . . . . . . 79

5.12 Saída do modelo obtido pela concatenação dos subsistemas . . . . . . . . . 81

5.13 Resultado do modelo ARX intracelular . . . . . . . . . . . . . . . . . . 82

5.14 Resultado do modelo ARX extracelular . . . . . . . . . . . . . . . . . . . 83

5.15 Modelagem de uma sequência de potenciais de ação . . . . . . . . . . . 85

5.16 Distribuição dos coeficientes do modelo intracelular . . . . . . . . . . . . 86

5.17 Modelagem de uma sequência de spikes . . . . . . . . . . . . . . 87

5.18 Distribuição dos coeficientes do modelo extracelular . . . . . . . . . . . . 88

5.19 Atraso na saída vs. sinal intracelular . . . . . . . . . . . . . . . . . . . 91

5.20 Erro residual do processo de modelagem . . . . . . . . . . . . . . . . . 92

5.21 Representação do modelo com ruído . . . . . . . . . . . . . . . . . . . . . . 92

5.22 Energia do erro para cada técnica de modelagem . . . . . . . . . . . . . . . 94

5.23 Resultados da modelagem adaptativa do sistema intracelular . . . . . . . . 96

5.24 Resultados da modelagem adaptativa do sistema extracelular . . . . . . . . 97

6.1 Modelagem inversa sobre o sinal extracelular . . . . . . . . . . . . . . 103

6.2 Resultados da simulação NLMS sobre o sinal extracelular . . . . . . . . . . . 104

6.3 Configuração para geração de uma sequência artificial de spikes . . . . . . . 106

6.4 Geração de uma série artificial de spikes . . . . . . . . . . . . . . . . . 107

6.5 Configuração para simulação de modelagem inversa MIMO . . . . . . . . . 108 
6.6 Resultado da simulação NLMS a partir do modelo MIMO . . . . . . . . . . 109

6.7 Erros de identificação vs. SNR para modelagem inversa . . . . . . . . . . . 111 


\section{Lista de Tabelas}

5.1 Coeficientes estimados para um único disparo isolado . . . . . . . . . . . 84

5.2 Valores médios dos coeficientes . . . . . . . . . . . . . . . . . . . . . 89

5.3 Valores médios dos coeficientes do modelo extracelular SIMO . . . . . . . . 90

5.4 Resultados da distribuição do erro residual . . . . . . . . . . . . . . . . . . 93

6.1 Coeficientes do modelo gerador de spikes para simulação . . . . . . . . . 110 


\section{Sumário}

1 Introdução

1.1 Motivação . . . . . . . . . . . . . . . . . . . . 15

1.1.1 O problema de Spike Sorting . . . . . . . . . . . . . . . . . 16

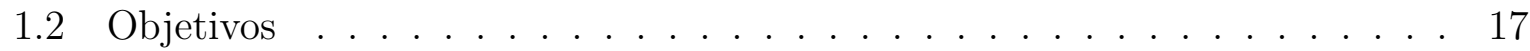

1.3 Métodos e Procedimentos . . . . . . . . . . . . . . . . . . . . . . . 19

1.4 A estrutura do trabalho . . . . . . . . . . . . . . . . . . . . 21

$2 \quad$ O sinal neuronal e seus modelos 23

2.1 O potencial de ação . . . . . . . . . . . . . . . . . . . . . 23

2.2 Propagação do potencial de ação . . . . . . . . . . . . . . . . . . . . . . 24

2.3 Aquisição experimental do sinal neuronal . . . . . . . . . . . . . . . . . 25

2.4 Métodos experimentais e modelos quantitativos . . . . . . . . . . . . . 27

2.4.1 Modelos de tempo contínuo . . . . . . . . . . . . . . . . 28

2.4.2 Modelos de tempo discreto . . . . . . . . . . . . . . . . 32

2.5 Contexto para uma nova abordagem . . . . . . . . . . . . . 36

$\begin{array}{lll}3 & \text { Identificação de Sistemas } & 38\end{array}$

3.1 Modelagem e Identificação de Sistemas . . . . . . . . . . . . . . . . . . . . 38

3.2 Etapas do processo de identificação . . . . . . . . . . . . . . . . . . . . 39

3.3 Modelos lineares e invariantes no tempo . . . . . . . . . . . . . . . . 41

3.3.1 Modelos AR e MA . . . . . . . . . . . . . . . . . . . 43

3.3 .2 Modelos ARMA . . . . . . . . . . . . . . . . . . . . 44

3.3.3 Modelos ARX, ARMAX e Box-Jenkins . . . . . . . . . . . . 45 
3.4 Estimação de parâmetros . . . . . . . . . . . . . . . . . . . . 46

3.4 .1 Método de Prony . . . . . . . . . . . . . . . . . . . . . . 47

3.4 .2 Método de Shanks . . . . . . . . . . . . . . . . . . . . . 49

3.4 .3 Identificação do sistema ARX . . . . . . . . . . . . . . . . . . . 51

3.4.4 Estimação das funções de autocorrelação . . . . . . . . . . . . . . . . 52

3.5 Conclusões . . . . . . . . . . . . . . . . . . . . 53

4 A modelagem proposta $\quad 55$

4.1 Modelo para um único neurônio . . . . . . . . . . . . . . . . . . . . 55

4.1.1 Modelo só-polo para o potencial de ação . . . . . . . . . . . . . . . 57

4.1.2 Estendendo o modelo intracelular . . . . . . . . . . . . . . . . . 59

4.1.3 Modelo média móvel para o sinal extracelular . . . . . . . . . . . . 60

4.1.4 Modelo do disparo como um sistema ARX . . . . . . . . . . . . . . 61

4.2 Modelo para múltiplos eletrodos . . . . . . . . . . . . . . . . . . . 62

4.3 Modelo para múltiplos neurônios ativos . . . . . . . . . . . . . . . . . . 64

4.4 Conclusões . . . . . . . . . . . . . . . . . . . . . . 67

5 A validação do modelo proposto $\quad 69$

5.1 Considerações sobre os dados experimentais . . . . . . . . . . . . . . . . 69

5.1.1 Ajustes de escala dos dados . . . . . . . . . . . . . . . . . 70

$5.1 .2 \quad$ Filtragem preliminar . . . . . . . . . . . . . . 70

5.1 .3 Variações na forma de onda do disparo . . . . . . . . . . . . . 72

5.2 A ordem dos modelos . . . . . . . . . . . . . . . . . . . 74

5.3 Modelo de um disparo isolado . . . . . . . . . . . . . . . . . . 76

5.3.1 Modelo só-polo intracelular . . . . . . . . . . . . . . . . 77

5.3.2 Modelo polo-zero intracelular . . . . . . . . . . . . . . . 78

5.3.3 Modelo média móvel extracelular . . . . . . . . . . . . . . . . . . . 79

5.3.4 Concatenação dos subsistemas . . . . . . . . . . . . . . . . . 80 
5.3.5 Resultados da modelagem ARX . . . . . . . . . . . . . . . . . 81

5.3.6 Valores estimados dos coeficientes . . . . . . . . . . . . . . 83

5.4 Representação de uma sequência de disparos . . . . . . . . . . . . . . . . . . . 84

5.4 Modelo intracelular . . . . . . . . . . . . . . . . 85

5.4 .2 Modelo extracelular . . . . . . . . . . . . . . . . 86

5.4 .3 Valores médios dos coeficientes . . . . . . . . . . . . . . 88

5.5 Múltiplos eletrodos de leitura . . . . . . . . . . . . . . . . . . . . . 89

5.6 Demais discussões relevantes . . . . . . . . . . . . . . . . . . . . . 90 90

5.6.1 Instante do disparo e sinal de entrada . . . . . . . . . . . . . . . 90

5.6 .2 Erro residual . . . . . . . . . . . . . . . . . . . . 91

5.6.3 Modelagem dinâmica adaptativa . . . . . . . . . . . . . . . . . 94

5.7 Conclusões . . . . . . . . . . . . . . . . . . . . . . . . . . . 98

$\begin{array}{lll}6 & \text { O modelo inverso } & 99\end{array}$

6.1 A representação do modelo inverso . . . . . . . . . . . . . . . . . . . . 99

6.2 Sistema inverso como um separador de fontes . . . . . . . . . . . 100

6.3 Solução adaptativa supervisionada . . . . . . . . . . . . . . . . . . . . . 102

6.3.1 Sistema inverso para um único neurônio . . . . . . . . . . . . . . . 102

6.3.2 Sistema inverso para múltiplos neurônios . . . . . . . . . . . . . 105

6.4 Discussão . . . . . . . . . . . . . . . . . . . . . . . 111

7 Conclusões e perspectivas $\quad 113$

7.1 Trabalhos futuros . . . . . . . . . . . . . . . . 115

$\begin{array}{ll}\text { Referências Bibliográficas } & 117\end{array}$

Apêndice A - Função custo para a estimação só-polo 122

Apêndice B - Solução do problema de estimação linear $\quad 124$ 
Apêndice C - Algoritmo RLS (Recursive Least Squares)

Apêndice D - Algoritmo NLMS (Normalized Least Mean Squares) 


\section{Introdução}

A modelagem matemática de sinais neuronais é um problema de grande relevância na neurociência. Esta questão foi impulsionada por avanços tecnológicos que permitiram a obtenção experimental do sinal neuronal em variadas situações, estabelecendo uma base para diversos modelos quantitativos encontrados na literatura (KOCH; SEGEV, 1998; STERRATT et al., 2011). Tais modelos têm sido amplamente empregados na solução de problemas computacionais (GAO et al., 2012; MENEZES; MONTEIRO, 2011) e para investigar o funcionamento de sistemas neuronais (MONTEIRO; BUSSAB; CHAUIBERLINCK, 2002; STEUBER; JAEGER, 2013).

São inúmeros os fatores físico-químicos envolvidos na geração do sinal neuronal, o que torna a modelagem uma tarefa especialmente difícil. Além disso, o comportamento de um neurônio é principalmente influenciado pelas conexões que realiza com as demais células nervosas, formando uma rede que por si só apresenta um desafio para representação matemática (DAYAN; ABBOTT, 2005). A maioria dos modelos existentes foi desenvolvida com o intuito de representar a dinâmica neuronal e sua interação com agentes externos. Entretanto, em diversas situações, uma parametrização simplificada associada somente com a forma de onda do sinal é de grande interesse.

\subsection{Motivação}

A construção de um modelo pode ser útil para representar de forma direta o sinal neuronal durante o disparo. Leituras intracranianas intracelulares e extracelulares tem sido historicamente utilizadas para o cálculo de parâmetros de modelos neuronais nãolineares de tempo contínuo, que procuram reproduzir explicitamente o funcionamento da membrana celular (GOLD et al., 2006; TABAK; MURPHEY; MOORE, 2000; WILLMS et al., 1999). Esses modelos, entretanto, podem apresentar um alto grau de complexidade, prejudicando simulações computacionais. Esse fato levou ao surgimento de modelos simplificados de tempo discreto, que permitiram a simulação de redes contendo diversos 
neurônios, abstraindo os processos fisiológicos da célula, mas ao mesmo tempo apresentando um comportamento qualitativamente similar ao de alguns tipos de neurônios conhecidos (GIRARDI-SCHAPPO; TRAGTENBERG; KINOUCHI, 2013). Modelos simplificados, no entanto, usualmente não fazem uso concreto de dados experimentais para estimativa de seus parâmetros. Nesse sentido, torna-se interessante a proposta de um modelo linear contendo um conjunto reduzido de parâmetros, e cujos valores são estimados a partir de leituras reais.

Além disso, existe um especial interesse sobre leituras extracelulares, que são mais simples de serem obtidas que leituras realizadas diretamente no corpo celular. O sinal extracelular é comumente captado por meio de arranjos de eletrodos posicionados no meio externo aos neurônios de uma determinada região cerebral. Consequentemente, o sinal observado contém uma mistura da atividade neuronal de várias células ativas nas proximidades do local onde os eletrodos foram inseridos. Separar os disparos de cada neurônio por meio do processamento dessa mistura permite identificar a atividade individual das células, e é um problema conhecido como spike sorting. Este problema depende diretamente da parametrização eficaz do sinal produzido durante o disparo, entre outros fatores. Um modelo simplificado da formação do sinal extracelular a partir de um estímulo pontual pode ser útil para entender as propriedades dos parâmetros relacionados ao disparo. Uma revisão sobre o spike sorting pode ser encontrada no trabalho de Gibson, Judy e Markovic (2012).

\subsubsection{O problema de Spike Sorting}

Técnicas de spike sorting baseiam-se na premissa de que o sinal captado em um eletrodo posicionado no meio externo apresenta características distintas para cada neurônio que estiver sendo observado. De um modo geral, essas técnicas são implementadas em três etapas principais (RUTISHAUSER; SCHUMAN; MAMELAK, 2006; QUIROGA; NÁDASDY; BEN-SHAUL, 2004): (i) detecção de spikes, (ii) extração de parâmetros e (iii) clustering dos spikes baseado nos parâmetros mapeados. A Figura 1.1 ilustra simplificadamente o processo de spike sorting a partir de um sinal extracelular.

Na etapa de detecção, o objetivo é encontrar o instante em que os spikes foram observados, preferencialmente de forma automática. Grande parte dos métodos aplicados nesta etapa envolve realçar o sinal para enfatizá-lo em relação ao ruído, e em seguida estabelecer um limiar a partir do qual pode-se considerar que um spike foi gerado (LEWICKI, 1998). Após a detecção, estes spikes são alinhados em relação a um ponto temporal em comum, 


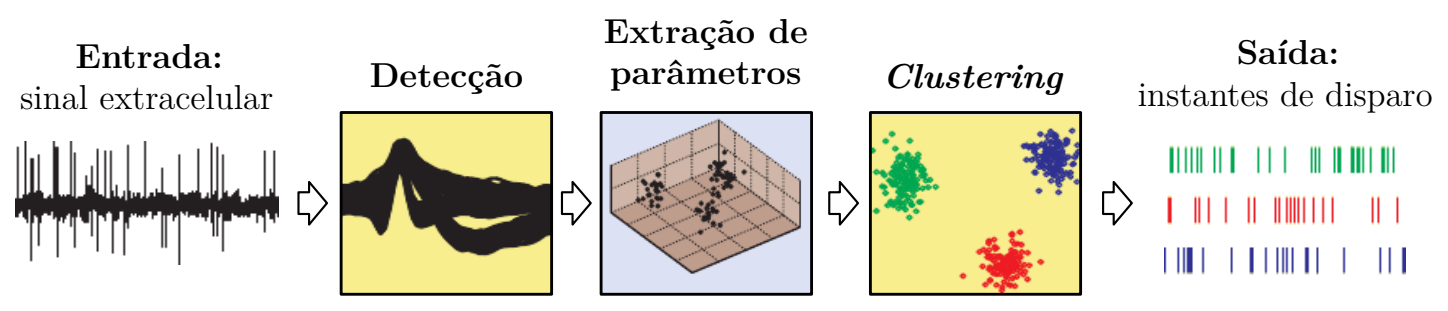

Figura 1.1: Etapas do processo de spike sorting: sinal bruto extracelular, detecção, extração de parâmetros, clustering, e instantes de disparo de cada célula.

de forma que suas características possam ser comparadas dentro de uma mesma janela de tempo.

A etapa de extração de parâmetros contempla transformar o sinal que compõe cada spike em um conjunto de parâmetros, para enfatizar a diferença entre spikes de neurônios distintos. Esta tarefa também envolve definir dentre esses parâmetros quais são os mais relevantes para a identificação do spike, em um processo conhecido como redução de dimensão. Um dos métodos mais comumente utilizados nesta etapa é o PCA (Principal Component Analysis) (GIBSON; JUDY; MARKOVIC, 2010).

A última etapa, chamada de clustering, compreende o agrupamento dos spikes de acordo com as semelhanças entre os parâmetros mapeados na etapa anterior. Cada grupo obtido deve idealmente corresponder a um neurônio diferente, e desta forma o objetivo final do spike sorting é alcançado. O processo todo torna-se menos eficiente quanto mais próximos estiverem os neurônios ativos e maiores forem os níveis de ruído afetando o meio extracelular.

Muitas das aplicações do spike sorting incluem a necessidade de operação em tempo real, inclusive com implementações do processo diretamente em hardware (e.g. sistemas de controle de próteses mecânicas). Apesar de existirem técnicas que procuram atender a estes critérios (GIBSON; JUDY; MARKOVIC, 2008), ainda há uma troca entre assertividade e complexidade na concepção e utilização desses métodos. Em geral, para se obter resultados com menores taxas de erro, processos mais complexos são utilizados, penalizando uma implementação em hardware de tempo real.

\subsection{Objetivos}

O objetivo principal deste trabalho é propor um modelo linear e invariante de tempo discreto na forma de uma função racional, para representar o spike neuronal observado 
por um eletrodo nas redondezas da célula neuronal. Essa abordagem proporciona uma alternativa de baixa complexidade ao modelo do spike neuronal, empregando conceitos de identificação de sistemas e processamento de sinais. Esse modelo é dissociado de considerações sobre os processos bioquímicos da célula neuronal, e não é derivado de nenhum modelo tradicional. A validação do modelo e estimação de seus parâmetros são feitas a partir de amostras dos sinais intracelular e extracelular obtidas in vivo. Apesar de o modelo resultante não compreender a dinâmica celular de geração do disparo, espera-se que esta parametrização seja útil no problema de identificação de neurônios a partir de misturas de spikes.

O modelo proposto produz em sua saída um sinal extracelular de forma semelhante ao observado nos experimentos, a partir de impulsos unitários ${ }^{1}$ aplicados em instantes adequados em sua entrada. Na Figura 1.2 é ilustrado o esquema geral de sua estrutura. Cada uma das $L$ entradas representa um neurônio ativo e contém um trem de impulsos, aleatoriamente espaçados no tempo, que darão origem ao potencial de ação do neurônio. O impulso representa um estímulo sobre o neurônio no exato instante de tempo necessário para gerar o potencial de ação observado. Além disso, o sistema produz $K$ saídas, sendo que cada uma delas representa a leitura do potencial elétrico por um eletrodo posicionado no meio externo às células da região. Esse sinal contém uma mistura com os spikes produzidos por todos os neurônios ativos na entrada.

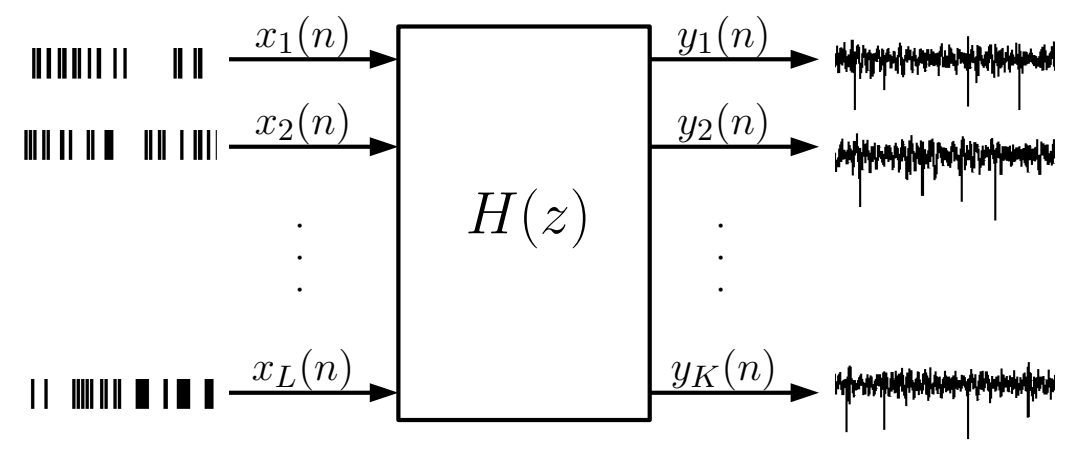

Figura 1.2: Modelo idealizado, com $L$ neurônios ativos sendo observados por $K$ eletrodos.

Uma vez obtido o modelo determinista e sua respectiva função de transferência, teremos uma representação matemática específica da área do cérebro em questão. Posteriormente, pode-se investigar a possibilidade de obter um sistema linear inverso, que idealmente seria capaz de transformar os sinais lidos no meio extracelular em impulsos unitários associados

\footnotetext{
${ }^{1}$ Neste texto será utilizada a expressão "impulso unitário"como referência à função impulso unitário de tempo discreto, também conhecida como delta de Kronecker.
} 
a cada neurônio que os originou, conforme ilustrado pela Figura 1.3.

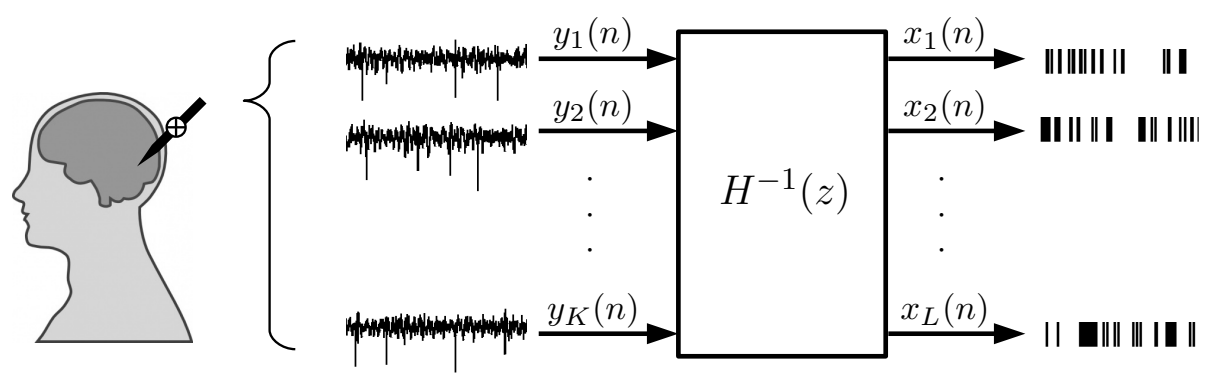

Figura 1.3: Modelo inverso utilizado como separador de impulsos

É possível vislumbrar que esta proposta possa servir como alternativa a técnicas comuns de spike sorting. Obter os coeficientes da função de transferência do sistema proposto é uma forma de parametrização do spike. Um ponto importante da discussão é identificar se essa parametrização é suficiente para distinguir spikes de neurônios diferentes. A vantagem, neste caso, está no fato de que o processo não necessitaria passar pelas etapas usualmente envolvidas neste tipo de problema. Os métodos utilizados na abordagem proposta são, via de regra, derivados de métodos comumente utilizados no processamento digital de sinais (HAYKIN, 1996; OPPENHEIM; SCHAFER, 2009; HYVÄRINEN; KARHUNEN; OJA, 2001), normalmente aplicados em sistemas de comunicações. No entanto, vale ressaltar que grande parte das técnicas de sistemas de comunicações baseiam-se no fato de que as características estatísticas dos sinais nas fontes são previamente conhecidas, o que não necessariamente é o caso geral do sistema formado pelos neurônios em uma região cerebral.

O desafio que surge como consequência é utilizar o resultado obtido no processo de concepção do sistema inverso. Deve-se investigar quais técnicas podem fazer melhor uso da informação extraída do sinal, por meio dos coeficientes da função de transferência, no processo de spike sorting como um todo.

\subsection{Métodos e Procedimentos}

Este trabalho baseia-se em amostras reais dos sinais neuronais, levados em consideração desde as etapas de concepção do modelo até a simulação e validação da proposta desenvolvida. Foram selecionadas leituras experimentais in vivo de sinais neuronais de camundongos, dentre os dados compartilhados pelo CRCNS (Collaborative Research in Computational Neuroscience) (HENZE et al., 2000b). Em cada leitura, são fornecidas as séries temporais do potencial de ação, obtido diretamente no corpo celular por meio de micropipetas de vidro, e do potencial elétrico observado simultaneamente no meio externo, 
através de eletrodos posicionados em uma área próxima à célula em questão. Este tipo de experimento torna possível o estudo das relações entre os sinais produzidos por um mesmo neurônio em diferentes locais de observação.

O procedimento, conforme descrito pelos autores (HENZE et al., 2000a), foi realizado com 30 camundongos anestesiados, mantidos vivos em um aparato especialmente preparado. A temperatura corporal dos animais foi mantida constante, e pequenos orifícios de 1,2 $\times 1,2 \mathrm{~mm}$ foram abertos em seus crânios para permitir a incursão dos eletrodos. Os eletrodos extracelulares foram montados com uma pequena inclinação em relação ao eletrodo intracelular, de forma que as pontas de ambos estivessem bem próximas quando dentro do cérebro do animal, conforme pode ser observado na Figura 1.4. Após a inserção dos eletrodos, os orifícios foram cobertos com parafina, mantendo o cérebro isolado do contato com o ambiente durante o experimento.
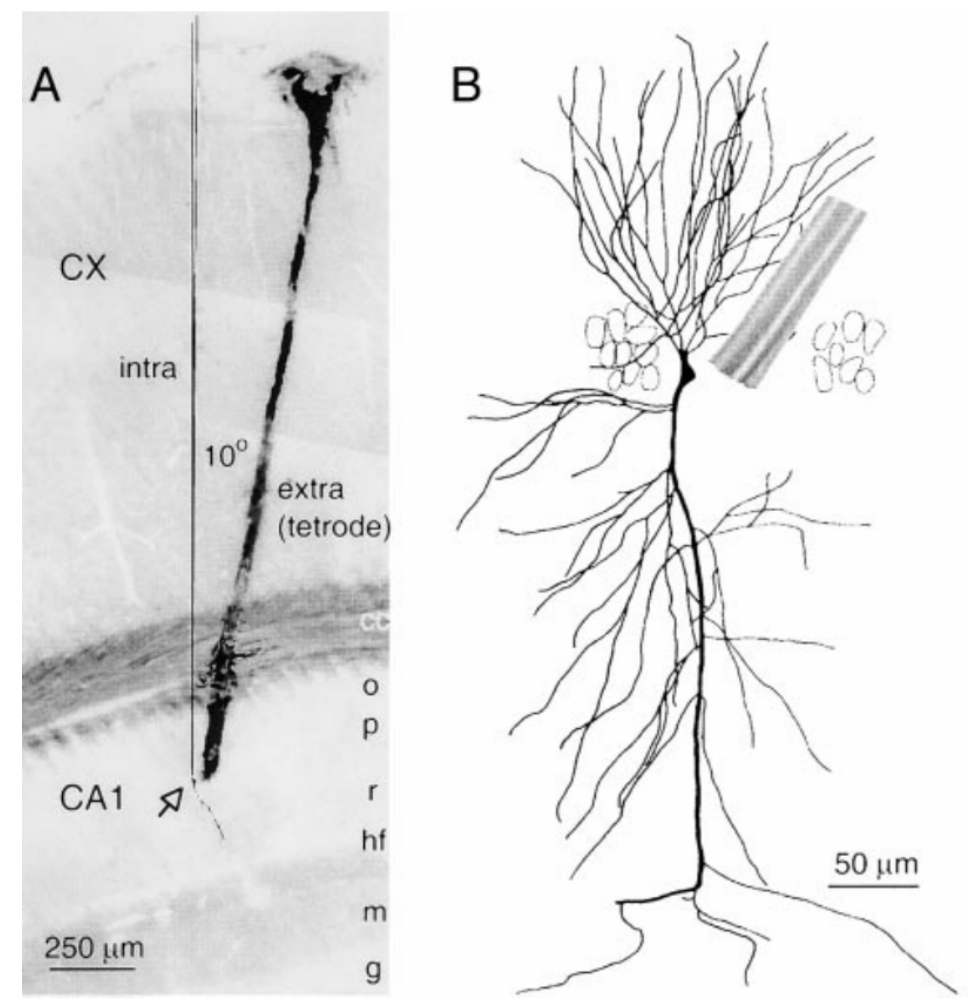

Figura 1.4: A) Posicionamento dos eletrodos para leitura simultânea. B) Ilustração do posicionamento em escala de um eletrodo extracelular. Extraído de (HENZE et al., 2000b).

Os eletrodos extracelulares são em geral montados em arranjos de quatro a seis elementos uniformemente espaçados, fornecendo múltiplos canais independentes de leitura do potencial fora da célula. Nestes experimentos, três tipos de eletrodos foram utilizados alternadamente: fios metálicos de $13 \mu \mathrm{m}$ de diâmetro cada, unidos em suas bases por um material isolante; um conjunto eletrodos de silicone espaçados de $25 \mu \mathrm{m}$ verticalmente; ou, 
em somente cinco camundongos, apenas um único eletrodo constituído de um fio de $60 \mu \mathrm{m}$ de diâmetro. Além disso, dois fios de $50 \mu \mathrm{m}$ de tungstênio foram inseridos no cerebelo para servir de sinal de referência aos potenciais elétricos observados. O sinal extracelular foi ainda amplificado de 1.000 a 8.000 vezes e filtrado em um passa-faixa de $1-3.000 \mathrm{~Hz}$ antes de ser digitalizado.

Ao final do experimento, a célula em questão foi marcada com corante e o cérebro do animal retirado e fatiado em secções de $60 \mu \mathrm{m}$ de espessura, o que permitiu definir o local exato de perfuração em cada caso. No total, 38 séries temporais contendo sinais estáveis foram obtidas com sucesso. Todas as leituras foram feitas na região do hipocampo; a maior parte dos disparos observados corresponde à atividade de células piramidais na camada conhecida como CA1 (HENZE et al., 2000a), local onde os eletrodos foram planejados para alcançar. Em uma última etapa, as séries temporais foram digitalizadas em 12 ou 16 bits, e amostradas com uma frequência de $10,20,25 \mathrm{ou} 50 \mathrm{kHz}$, dependendo do experimento realizado. Os valores foram então registrados em arquivos binários, e disponibilizados publicamente pela CRCNS em seu website (HENZE et al., 2000b).

\subsection{A estrutura do trabalho}

Este trabalho é iniciado por uma breve introdução ao funcionamento biológico do neurônio, apresentada no Capítulo 2. Apresentamos uma revisão do processo de geração do potencial de ação e sua transmissão via conexões sinápticas entre os neurônios. Além disso, é feita uma discussão das diferenças entre o sinal observado dentro do neurônio e o sinal observado em um meio externo, por meio de eletrodos específicos para cada caso. O capítulo termina com um resumo simples dos modelos neuronais mais conhecidos na literatura. Veremos que a proposta de um modelo com o foco em parametrizar o sinal neuronal pode ser útil para entender o problema de separação dos spikes sob a perspectiva de sinais de comunicações, guardadas as devidas restrições.

No Capítulo 3, é apresentada uma revisão sobre métodos de identificação de sistemas pertinentes ao problema abordado por este trabalho. São estudados alguns modelos lineares de tempo discreto comumente encontrados na literatura. As técnicas de estimação aplicáveis a estes modelos são discutidas, bem como algumas questões práticas e de aplicação.

Em seguida, é discutida a proposta principal do trabalho, no Capítulo 4, iniciando com a discussão do modelo para um disparo isolado de um único neurônio. Esse caso é 
então dividido entre subsistemas intracelular, para o potencial de ação, e extracelular, para o spike. Ambos os subsistemas são associados em série para formar um sistema linear representativo da forma de onda do disparo neuronal. A estrutura do modelo é estendida para o caso de múltiplos eletrodos (múltiplas saídas). Levando em conta as limitações dos dados disponíveis, é proposta uma estrutura mais geral, incluindo também múltiplas células ativas (múltiplas entradas e múltiplas saídas).

O Capítulo 5 concentra os resultados de simulações e análises sobre os dados experimentais. Esse capítulo inicia-se com algumas considerações sobre os sinais reais e as etapas de pré-processamento utilizadas. Como ponto de partida do processo de modelagem, estabelece-se um critério para definir a ordem de cada modelo. Em seguida apresentam-se os resultados de um disparo isolado, que são replicados para uma sequência de disparos de um mesmo neurônio. As simulações são estendidas diretamente para o caso de múltiplas saídas. Demais discussões importantes para reprodução do processo de modelagem complementam o capítulo.

O Capítulo 6 é dedicado à investigação de técnicas que possibilitem encontrar um sistema inverso ao do modelo proposto. Duas principais abordagens são discutidas: a solução via modelagem inversa, ou equalização multiusuário, utilizando algoritmos adaptativos, e uma formulação inicial como um problema de separação de fontes. As limitações de cada caso são apresentadas, bem como as possíveis aplicações de métodos conhecidos de processamento de sinais.

Por fim, o Capítulo 7 apresenta as conclusões do trabalho e principais questões em aberto para serem abordadas em possíveis trabalhos futuros.

Além disso, este trabalho contém quatro apêndices, com o intuito de auxiliar discussões mais extensas em algumas etapas. O Apêndice A fornece a função de custo para o desenvolvimento da solução do problema de estimação do modelo só-polo, a partir do problema de predição progressiva. No Apêndice B, por sua vez, pode-se encontrar o detalhamento da solução do caso mais geral do problema de estimação linear. Ambos são utilizados na formulação teórica da modelagem do sinal de interesse a partir de técnicas de identificação de sistemas. Os Apêndices C e D contêm, respectivamente, descrições dos algoritmos RLS (Recursive Least Squares) e LMS (Least Mean Squares) Normalizado, utilizados em simulações de técnicas adaptativas sobre a estrutura do modelo.

Parte deste trabalho resultou em um artigo científico publicado em periódico da área (PALMIERI; MONTEIRO; MIRANDA, 2015), contendo os principais resultados do processo de modelagem proposto para o spike neuronal. 


\section{O sinal neuronal e seus modelos}

O sinal neuronal é o elemento fundamental na transmissão de informações dentro do sistema nervoso. Esse sinal é a consequência fisiológica do potencial elétrico produzido na membrana da célula, e sofre variações a fim de produzir um estímulo que é transmitido a outras células através das sinapses. O entendimento detalhado destes processos deuse a partir de observações experimentais do sinal neuronal, e possibilitou o surgimento de modelos quantitativos capazes de simular o comportamento da célula neuronal. Este capítulo contém uma breve discussão do funcionamento fisiológico do neurônio, baseando-se em referências comumente encontradas sobre o assunto (BEAR; CONNORS; PARADISO, 2006; PURVES et al., 2011). Além disso, são apresentadas as classes mais relevantes de modelos quantitativos para o neurônio, de forma a estabelecer um contexto para a proposta do trabalho.

\subsection{O potencial de ação}

A diferença de concentração de íons entre o interior e exterior de uma célula resulta na formação de um potencial elétrico em sua membrana. O valor desse potencial está sujeito a variações quando a permeabilidade da membrana é alterada. Neurônios notadamente possuem canais iônicos e bombas iônicas especializados em permitir a passagem de determinados íons para dentro (ou para fora) do corpo celular, e, dessa forma, produzir variações consideráveis no potencial elétrico da membrana. Quando o potencial atinge um valor limiar (em torno de $-55 \mathrm{mV}$ ), um impulso nervoso é produzido. Esse impulso é chamado de potencial de ação, e percorre o corpo celular e o axônio, até ser transmitido para neurônios com os quais a célula original está conectada.

O intervalo de tempo em que ocorre um potencial de ação pode ser divido em 4 fases principais: repouso, fase ascendente, fase descendente e hiperpolarização. Uma ilustração do potencial de ação e suas respectivas fases pode ser vista na Figura 2.1. Originalmente, um neurônio mantém a maior parte dos canais fechados, o que resulta em um potencial 
de repouso na ordem de $-70 \mathrm{mV}$. Ao receberem um estímulo, alguns dos canais abrem e possibilitam a entrada de íons de sódio para dentro da célula, ao passo que demais canais permitem a saída de íons de potássio. Quando o estímulo é forte o bastante para que o influxo de sódio se sobreponha ao efluxo de potássio, o sistema entra em um estado de realimentação positiva, e o potencial aumenta rapidamente em direção ao valor de potencial de equilíbrio do sódio.

O aumento do potencial continua até atingir um valor máximo em torno de $+40 \mathrm{mV}$. Neste instante, canais de sódio voltam a se fechar, de forma que o efluxo de potássio torna-se o fenômeno dominante, e o potencial entra na fase descendente. A recuperação do potencial de repouso, no entanto, não é imediata, e como a permeabilidade ao sódio está reduzida, o potencial cai em direção ao potencial de equilíbrio do potássio (em torno de $-80 \mathrm{mV})$. Então os canais de potássio também fecham e as concentrações iniciais são restabelecidas lentamente por meio da ação das bombas iônicas. Nesse período, a membrana passa por um breve intervalo durante o qual não é capaz de produzir novos potenciais de ação, pois os canais não estão aptos a entrar no estado ativo imediatamente. Esse intervalo limita a frequência máxima na qual um impulso pode ser gerado em um mesmo neurônio, mas também impossibilita que o sinal retorne pelo caminho por onde já passou na membrana, direcionando a propagação do potencial. Após a recuperação dos canais iônicos, a membrana fica sujeita aos estímulos para que a célula possa disparar novamente.

\subsection{Propagação do potencial de ação}

O potencial de ação pode ser gerado nos dendritos quando da recepção de um impulso vindo de outra célula. Esse impulso irá percorrer o corpo celular e posteriormente o axônio, em direção às sinapses do terminal axônico. Durante seu percurso, o potencial de ação comporta-se como um sinal elétrico, passando de uma região da membrana para as regiões adjacentes ainda não estimuladas. Enquanto percorre o corpo celular, o sinal é propagado principalmente pela membrana. Ao entrar no axônio, o potencial de ação passa a ser transmitido dentro do próprio citoplasma, uma vez que esta parte da célula é isolada pela bainha de mielina. Por fim, encontra as sinapses localizadas na terminação do axônio.

Nas sinapses, o potencial de ação faz com que vesículas liberem moléculas dos neurotransmissores nos receptores da célula seguinte. Os neurotransmissores são substâncias químicas que irão resultar num estímulo excitatório (ou inibitório), podendo ocasionar um potencial de ação no neurônio receptor. O mecanismo de transmissão sináptica permite que 


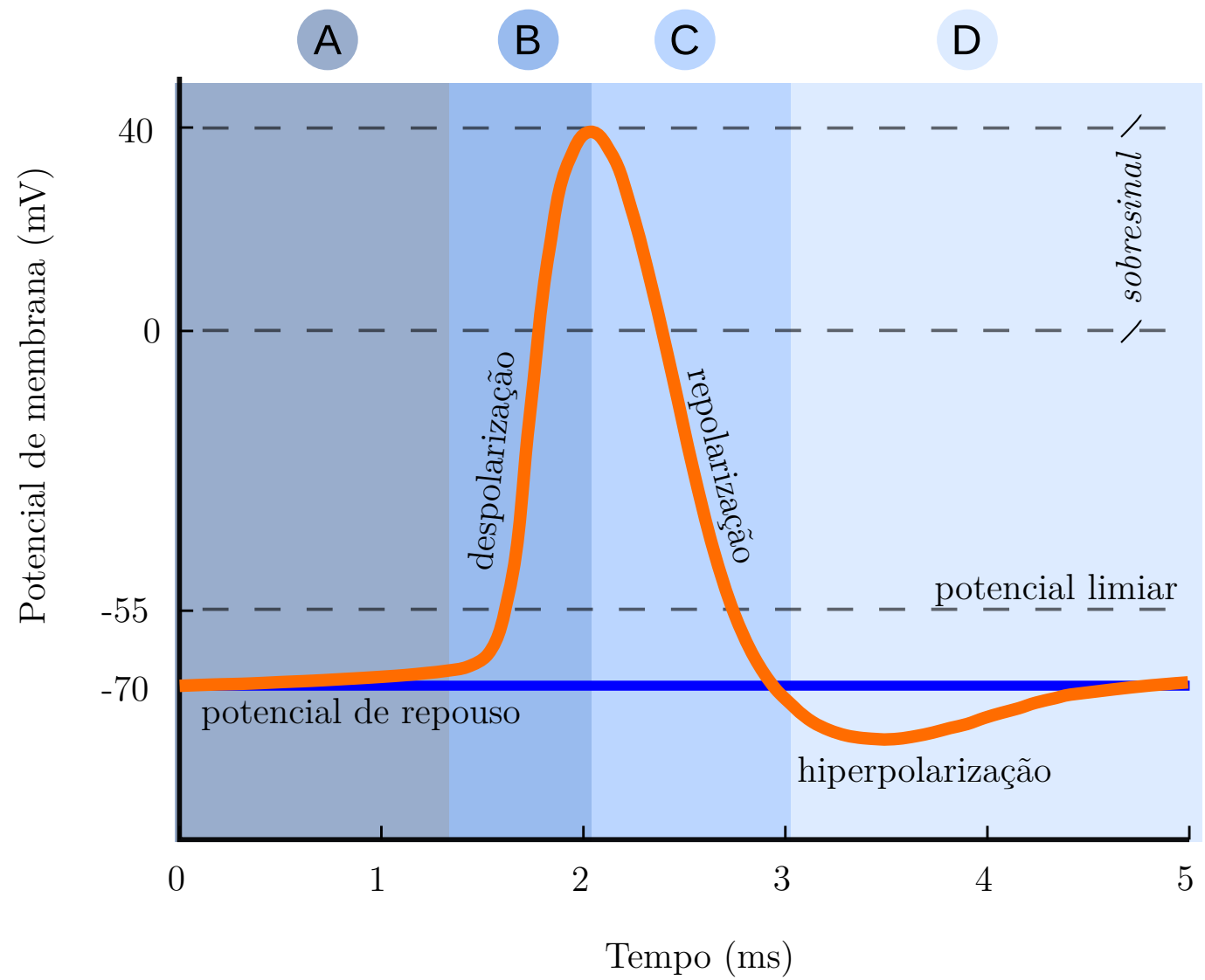

Figura 2.1: Principais fases do potencial de ação: A) potencial de repouso, B) fase ascendente, C) fase descendente e D) hiperpolarização.

o potencial de ação seja transmitido de um neurônio a outro. Dessa forma, o cérebro pode ser considerado uma rede de células neuronais trocando sinais entre si. Ao estudarmos o comportamento de uma determinada região cerebral, devemos levar em conta que o comportamento de um neurônio é altamente influenciado pelas conexões que faz com as células adjacentes, o que adiciona complexidade à tarefa de modelar o funcionamento da região em questão.

\subsection{Aquisição experimental do sinal neuronal}

A medição do potencial de ação por meio de eletrodos pode ser feita de duas formas: (i) intracelular, diretamente no corpo da célula, e (ii) extracelular, no meio externo ao neurônio (GOLD et al., 2006). Na Figura 2.2 é ilustrado o potencial elétrico durante o disparo, de acordo com o posicionamento do eletrodo. Além do formato da onda, é notável a diferença na ordem de grandeza dos sinais obtidos (de milivolts no caso da leitura 
intracelular, para microvolts no caso da extracelular).

A leitura intracelular requer a penetração da membrana por microeletrodos de metal ou micropipetas de vidro cuidadosamente posicionados, o que representa um certo grau de dificuldade, especialmente em células neuronais de tamanho reduzido, como é o caso na maioria dos vertebrados. O sinal obtido em uma leitura intracelular, entretanto, quantifica diretamente o potencial produzido devido à diferença de concentrações iônicas dentro e fora da membrana plasmática, e qualquer ocorrência de impulso está diretamente associada à atividade do neurônio observado. Além disso, aquisições de sinal diretamente na célula normalmente resultam em uma relação sinal-ruído maior, facilitando o processamento do sinal obtido.

Como consequência do potencial de ação, o fluxo de íons através da membrana produz uma corrente que pode ser percebida no meio exterior à célula. Eletrodos posicionados nas proximidades da célula conseguem obter uma leitura do potencial sem perfurar a membrana, requerendo, em geral, um aparato mais simples que no caso da leitura intracelular. A leitura, nesse caso, poderá conter o potencial de ação de mais de um neurônio que esteja em atividade na mesma região, resultando em uma mistura de múltiplos sinais. Esse é o fato motivador do problema do spike sorting.
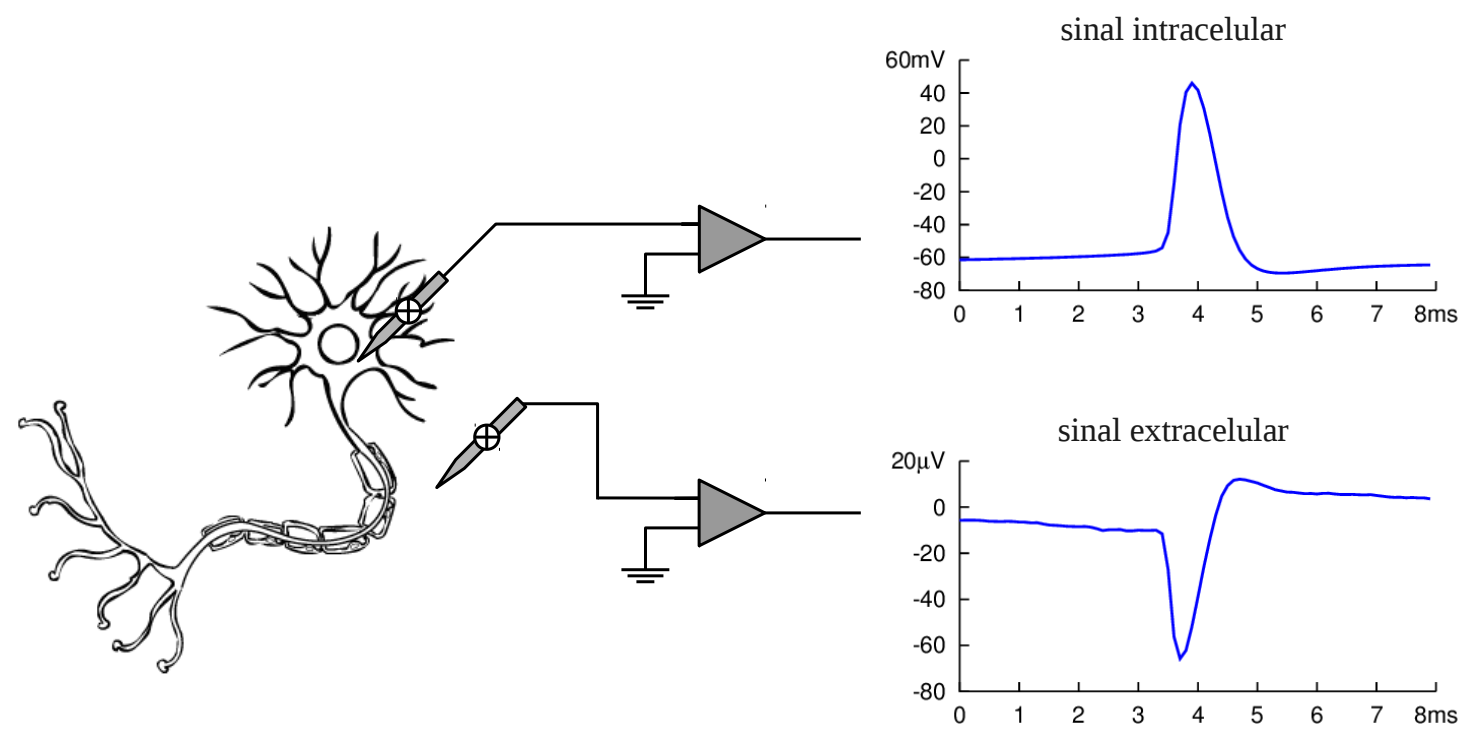

Figura 2.2: Leitura intracelular vs. leitura extracelular.

Além dos impulsos produzidos por neurônios próximos, a leitura extracelular possui um componente importante, chamado de LFP (Local Field Potential). O LFP é um sinal formado pela sobreposição de traços dos potenciais e correntes resultantes da atividade 
sináptica de baixa frequência de inúmeros neurônios de uma região. Esses sinais conseguem propagar-se por uma distância maior que componentes de alta frequência como o potencial de ação, uma vez que os tecidos cerebrais corticais em geral possuem características capacitivas, atuando sobre o sinal extracelular como um filtro passa-baixas (NIEDERMEYER; SILVA, 1998). Apesar de não ser possível identificar spikes no LFP, esse é um sinal que carrega uma certa quantidade de informações sobre a cooperação entre os neurônios de uma mesma região, sendo utilizado em técnicas que exploram alternativas à leitura de impulsos neuronais (SCHERBERGER; JARVIS; ANDERSEN, 2005).

\subsection{Métodos experimentais e modelos quantitativos}

O estudo dos sinais neuronais sofreu uma grande evolução em meados do século XX com a possibilidade de leitura do potencial produzido isoladamente por uma única célula. Um dos principais avanços foi o surgimento do método conhecido como voltage clamp, desenvolvido por Kenneth S. Cole (COLE, 1949). Esse método permite manipular o potencial elétrico na membrana do neurônio para medir as variações de corrente resultantes. Posteriormente, Alan Hodgkin e Andrew Huxley utilizaram essa técnica para entender como a dinâmica da condutância da membrana é influenciada por cada tipo de íon presente no processo de geração do potencial de ação (HODGKIN; HUXLEY, 1952a). Nessa época surgiram as primeiras micropipetas com pontas na ordem de $10 \mathrm{~nm}$, que permitiam a leitura do potencial de ação diretamente no corpo de uma célula, produzindo observações com melhores relações sinal-ruído.

Uma evolução da técnica de voltage clamp resultou no método chamado de patch clamp, criado por Erwin Neher no final dos anos 1970. Esse método permitiu a investigação mais detalhada do funcionamento dos canais iônicos isolando pequenos trechos da membrana contendo idealmente um único canal (NEHER; SAKMANN; STEINBACH, 1978). Isso possibilitou analisar as fases do potencial de ação como consequência do funcionamento dos canais iônicos. Os canais de sódio, um dos principais íons envolvidos no processo de condução de corrente pela membrana, puderam ser compreendidos por três características principais: (i) a abertura do canal ocorre com um certo atraso em relação ao aumento do potencial, (ii) os canais permanecem abertos por cerca de $1 \mathrm{~ms}$ e então tornam-se inativos e (iii) ao tornarem-se inativos, eles não podem abrir por um certo período de tempo. Essas características são responsáveis pela forma de onda e suas respectivas fases observadas em um potencial de ação típico.

Os avanços na leitura do sinal neuronal permitiram entender mais profundamente 
os processos biológicos e químicos envolvidos na geração do potencial de ação. Como consequência, surgiram os primeiros modelos matemáticos com o intuito de simular as propriedades elétricas observadas no neurônio. Desde então, diversos modelos foram propostos, e a modelagem neuronal ainda é uma área em constante evolução na neurociência. De uma forma geral, podemos dividir os modelos mais relevantes em dois tipos: (i) modelos de tempo contínuo e (ii) modelos de tempo discreto.

\subsubsection{Modelos de tempo contínuo}

Os primeiros modelos que surgiram a partir de observações utilizando técnicas experimentais avançadas foram sistemas dinâmicos de tempo contínuo. Estes modelos buscavam reproduzir a dinâmica do potencial elétrico produzido na membrana neuronal pela ação dos canais de íons utilizando um sistema de equações diferenciais (IZHIKEVICH, 2007). A obtenção dos parâmetros destas equações foi um dos primeiros desafios para a modelagem, e em geral soluções empíricas foram utilizadas para produzir resultados bem próximos ao comportamento real do neurônio.

\section{O modelo de Hodgkin-Huxley}

Um dos primeiros e mais relevantes modelos quantitativos da neurociência é o modelo Hodgkin-Huxley (HODGKIN; HUXLEY, 1952b). Baseado em observações experimentais utilizando o voltage clamp, o modelo permite reproduzir com razoável assertividade a corrente produzida durante a ação dos canais iônicos. Este modelo representa a membrana neuronal como um circuito elétrico, com componentes resistivas variáveis para cada tipo de canal, uma condutância intrínseca, além da resistência característica geral. Na Figura 2.3 é ilustrado o circuito elétrico equivalente ao modelo proposto.

Em situações de equilíbrio, pode-se observar um potencial elétrico $E(t)$ entre o meio externo e o citoplasma, devido à diferença de concentração dos íons, conhecido como potencial de Nernst. Essa diferença de concentração é mantida de forma ativa pelos canais de íons da membrana. Dessa forma, a corrente que atravessa a membrana no sentido de fora para dentro pode ser descrita como:

$$
I=I_{c}+I_{i}
$$

em que $I_{c}$ representa a corrente capacitiva e $I_{i}$ é o somatório de todas as correntes produzidas pela ação dos canais de íons. No modelo original, ela está associada aos três principais componentes: canais de sódio $\left(I_{N a}\right)$, canais de potássio $\left(I_{K}\right)$, e demais íons, 


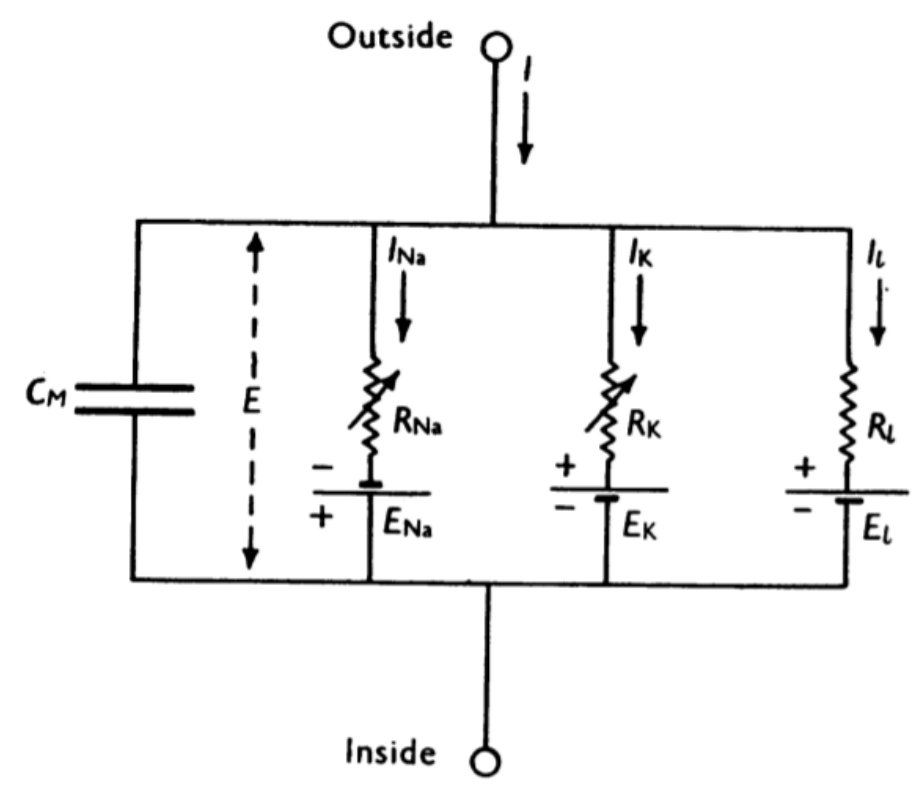

Figura 2.3: Modelo originalmente concebido por Hodgkin e Huxley (HODGKIN; HUXLEY, 1952b)

também chamada de corrente de vazamento $\left(I_{L}\right)$. Essas correntes são calculadas a partir das condutâncias individuais de cada tipo de canal, representadas no modelo original pelos elementos resistivos $R_{N a}, R_{K}$ e $R_{L}$. As condutâncias, por sua vez, são funções de três variáveis estabelecidas pela solução de um sistema de equações diferenciais, cujos coeficientes foram obtidos empiricamente por Hodgkin e Huxley. Essas variáveis, junto com o valor do potencial medido entre o meio interno e externo da membrana, formam um espaço de fases de quatro dimensões. A Figura 2.4 apresenta o resultado obtido pelos autores com a solução numérica do sistema de equações proposto.

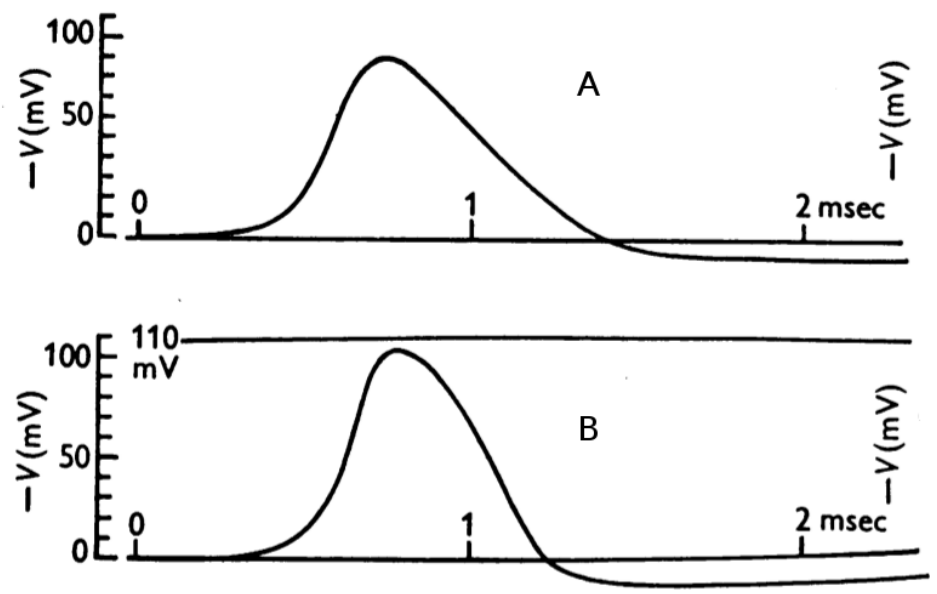

Figura 2.4: Resultados obtidos por Hodgkin e Huxley (HODGKIN; HUXLEY, 1952b). A) potencial de ação calculado a partir das equações do modelo, e B) potencial observado em um neurônio real de lula gigante. 


\section{O modelo de FitzHugh-Nagumo}

O modelo de FitzHugh-Nagumo foi proposto inicialmente em 1961 por Richard FitzHugh (FITZHUGH, 1961). No ano seguinte, foi estendido por Nagumo, que apresentou o circuito elétrico equivalente ao modelo (NAGUMO; ARIMOTO; YOSHISAWA, 1962). Esta proposta pode ser considerada uma simplificação do modelo de Hodgkin-Huxley, reduzindo a dimensão do espaço de fases do sistema, que passa a ser representado apenas por duas variáveis. A primeira variável representa a tensão através da membrana neuronal, e a segunda funciona como uma variável de recuperação após o momento do disparo. O sistema completo é descrito através das seguintes equações:

$$
\begin{aligned}
& \dot{V}=f(V)-W+I_{e x t} \\
& \dot{W}=a(b V-c W)
\end{aligned}
$$

em que $V$ é o potencial elétrico na membrana, $W$ a variável de recuperação, $f(V)$ um polinômio de terceiro grau, e $a, b$ e $c$ constantes do sistema. A variável $I_{\text {ext }}$ representa a corrente passando pela membrana neuronal, responsável pela ativação do potencial de ação, podendo ser utilizada para simular a resposta do neurônio a uma injeção de corrente. Esse modelo foi também chamado de oscilador de Bonhoeffer-Van der Pol pois contém como caso especial um oscilador de Van der Pol (para $a=b=0$ ).

O fato de o modelo possuir apenas duas variáveis facilitou a solução numérica do sistema de equações em computadores analógicos, utilizados na época por FitzHugh. Além disso, essa abordagem permitiu visualizar a trajetória formada pela simulação do modelo no espaço de fases em um gráfico de duas dimensões, o que simplificou muitas das análises realizadas sobre o seu funcionamento. No entanto, as simplificações utilizadas tornaram o modelo mais abstrato que o seu antecessor, de forma que a dinâmica fisiológica do neurônio não é refletida diretamente nas equações do sistema.

\section{O modelo de Morris-Lecar}

O modelo de Morris-Lecar também é uma simplificação do modelo de Hodgkin-Huxley utilizando um sistema de apenas duas equações. Foi proposto em 1981 por Carthy Morris e Harold Lecar, com base em observações do potencial de ação dos neurônios de crustáceos marinhos da espécie Balanus nubilus (MORRIS; LECAR, 1981). Esse modelo também se baseia nas condutâncias da membrana neuronal em relação aos diferentes tipos de íons, conforme ilustrado na Figura 2.3. No entanto, neste caso, as condutâncias são dadas puramente em função da tensão através da membrana em um determinado instante. Dessa 
forma, as únicas variáveis do sistema de equações diferenciais são a tensão na membrana $V$ e a variável de recuperação $W$. Esta última tem a função de simular principalmente o efeito da abertura dos canais de potássio no potencial de ação. O sistema de equações do modelo é dado por:

$$
\begin{aligned}
& C \dot{V}=-g_{C a} M_{s s}(V)\left[V-V_{C a}\right]-g_{k} W\left[V-V_{K}\right]-g_{L}\left[V-V_{L}\right]+I_{e x t} \\
& T_{w}(V) \dot{W}=W_{s s}(V)-W
\end{aligned}
$$

sendo $V_{C a}, V_{K}$ e $V_{L}$ os potenciais de equilíbrio do cálcio, potássio e dos demais íons que atravessam a membrana neuronal. Note que, neste caso, o íon responsável pela despolarização é o cálcio e não o sódio, como encontrado nos modelos anteriores. Os termos $M_{s s}(V)$ e $W_{s s}(V)$ são funções de probabilidade da condutância, e foram propostas analiticamente pelos autores no modelo original com o intuito de simular a dinâmica dos canais iônicos. A função $T_{s s}(V)$ funciona como uma constante de tempo para operação dos canais de potássio, e está relacionada principalmente com as fases descendente e de hiperpolarização do potencial de ação. Esses parâmetros foram estudados empiricamente pelos autores, e podem ser adaptados para simular outros tipos de neurônio.

Assim como o modelo de FitzHugh-Nagumo, o modelo dado por (2.3) permite utilizar gráficos planos para visualização das duas variáveis do sistema, facilitando a análise de sua operação. Uma das vantagens desta proposta, entretanto, é a possibilidade de refinar os parâmetros para uma variedade maior de cenários de simulação. As funções das condutâncias podem ser alteradas para refletir um modelo alternativo, sem acrescentar novas variáveis ao sistema de equações diferenciais. Isto permite ao modelo descrever não somente as principais classes de oscilação de neurônio originalmente estudadas por Hodgkin-Huxley, mas também outros tipos de comportamento (TSUMOTO et al., 2006).

\section{O modelo de Hindmarsh-Rose}

O modelo de Hindmarsh-Rose foi proposto em 1982 como uma generalização do modelo de FitzHugh-Nagumo, inicialmente também utilizando um sistema de equações diferenciais de duas dimensões (HINDMARSH; ROSE, 1982). Assim como os demais modelos aqui apresentados, esse também baseia-se na representação das condutâncias dos principais íons associados à geração do potencial de ação. Posteriormente, a proposta foi aperfeiçoada pelos mesmos autores, alterando alguns termos e incluindo mais uma variável 
(HINDMARSH; ROSE, 1984), de forma que seu conjunto de equações é dado por:

$$
\begin{aligned}
\dot{V} & =f(V)+W+I_{e x t}-Z \\
\dot{W} & =g(V)-W \\
\dot{Z} & =r\left[s\left(X-x_{r}\right)-Z\right]
\end{aligned}
$$

em que $s, r, x_{r}$ são constantes do modelo, e $Z$ uma variável chamada de corrente de adaptação, relacionada com alterações no potencial observadas logo após o término de uma sequência contínua de disparos. Outra diferença importante desse modelo em relação ao seu antecessor é a introdução da função $g(V)$. Essa função, bem como a $f(V)$, foram propostas pelos autores por meio de leituras experimentais da corrente e da tensão através da membrana do neurônio de um caracol da espécie Lymnaea stagnalis, utilizando a técnica de voltage clamp. No modelo original, estas funções são dadas, respectivamente, por um polinômio de terceiro grau e por um polinômio de segundo grau

$$
\begin{aligned}
& f(V)=-a V^{3}+b V^{2} \\
& g(V)=c-d V^{2}
\end{aligned}
$$

com parâmetros $a, b, c$ e $d$, determinados empiricamente. Os resultados obtidos com a simulação numérica desse modelo mostraram uma relação quase linear entre a frequência de disparo e a corrente, o que se aproxima do comportamento observado em um neurônio real. As modificações introduzidas permitiram a simulação de uma variedade maior de dinâmicas da célula neuronal em comparação com modelos anteriores.

\subsubsection{Modelos de tempo discreto}

A origem de modelos de tempo discreto pode ser traçada a partir de modelos como o de McCulloch-Pitts, baseados na discretização do próprio evento de disparo do neurônio, pois são sistemas que possuem apenas dois estados possíveis para uma célula (ativa ou em repouso). Este tipo de abordagem permitiu um alto grau de simplificação, e deu origem a uma grande variedade de modelos, servindo de base para muitas das redes neurais artificiais estudadas atualmente.

Além disso, recentemente, métodos baseados em mapas iteráveis surgiram como alternativas mais pragmáticas aos modelos tradicionais baseados na dinâmica fisiológica do neurônio. Modelos de tempo contínuo nem sempre permitem que a solução exata de suas equações sejam encontradas, principalmente no caso dos sistemas não lineares. Não raro, a busca por soluções precisas leva a integração numérica de equações, após a 
discretização do sistema original. A necessidade de simular redes complexas com muitas células fez com que estes modelos evoluíssem para modelos puramente discretos, na forma de um sistema de variáveis atualizadas iterativamente (AIHARA; TAKABE; TOYODA, 1990; GIRARDI-SCHAPPO; TRAGTENBERG; KINOUCHI, 2013). Estes novos modelos também permitiram reduzir o custo computacional intrínseco do processo de simulação de modelos de tempo contínuo, de forma a serem aplicáveis em redes com um grande número de elementos e mantendo algumas das propriedades observadas no sinal neuronal (IBARZ; CASADO; SANJUÁN, 2011). Apresentamos a seguir dois modelos popularmente encontrados na literatura e que resultam de perspectivas diferentes da modelagem em tempo discreto.

\section{O neurônio artificial de McCulloch-Pitts}

Este modelo surge de uma abordagem alternativa à dos modelos baseados na dinâmica elétrica do potencial de ação. Foi originalmente proposto por Warren McCulloch e Walter Pitts em 1943, com o objetivo principal de investigar como o cérebro é capaz de produzir padrões complexos a partir de unidades simples conectadas entre si (MCCULLOCH; PITTS, 1943). O modelo proposto é altamente simplificado, de tal modo que passou a ser conhecido como neurônio artificial, pois abstrai grande parte dos fenômenos envolvendo a condução elétrica do sinal neuronal.

O modelo McCulloch-Pitts possui múltiplas entradas e apenas uma saída. O valor produzido na saída é dado pela soma ponderada dos valores de entrada, após passar por uma função não-linear, chamada de função de ativação. Além disso, uma de suas entradas é mantida constante, com o propósito de servir como um limiar de ativação, também chamado de bias. A Figura 2.5 ilustra a estrutura de um neurônio de McCulloch-Pitts. Considerando um neurônio com $K$ entradas $x_{i}(n)(\operatorname{com} i=1,2, \ldots, K)$ e bias $x_{0}$, sua saída $y(n)$ será dada por:

$$
y(n)=f\left(x_{0}+\sum_{i=1}^{K} w_{i} x_{i}(n)\right)
$$

sendo $w_{i}$ os pesos de cada entrada e $f($.$) uma função de ativação com algumas propriedades$ desejadas. Em geral, essa função deverá produzir um pulso quando a soma ponderada das entradas for maior que um determinado limiar, situação em que o neurônio é dito ativado. As funções de ativação mais utilizadas são sigmoides e a função degrau.

Note que estes elementos possuem uma relação com a estrutura do neurônio biológico: os pesos $w_{i}$ das entradas mimetizam, de forma bastante simplificada, o funcionamento de neurotransmissores sinápticos, que podem reforçar ou cancelar o sinal lido em cada uma 
das inúmeras conexões feitas pelo neurônio; o soma, ou corpo celular, é representado pela adição desses sinais após passarem pelos dendritos; por fim, o axônio é representado pela saída do modelo, que pode ser conectada a entradas de demais células em uma rede.

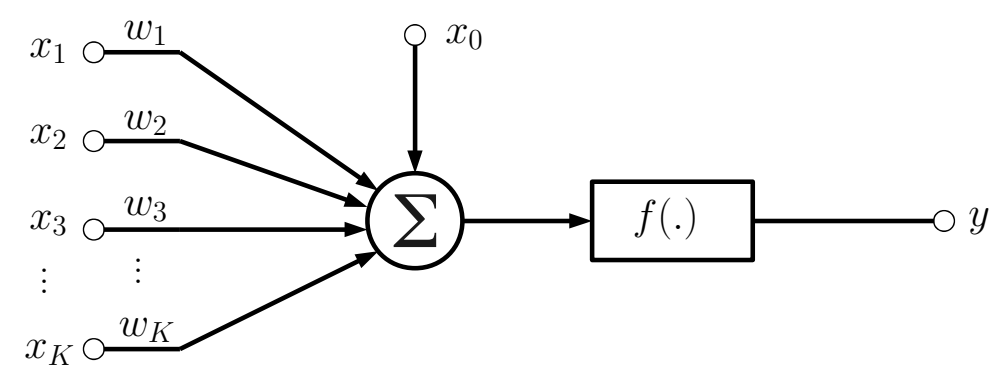

Figura 2.5: Esquema básico do neurônio de McCulloch-Pitts.

A proposta original é bastante simplificada, operando apenas com valores booleanos nos sinais de entrada e saída, e com valores estáticos para os pesos e o limiar, sem capacidade de aprendizado ou adaptação. Essa simplicidade, no entanto, permitiu a construção de modelos de redes neuronais contendo um grande número de células. O surgimento das primeiras redes neurais artificiais foi posteriormente impulsionado pela proposta do perceptron por Rosenblatt (ROSENBLATT, 1962), derivado diretamente do modelo de McCulloch-Pitts.

\section{Mapas iteráveis de Rulkov}

Modelos de tempo discreto baseados em mapas iteráveis surgiram como uma evolução das equações obtidas após a discretização dos modelos convencionais de tempo contínuo baseados nas condutâncias iônicas (IBARZ; CASADO; SANJUÁN, 2011). Atualmente, estes modelos abstraem a dinâmica fisiológica do neurônio, com o intuito principal de fornecer uma formulação matemática simplificada que simule o comportamento observado do potencial de ação.

Nikolai Rulkov propôs uma série de modelos que seguem essa abordagem, dentre os quais o mais popular é chamado de modelo não-caótico de Rulkov (RULKOV, 2002). Este modelo é um mapa bidimensional: uma das variáveis representa o valor do potencial de ação em cada instante de tempo, e é chamada de variável rápida; a outra variável tem a função de representar o processo de recuperação do neurônio após um disparo, e é 
conhecida como variável lenta. As equações do modelo são dadas por:

$$
\begin{aligned}
& x(n+1)=F[x(n), y(n)+\beta(n)] \\
& y(n+1)=y(n)-\mu[x(n)-\sigma]
\end{aligned}
$$

Nesse sistema, $x(n)$ representa a tensão entre a membrana neuronal, ou o potencial de ação, e portanto é a variável rápida. Por sua vez, $y(n)$ é a variável lenta, análoga à variável de recuperação do modelo de FitzHugh-Nagumo. O parâmetro $\mu$ é utilizado para garantir que a variável $y(n)$ seja atualizada apenas com pequenas variações, de forma que $0<\mu \ll 1$, resultando em um comportamento mais lento que a outra variável. $\mathrm{O}$ parâmetro $\sigma$ é utilizado para regular o regime de disparo do neurônio, e também pode incluir o efeito de uma corrente contínua sendo injetada no corpo celular. No caso de um neurônio sendo estimulado por uma corrente que varia no tempo, utiliza-se o parâmetro $\beta(n)$ como entrada do sistema.

Uma parte importante do modelo é a função $F(x, y)$. Esta é uma função não-linear, proposta por Rulkov como sendo:

$$
F(x, y)= \begin{cases}\alpha /(1-x)+y, & x \leq 0 \\ \alpha+y, & 0<x<\alpha+y \\ -1, & x \geq \alpha+y\end{cases}
$$

O parâmetro $\alpha$ está diretamente relacionado com o regime de disparo do neurônio, estabelecendo um valor mínimo a partir do qual o neurônio deixa de emitir potenciais de ação isolados e passa a atuar em sequências de disparos espaçadas uniformemente no tempo. A Figura 2.6 ilustra os possíveis estados do neurônio com relação ao regime de disparo, de acordo com os valores dos parâmetros $\sigma$ e $\alpha$.

Rulkov utilizou a abordagem de mapas bidimensionais iteráveis para propor variações desse modelo, notadamente conhecidos como o modelo supercrítico de Rulkov (SHILNIKOV; RULKOV, 2004) e o modelo caótico de Rulkov (RULKOV, 2001). Esses modelos utilizam as Equações 2.7 com variações da função $F(x, y)$ de forma a produzir diferentes trajetórias para as variáveis do sistema. 


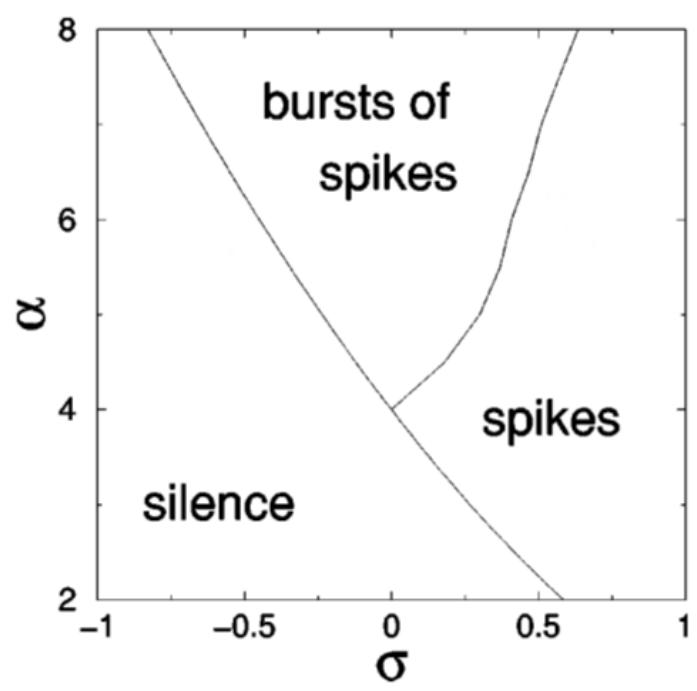

Figura 2.6: Diagrama de bifurcação do modelo de Rulkov para os parâmetros $\sigma$ e $\alpha$, entre os estados de silêncio (inativo), disparos isolados e trem de disparos consecutivos. Extraído de (RULKOV, 2002).

\subsection{Contexto para uma nova abordagem}

Conhecer os processos biológicos envolvidos na geração do potencial de ação foi fundamental para o surgimento dos primeiros modelos matemáticos do neurônio. Hodgkin e Huxley foram pioneiros nesse campo, desenvolvendo um modelo baseado em um sistema de equações diferenciais que representa a dinâmica das condutâncias dos principais canais de íons envolvidos na geração do potencial de ação. Essa abordagem forneceu a base para uma classe de modelos de tempo contínuo baseados em sistemas não-lineares. Particularmente, esses modelos consideram de forma explícita as propriedades físico-químicas da membrana neuronal durante o disparo, com a finalidade de representar de forma mais próxima da realidade o sinal observado. Nesses modelos, o ajuste dos parâmetros em geral é feito por meio de leituras em laboratório do sinal neuronal (GOLD et al., 2006; TABAK; MURPHEY; MOORE, 2000; WILLMS et al., 1999). Entretanto, são modelos que apresentam maior complexidade para simulações computacionais em grande escala e para estudos analíticos envolvendo múltiplos neurônios, devido a não-linearidades e ao número elevado de parâmetros em alguns casos (GOLD; HENZE; KOCH, 2007).

Uma outra família de modelos abstraiu rapidamente os fenômenos fisiológicos de forma a representar apenas a essência do funcionamento de um neurônio. Essa família tem como representante principal o modelo de McCulloch-Pitts (MCCULLOCH; PITTS, 1943), que possui um alto grau de simplificação, com o intuito de servir como base para a formação 
de grandes redes complexas a partir de um modelo bastante básico. Além disso, mais recentemente, pode-se encontrar modelos de tempo discreto que derivam do processo de discretização dos modelos de tempo contínuo, com maiores simplificações, e que já não possuem ligação tão direta com os fenômenos fisiológicos envolvidos. Essa classe de modelos, em geral é mais utilizada em implementações práticas, especialmente envolvendo uma grande quantidade de neurônios (HSU et al., 1996; MESBAH et al., 2014). Um exemplo conhecido desse tipo de representação são os mapas iteráveis de Rulkov.

A abordagem utilizada neste trabalho, no entanto, diverge de certa forma das classes mais comuns de modelos. Sua principal particularidade é utilizar um sistema linear para representação do sinal neuronal durante o disparo, ao invés de um sistema de equações não-lineares. A simulação do modelo é imediata, uma vez encontrados os parâmetros da função de transferência do sinal neuronal. Em outras palavras, não se exige a solução numérica de equações diferenciais para encontrar a saída do modelo em um determinado instante. Dessa forma, a abordagem apresenta um grau de simplificação comparável aos modelos de tempo discreto apresentados, bem como um alto nível de abstração em relação aos processos fisiológicos.

Porém, este modelo, diferentemente dos demais, não possui a lógica da transição de estados de um neurônio para determinar se realiza um disparo ou se permanece em silêncio. A frequência e os instantes de cada disparo não fazem parte do modelo, e são dadas somente pela entrada do sistema, que é exatamente um trem de impulsos unitários contendo o instante em que se espera que o neurônio produza um potencial de ação. Portanto, ressalta-se que o modelo proposto não representa completamente a dinâmica neuronal é preciso que os instantes de disparo sejam previamente conhecidos, ou produzidos por algum outro sistema acoplado à sua entrada.

Além disso, o modelo proposto neste trabalho foi criado com o objetivo principal de permitir a análise utilizando técnicas conhecidas de processamento de sinais e de sistemas lineares de tempo discreto. Esse fato será explorado para investigar as possíveis soluções para produzir um sistema equivalente inverso, capaz de identificar ou separar spikes de uma mistura de sinais neuronais de origens distintas. 


\section{Identificação de Sistemas}

Neste capítulo é apresentada uma sucinta revisão sobe a teoria de identificação de sistemas, de forma a introduzir os conceitos utilizados no desenvolvimento do trabalho. Esta teoria fundamenta a abordagem utilizada para propor um modelo para o disparo neuronal, baseando-se em observações dos sinais envolvidos. As formas lineares mais comuns para sistemas de tempo discreto são expostas, partindo de modelos autoregressivos e média móvel, até estruturas mais completas do tipo Box-Jenkins. Orientando-se às estruturas mais relevantes ao problema em questão, são selecionadas e discutidas as técnicas de estimação de parâmetros a serem aplicadas em cada caso. Veremos que estas técnicas baseiam-se no método dos mínimos quadrados aplicado em função do erro de estimação, e suas soluções são detalhadas ao longo de cada seção. Neste capítulo também é apresentada uma visão mais ampla do processo de identificação de sistemas, na qual inspiram-se as etapas em que o trabalho como um todo é organizado.

\subsection{Modelagem e Identificação de Sistemas}

De um modo geral, modelos são representações usadas para descrever e analisar sistemas e seus componentes. Diversos níveis de precisão e complexidade podem ser utilizados para criar algo que seja considerado um modelo; desde construções gráficas simples, até fórmulas matemáticas de alta complexidade. Modelos analíticos, ou matemáticos, são modelos que fazem uso de ferramentas matemáticas para descrever o comportamento de um sistema. Esses tipos de modelos possuem aplicações em várias áreas do conhecimento, como engenharia, física, biologia, economia, entre outros.

A identificação de sistemas é o processo de construir modelos matemáticos baseados em observações dos sinais associados a um sistema. Esta tarefa normalmente também é chamada de modelagem, embora alguns autores façam distinção entre os termos (LJUNG, 1999, cap. 1). Em geral, compreende desde o processo experimental de coleta de dados, passando pela escolha de uma estrutura para o modelo, estimação de seus parâmetros 
(quando aplicável), até a validação e simulação de modelos propostos.

O primeiro requisito para se identificar um sistema é ter algum conhecimento sobre os sinais que a ele estão relacionados. Em alguns casos, a identificação se dá apenas a partir de amostras dos sinais de entrada e saída, sem nenhum conhecimento sobre detalhes internos do sistema que se está identificando. O modelo assim resultante será chamado de modelo do tipo caixa preta; este é o alvo da maior parte das técnicas e algoritmos de identificação conhecidos. Se, por outro lado, houver disponibilidade de informações sobre os princípios físicos que governam o sistema e estes puderem ser aplicados na construção de um modelo, teremos um modelo do tipo caixa branca, cujas componentes possuem uma relação direta com a dinâmica do sistema representado, e normalmente sua concepção segue as particularidades de cada caso.

Um problema particular na identificação de sistemas é o da modelagem paramétrica. Especificamente, a saída $y(n)$ de um sistema de tempo discreto qualquer pode ser representada de forma abstrata a partir de um mapeamento $F($.$) aplicado à sua entrada x(n)$, ou seja,

$$
y(n)=F[x(n)]
$$

em que o mapeamento $F($.$) representa uma operação genérica. Esse sistema permite uma$ modelagem paramétrica quando

$$
\hat{y}(\boldsymbol{\theta}, n)=\mathcal{M}[\boldsymbol{\theta}, x(n)]
$$

em que o vetor $\boldsymbol{\theta}=\left[\begin{array}{llll}\theta_{1} & \theta_{2} & \ldots & \theta_{N}\end{array}\right]^{T}$ representa um conjunto de parâmetros que, associado a uma entrada $x(n)$, produz a saída $\hat{y}(\boldsymbol{\theta}, n)$, idealmente igual (ou suficientemente próxima) à saída do sistema original $y(n)$. Portanto, a tarefa de modelagem paramétrica é encontrar a estrutura para $\mathcal{M}$, e os valores de $\boldsymbol{\theta}$ que melhor aproximam o sistema em questão.

\subsection{Etapas do processo de identificação}

A tarefa de identificação de um sistema pode ser entendida como um processo maior que abrange desde a obtenção de amostras dos sinais envolvidos, até a validação do modelo proposto. Diversos autores sugerem suas próprias abordagens para a tarefa de identificação como um todo (LJUNG, 1999; AGUIRRE, 2007; BOX; JENKINS; REINSEL, 2008), que de forma geral pode ser resumida a algumas etapas mais relevantes. A seguir, apresentamos uma breve explicação de cada uma dessas etapas.

Coleta de Dados A primeira tarefa para se identificar um sistema desconhecido é obter 
amostras dos seus sinais de entrada e saída. Essa etapa inclui o planejamento do experimento, definindo quais sinais são mais relevantes e as condições de operação do sistema no momento em que os dados são capturados, de forma que as amostras obtidas carreguem o máximo possível de informações sobre o fenômeno em questão. Os detalhes técnicos envolvidos nesta etapa (como por exemplo taxa de amostragem, nível de ruído, entre outros) podem afetar a qualidade do modelo produzido no restante do processo.

Escolha da representação matemática Definir uma representação matemática para o modelo pode ser feito de diversas maneiras. Quando há algum conhecimento prévio sobre o funcionamento do sistema que se busca identificar, a representação poderá incorporar as informações que forem necessárias, de forma que o modelo resultante não será totalmente um modelo caixa preta. Em algumas ocasiões, a representação proposta é obtida após um estudo aprofundado do fenômeno ou dos sinais observados experimentalmente. Em outras, a representação é proposta por meio de sucessivas tentativas e erros. A escolha deve levar em conta os requisitos para o modelo, de forma a ponderar sobre as vantagens e desvantagens que um tipo de representação apresenta. Um modelo linear e invariante no tempo pode ser mais vantajoso que representações não-lineares complexas, mas não necessariamente será o que melhor descreve qualquer sinal (LJUNG, 1999, cap. 1). Nesta etapa, é estabelecida uma estrutura conceitual que irá conter as relações entre os parâmetros do modelo.

Estimação dos Parâmetros Uma vez escolhida a representação matemática do modelo, deve-se buscar a melhor forma de estimar os parâmetros por ela estabelecidos. Nessa etapa são definidos os critérios e técnicas que serão utilizados para produzir as estimativas dos parâmetros de forma que sejam representativas do sistema em questão. Esta tarefa dependerá significativamente dos dados coletados e das limitações das informações por eles carregadas.

Validação e Teste As etapas anteriores definem um modelo que produz uma aproximação dos sinais do sistema. O modelo é então avaliado, comparando-se suas saídas com as do sistema que está sendo modelado. Essa etapa compreende a definição de critérios que permitirão avaliar a qualidade do modelo e dizer se ele é apropriado para representar o fenômeno desejado. Se o resultado observado não for considerado apropriado, o modelo proposto pode ser rejeitado.

Esse processo normalmente é executado de forma repetitiva até que os requisitos estabelecidos sejam satisfeitos. Após cada validação, o modelo pode ser aperfeiçoado 
procurando uma nova representação, fazendo ajustes na estrutura utilizada ou recomeçando o processo, uma vez que o modelo obtido seja rejeitado. Em situações práticas, essas etapas são usualmente adaptadas para incorporar as particularidades do modelo que se está construindo. Na Figura 3.1 é ilustrada a divisão do processo nas etapas aqui discutidas, com uma breve descrição da aplicação de cada uma delas no modelo desenvolvido neste trabalho.

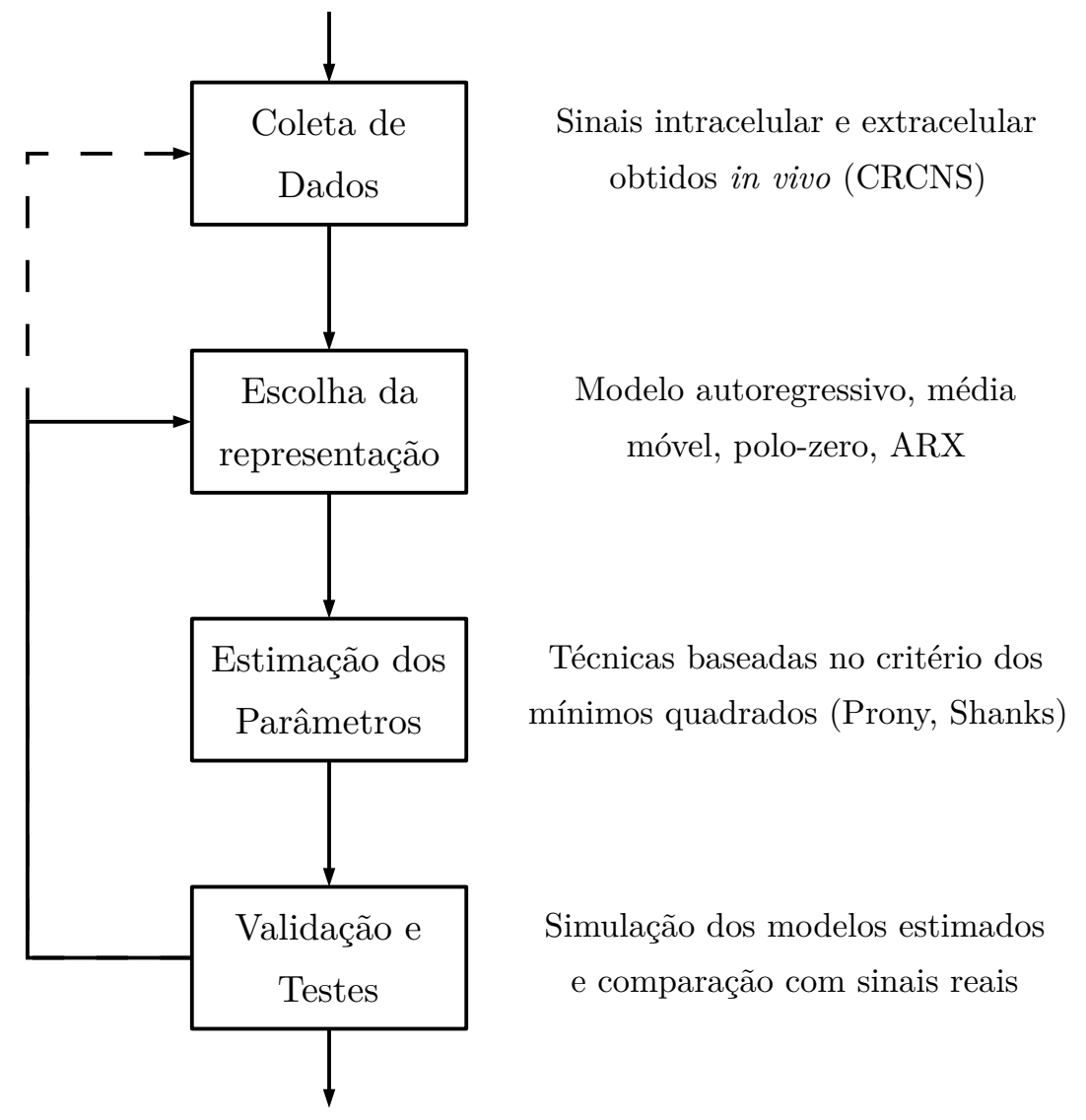

Figura 3.1: Etapas do processo de identificação de sistemas e suas aplicações no modelo desenvolvido neste trabalho.

\subsection{Modelos lineares e invariantes no tempo}

Sistemas lineares são aqueles que satisfazem o princípio da superposição (OPPENHEIM; SCHAFER, 2009, cap. 1). Quando os parâmetros de um sistema linear não variarem no tempo, esse sistema será chamado LTI (Linear Time Invariant), um caso de especial interesse na área de processamento de sinais. Uma propriedade importante de sistemas LTI é que eles podem ser completamente caracterizados por sua resposta ao impulso. Se 
considerarmos que todo sinal de tempo discreto pode ser expresso como uma soma de impulsos devidamente ponderados e deslocados no tempo, podemos escrever o sistema genérico da Equação 3.1 como

$$
y(n)=F\left[\sum_{k=-\infty}^{\infty} x(k) \delta(n-k)\right] .
$$

Se o sistema for linear, então

$$
y(n)=\sum_{k=-\infty}^{\infty} x(k) F[\delta(n-k)]
$$

devido ao princípio da superposição. Se o sistema é linear e invariante no tempo, teremos que sua resposta ao impulso será $h(n-k)=F[\delta(n-k)]$, de forma que

$$
y(n)=\sum_{k=-\infty}^{\infty} x(k) h(n-k) .
$$

Nota-se que a saída do sistema é definida a partir da sequência de entrada e da resposta ao impulso. Esta resposta também é escrita de forma compacta como

$$
y(n)=x(n) * h(n)
$$

em que * denota a operação de convolução. Consequentemente, esse sistema possuirá as mesmas propriedades da convolução, ou seja, será comutativo, distributivo e associativo. Essas propriedades são úteis quando da análise de sistemas LTI, que podem por exemplo ser decompostos em subsistemas associados em série ou em paralelo (OPPENHEIM; SCHAFER, 2009, cap. 2).

A representação para um sistema LTI utilizada em (3.5) no entanto nem sempre é eficiente. Em sistemas autoregressivos, será uma soma de infinitos elementos, o que torna o cálculo da saída do sistema pouco prático. No caso de sistemas causais, temos que

$$
h(n)=0 \quad \forall n<0
$$

de forma que podemos representar a saída do sistema em função direta dos seus valores passados e dos valores passados do sinal de entrada (PROAKIS; MANOLAKIS, 1996, cap. 2), ou seja

$$
y(n)=F[y(n-1), y(n-2), \ldots, y(n-p), x(n), x(n-1), \ldots, x(n-q)]
$$


que, no caso de um sistema LTI, assume a forma da equação de diferenças

$$
y(n)=\sum_{k=1}^{p} a_{k} y(n-k)+\sum_{k=0}^{q} b_{k} x(n-k)
$$

em que $p$ e $q$ são o número de atrasos considerados nas amostras dos sinais de saída e de entrada, respectivamente.

\subsubsection{Modelos AR e MA}

A Equação 3.9 é o caso geral de dois tipos comuns de sistemas LTI. No caso em que $q=0$ e $p>0$, a saída do sistema em um dado instante é dada somente pela soma de seus valores passados, e pelo valor do sinal de entrada mais atual. Temos um sistema autoregressivo (AR), também chamado de sistema só-polo, e podemos escrever, no domínio Z:

$$
Y(z)=\sum_{k=1}^{p} a_{k} Y(z) z^{-k}+b_{0} X(z)
$$

resultando na função de transferência

$$
\frac{Y(z)}{X(z)}=\frac{g_{f}}{A(z)}=\frac{g_{f}}{1-\sum_{k=1}^{p} a_{k} z^{-k}}
$$

em que $g_{f}=b_{0}$ representa um ganho geral do sistema. Um modelo que possua um sistema autoregressivo como componente é também chamado de IIR (Infinite Impulse Response), pois sua resposta ao impulso na forma da Equação 3.5 possui infinitos termos.

Se o sistema não possuir nenhum polo (i.e. não houver a presença de termos $a_{k}$ ), mas possuir $q>0$ zeros, temos um sistema do tipo média móvel (MA), também chamado só-zero. Podemos escrever, no domínio Z:

$$
Y(z)=\sum_{k=0}^{q} b_{k} X(z) z^{-k}
$$

o que determina a função de transferência na forma

$$
\frac{Y(z)}{X(z)}=B(z)=\sum_{k=0}^{q} b_{k} z^{-k}
$$

Esta função é também conhecida como FIR (Finite Impulse Response), pois sua resposta ao impulso terá um número finito de termos (exatamente $q+1$ termos), pois são equivalentes as representações das Equações 3.5 e 3.13. Os valores de $p$ e $q$ são as ordens dos polinômios de cada modelo, e portanto os sistemas (3.11) e (3.13) também são denotados $\operatorname{AR}(p)$ e 
$\operatorname{MA}(q)$, respectivamente.

\subsubsection{Modelos ARMA}

Quando, na Equação (3.9), tivermos que $p>0$ e $q>0$, temos um sistema do tipo autoregressivo média móvel (ARMA), ou polo-zero. Este sistema pode ser escrito como

$$
Y(z)=\sum_{k=1}^{p} a_{k} Y(z) z^{-k}+\sum_{k=0}^{q} b_{k} X(z) z^{-k}
$$

de modo que a função de transferência é dada por

$$
\frac{Y(z)}{X(z)}=\frac{B(z)}{A(z)}=\frac{\sum_{k=0}^{q} b_{k} z^{-k}}{1-\sum_{k=1}^{p} a_{k} z^{-k}} .
$$

Essa função é o resultado da associação em série dos sistemas dados por (3.11) e (3.13), e seu conjunto de parâmetros será um vetor $\boldsymbol{\theta}=\left[\begin{array}{llllllll}a_{1} & a_{2} & \ldots & a_{p} & b_{0} & b_{1} & \ldots & b_{q}\end{array}\right]^{T}$. Podemos também definir o vetor $\phi(n)=\left[\begin{array}{llllll}y(n-1) & y(n-2) & \ldots & y(n-p) & x(n) & x(n-1)\end{array}\right.$

$\ldots x(n-q)]^{T}$, o que permite reescrever a Equação (3.9) como

$$
y(n)=\boldsymbol{\phi}^{T}(n) \boldsymbol{\theta} .
$$

O modelo descrito pela Equação 3.15 é comumente utilizado na representação de sinais estocásticos. Neste contexto, a entrada $x(n)$ é um sinal aleatório, usualmente um ruído branco, o que torna a saída também um sinal aleatório (BELLANGER, 1989). No entanto, algumas aplicações utilizam a mesma estrutura para representar sinais deterministas. Nesse caso, o sinal $x(n)$ será um sinal determinista, e para efeitos de modelagem é considerado como sendo um impulso unitário, de forma que o sinal de saída é descrito completamente pelos parâmetros do modelo (HAYES, 1996, cap. 4). A implementação de um modelo ARMA é possível por meio de uma sequência de operadores de atraso sobre a saída e a entrada, como ilustrado pela Figura 3.2. 


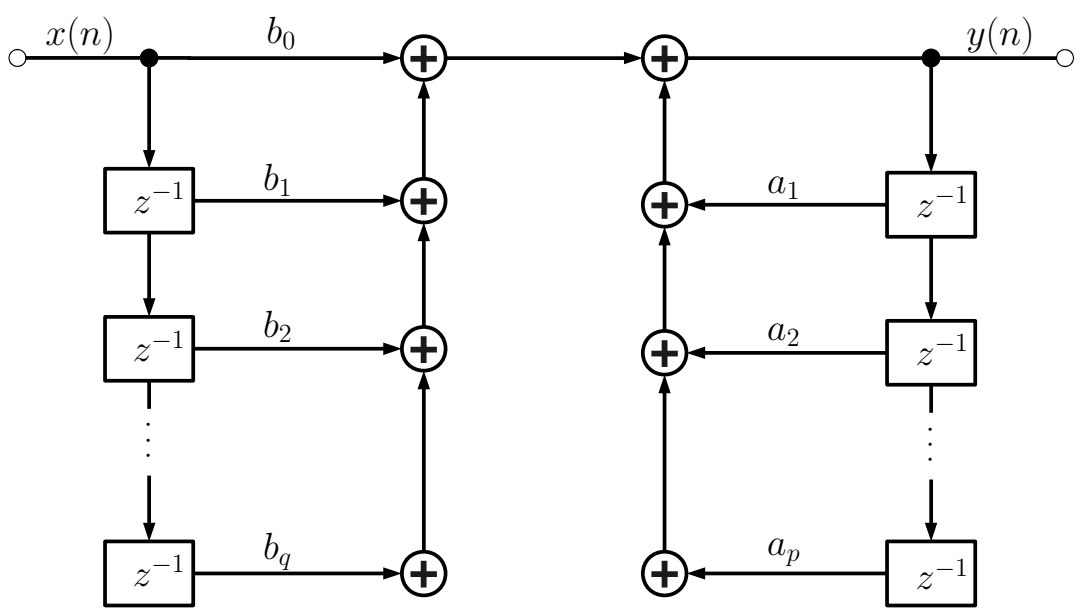

Figura 3.2: Estrutura do modelo ARMA, na forma de uma composição de atrasos sobre os sinais de entrada e saída.

\subsubsection{Modelos ARX, ARMAX e Box-Jenkins}

Uma representação mais geral que a do modelo ARMA inclui a adição de sinal de entrada qualquer ao modelo, passando por um segundo sistema do tipo média móvel. Esta adição resulta em um modelo do tipo ARMAX (Autoregressive Moving Average with Exogenous Inputs). Se denotarmos a transformada Z da entrada por $U(z)$, sua saída será dada por

$$
Y(z)=\frac{C(z)}{A(z)} U(z)+\frac{B(z)}{A(z)} X(z) .
$$

O sinal $u(n)$ no domínio do tempo é qualquer entrada que afete o comportamento do sistema; esta é uma configuração bastante conhecida de sistemas de controle. No caso particular em que $B(z)=0$, essa representação é chamada ARX (Autoregressive with Exogenous Inputs). Por outro lado, o modelo ARMA visto anteriormente é obtido quando não houver entrada exógena, ou seja, $U(z)=0$. A diferença entre os sinais $x(n)$ e $u(n)$ deve ser ressaltada: em $x(n)$, temos um sinal cuja função é excitar o sistema, também chamado de sinal de distúrbio, e não uma entrada propriamente dita. Esse sinal será um impulso unitário no caso de sistemas deterministas, e um ruido branco no caso de sistemas estocásticos. O sinal $u(n)$, por sua vez, em geral carrega alguma informação, e poderá ser qualquer tipo de sinal que guie o comportamento do sistema.

O caso mais geral da estrutura aqui exposta, no entanto, é o modelo Box-Jenkins 
(BOX; JENKINS; REINSEL, 2008). Esse modelo segue a relação

$$
Y(z)=\frac{C(z)}{D(z)} U(z)+\frac{B(z)}{A(z)} X(z) .
$$

Pode-se perceber que todos os modelos discutidos nesta seção derivam de casos particulares dessa equação. A Figura 3.3 ilustra a estrutura do modelo Box-Jenkins como a associação de funções de transferência.

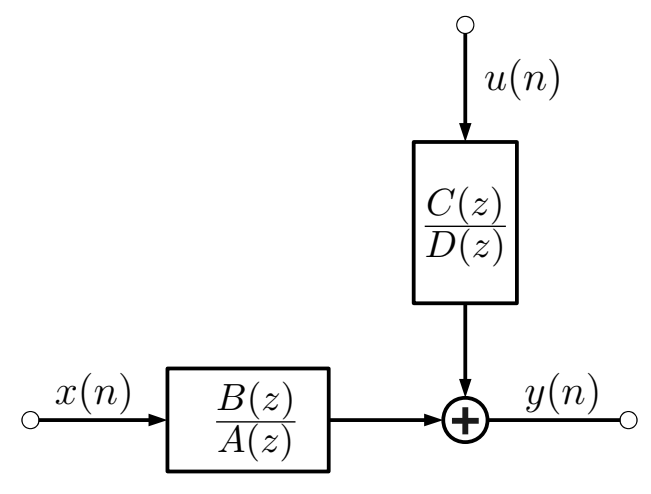

Figura 3.3: Diagrama de blocos do modelo Box-Jenkins.

\subsection{Estimação de parâmetros}

O conjunto de parâmetros de um modelo pode ser calculado utilizando diversas técnicas. Em geral, procura-se encontrar uma estimativa dos parâmetros que satisfaça um critério pré-definido para a qualidade da resposta do modelo em comparação com o sinal original. Uma ampla classe de técnicas baseia-se em funções da diferença entre a saída do sistema a ser identificado $y(n)$ e a saída produzida pelo modelo $\hat{y}(\boldsymbol{\theta}, n)$, que define o erro de estimação como sendo

$$
e(n)=y(n)-\hat{y}(\boldsymbol{\theta}, n)
$$

de forma que a função de custo pode ser genericamente representada por

$$
J=f[y(n)-\hat{y}(\boldsymbol{\theta}, n)]=f[e(n)] .
$$

Um critério comumente utilizado é o LS (Least Squares), em que $f($ ) é a energia do erro de estimação. Portanto, pode-se escrever a função custo como sendo

$$
J_{L S}=\sum_{n=0}^{\infty}|e(n)|^{2} .
$$


Os valores dos parâmetros $\boldsymbol{\theta}$ que melhor representam o sistema segundo esse critério são dados pela minimização da função custo

$$
\hat{\boldsymbol{\theta}}=\arg \min _{\boldsymbol{\theta}} J_{L S}
$$

a partir de um conjunto de amostras do sinal que se deseja identificar. Adiante, veremos algumas técnicas que fazem uso desse critério para produzir estimativas dos parâmetros de modelos LTI, e que são de interesse para este trabalho. A primeira delas é o método de Prony, que utiliza o critério LS somente para os parâmetros do denominador de um sistema ARMA determinista. Posteriormente, essa técnica foi modificada por Shanks para incluir o cálculo do numerador também considerando-se o LS (HAYES, 1996, cap. 4). Em seguida, com uma técnica análoga, veremos que é possível calcular os parâmetros de um modelo ARX.

\subsubsection{Método de Prony}

O método de Prony é uma técnica utilizada para estimar os coeficientes de um modelo ARMA determinista, como definido em (3.15). Supõe-se que o sinal $y(n)$, possa ser modelado por um sistema com $p$ polos e $q$ zeros, e cuja entrada é um impulso unitário. Sua função de transferência é portanto

$$
H(z)=\frac{B(z)}{A(z)}=\frac{\sum_{k=0}^{q} b_{k} z^{-k}}{1-\sum_{k=1}^{p} a_{k} z^{-k}} .
$$

Deseja-se estimar os coeficientes $a_{k}$ e $b_{k}$, de forma que a resposta ao impulso $h(n)$ do modelo obtido seja o mais próximo possível o sinal $y(n)$. Como neste caso $\hat{y}(n)=h(n)$, o erro a ser minimizado será dado por

$$
e(n)=y(n)-h(n)
$$

A transformada $\mathrm{Z}$ desta relação, considerando que $H(z)=B(z) / A(z)$, resulta em

$$
E(z)=Y(z)-\frac{B(z)}{A(z)}
$$

Multiplicando ambos os lados da equação por $A(z)$, temos um erro redefinido como

$$
E_{a}(z) \triangleq A(z) E(z)=A(z) Y(z)-B(z)
$$


Aplicando a antitransformada Z em (3.26) conjuntamente com (3.23), temos a função de erro no domínio do tempo:

$$
e_{a}(n)=y(n)-\sum_{k=1}^{p} a_{k} y(n-k)-\sum_{k=0}^{q} b_{k} \delta(n-k) .
$$

O método de Prony propõe encontrar inicialmente os coeficientes $a_{k}$, considerando o sistema como sendo do tipo só-polo. Como o termo contendo $b_{k}$ é nulo para $n>q$ na Equação 3.27, podemos escrever

$$
e_{a}(n) \triangleq e(n)=y(n)-\sum_{k=1}^{p} a_{k} y(n-k), \quad n>q
$$

em que $e(n)$ é o erro de predição progressiva do sinal $y(n)$. Isso sugere como vetor de coeficientes ótimos $a_{k}$ aquele que minimiza a função custo

$$
J_{\text {Prony }}=\sum_{n=q+1}^{\infty}|e(n)|^{2} .
$$

Uma definição da função de custo associada ao problema de predição linear para os coeficientes do denominador, a partir do sistema só-polo equivalente, pode ser encontrada em mais detalhes no Apêndice A deste trabalho. A minimização desta função é feita igualando-se a zero a derivada de $J_{\text {Prony }}$ em relação aos coeficientes $a_{k}$. A solução é dada por um conjunto de equações que dependem das funções de autocorrelação do sinal $y(n)$, conhecidas como equações de normais de Prony (HAYES, 1996, cap. 4):

$$
\sum_{k=1}^{p} a_{k} r_{y y}(m, k)=r_{y y}(m, 0), \quad m=1,2, \ldots, p .
$$

Os termos $r_{y y}(m, k)$ são os elementos da matriz de autocorrelação determinista do sinal $y(n)$, definidas pela relação

$$
r_{y y}(m, k)=\sum_{n=q+1}^{\infty} y(n-k) y(n-m)
$$

que é uma função simétrica, ou seja $r_{y y}(m, k)=r_{y y}(k, m)$. Vale notar que também podemos 
escrever a Equação 3.30 na forma matricial:

$$
\underbrace{\left[\begin{array}{ccccc}
r_{y y}(1,1) & r_{y y}(1,2) & r_{y y}(1,3) & \cdots & r_{y y}(1, p) \\
r_{y y}(2,1) & r_{y y}(2,2) & r_{y y}(2,3) & \cdots & r_{y y}(2, p) \\
r_{y y}(3,1) & r_{y y}(3,2) & r_{y y}(3,3) & \cdots & r_{y y}(3, p) \\
\vdots & \vdots & \ddots & \vdots & \\
r_{y y}(p, 1) & r_{y y}(p, 2) & r_{y y}(p, 3) & \cdots & r_{y y}(p, p)
\end{array}\right]}_{\mathbf{R}_{y y}} \underbrace{\left[\begin{array}{c}
a_{1} \\
a_{2} \\
a_{3} \\
\vdots \\
a_{p}
\end{array}\right]}_{\mathbf{a}}=\underbrace{\left[\begin{array}{c}
r_{y y}(1,0) \\
r_{y y}(2,0) \\
r_{y y}(3,0) \\
\vdots \\
r_{y y}(p, 0)
\end{array}\right]}_{\mathbf{r}_{y y}} .
$$

Logo, a solução procurada será dada por

$$
\mathbf{a}=\mathbf{R}_{y y}^{-1} \mathbf{r}_{y y}
$$

e portanto $\mathbf{R}_{y y}$ é uma matriz $p \times p$ simétrica e $\mathbf{r}_{y y}$ um vetor $p \times 1$. A demonstração dessa solução para o caso geral de estimação linear está resumida no Apêndice B deste trabalho.

Com os coeficientes $a_{k}$ que minimizam $J_{\text {Prony }}$ é possível obter os coeficientes $b_{k}$. Para tal, considera-se que o erro de modelagem para as $q$ primeiras amostras é nulo. Assim, com $e_{a}(n)=0$ em (3.27) tem-se

$$
b_{k}=y(k)+\sum_{l=1}^{p} a_{l} y(k-l), \quad k=0,1, \ldots, q .
$$

Note que esta última equação não é uma solução baseada no LS, e sim um sistema em termos das primeiras $q$ amostras do sinal. Esse é o fator motivador para o método de Shanks, uma melhoria proposta para o método de Prony.

\subsubsection{Método de Shanks}

No método de Shanks, a função $H(z)$ em (3.23) é obtida em duas etapas. O diagrama de blocos da Figura 3.4 ilustra os sinais envolvidos na configuração utilizada. Na primeira

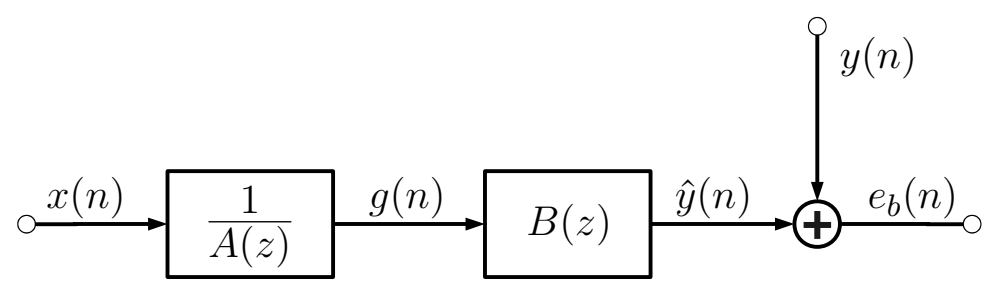

Figura 3.4: Diagrama de blocos dos sinais envolvidos nas etapas do método de Shanks. 
etapa, o modelo é considerado como sendo um sistema só-polo, e os coeficientes $a_{k}$ do denominador são obtidos através do método de Prony, usando a Equação 3.33 para $q=0$. Na segunda etapa, a saída $g(n)$ do modelo só-polo é utilizada como entrada para um sistema do tipo média móvel, de forma que a saída do modelo composto é dada por

$$
\hat{y}(n)=\sum_{k=0}^{q} b_{k} g(n-k) .
$$

Portanto, pode-se definir um novo erro de estimação a ser minimizado, desta vez em termos dos coeficientes do numerador:

$$
e_{b}(n)=y(n)-\hat{y}(n)=y(n)-\sum_{k=0}^{q} b_{k} g(n-k) .
$$

Novamente utilizando o critério dos mínimos quadrados, o vetor de coeficientes ótimos é aquele que minimiza a função custo $J_{b}$ definida como

$$
J_{b}=\sum_{n=0}^{\infty}\left|e_{b}(n)\right|^{2} .
$$

A solução neste caso também é encontrada igualando-se a zero as derivadas parciais desta função em relação a cada coeficiente. O vetor ótimo é dado em termos das funções de autocorrelação determinista

$$
\sum_{k=0}^{q} b_{k} r_{g g}(m, k)=r_{g y}(m, 0), \quad m=0,1, \ldots, q
$$

em que $r_{g g}(m, k)$ é a função de autocorrelação do sinal de saída do modelo só-polo $g(n)$, e $r_{g y}(m, k)$ a função de correlação cruzada entre o sinal de saída do modelo só-polo e o sinal desejado $y(n)$. Esta equação também pode ser escrita em forma matricial como

$$
\mathbf{b}=\mathbf{R}_{g g}^{-1} \mathbf{r}_{g y}
$$

em que $\mathbf{R}_{g g}$ é uma matriz $(q+1) \times(q+1)$ e $\mathbf{r}_{g y}$ um vetor $(q+1) \times 1$. Associando o sistema média móvel assim encontrado à saída do modelo só-polo, temos um sinal $\hat{y}(n)$ que é uma estimativa para o sinal desejado utilizando um sistema polo-zero. A diferença do método de Shanks para método de Prony está na forma como os coeficientes $b_{k}$ são obtidos: enquanto no caso de Prony estes são dados pela Equação 3.34, que zeram o erro em relação às primeiras $q$ amostras, em Shanks utiliza-se a Equação 3.38, baseada no LS sobre todo o conjunto de amostras considerado. 


\subsubsection{Identificação do sistema ARX}

Um sistema ARX é um sistema autoregressivo que possui como entrada somente um sinal $u(n)$, de forma que a Equação 3.17 resume-se a

$$
Y(z)=\frac{C(z)}{A(z)} U(z)
$$

Esta relação pode também ser descrita pela equação de diferenças

$$
y(n)=a_{1} y(n-1)+\ldots+a_{p} y(n-p)+c_{0} u(n)+\ldots+c_{q} u(n-q)
$$

de forma que podemos definir o vetor de parâmetros $\boldsymbol{\theta}=\left[\begin{array}{llllllll}a_{1} & a_{2} & \ldots & a_{p} & c_{0} & c_{1} & \ldots & c_{q}\end{array}\right]^{T}$, e o vetor de dados $\phi(n)=\left[\begin{array}{llllllll}y(n-1) & y(n-2) & \ldots & y(n-p) & u(n) & u(n-1) & \ldots\end{array}\right.$ $u(n-q)]^{T}$, e portanto a saída do sistema é dada por

$$
\hat{y}(n)=\phi^{T}(n) \boldsymbol{\theta}
$$

Assim como nos métodos vistos anteriormente, podemos novamente utilizar o critério dos mínimos quadrados (LS) para estimar os coeficientes ótimos para este modelo (LJUNG, 1999, cap. 1). Seja o erro de estimação $e_{\text {arx }}(n)$ dado por

$$
e_{a r x}(n)=y(n)-\hat{y}(n)=y(n)-\boldsymbol{\phi}^{T}(n) \boldsymbol{\theta}
$$

a função custo a ser minimizada, será portanto

$$
J_{\text {arx }}=\sum_{n=0}^{\infty}\left|e_{\text {arx }}(n)\right|^{2}=\sum_{n=0}^{\infty}\left|y(n)-\boldsymbol{\phi}^{T}(n) \boldsymbol{\theta}\right|^{2} .
$$

A solução é dada por um sistema de equações, em termos das funções de autocorrelação

$$
\sum_{n=0}^{\infty} \boldsymbol{\phi}(n) \boldsymbol{\phi}^{T}(n) \boldsymbol{\theta}=\sum_{n=0}^{\infty} \boldsymbol{\phi}(n) y(n)
$$

escritas também em forma matricial

$$
\boldsymbol{\theta}=\mathbf{R}_{\phi \phi}^{-1} \mathbf{r}_{\phi y}
$$

Nota-se que esta solução segue a mesma forma das técnicas baseadas no LS, como Prony e Shanks. Porém, aqui considera-se a correlação entre o vetor contendo não somente as amostras passadas do sinal de saída, mas também as amostras do sinal de entrada $u(n)$, uma vez que supõe-se que este carregue alguma informação sobre o sistema a ser modelado, o que não é o caso do distúrbio de entrada de um sistema puramente ARMA. 


\subsubsection{Estimação das funções de autocorrelação}

Os métodos de estimação de parâmetros até aqui discutidos dependem diretamente do cálculo das funções de autocorrelação. Na prática, este cálculo é feito utilizando-se um número finito de amostras dos sinais envolvidos, produzindo assim estimativas para os valores destas funções. Estas estimativas normalmente são feitas utilizando-se duas técnicas principais: o método da autocorrelação e o método da covariância (HAYES, 1996; OPPENHEIM; SCHAFER, 2009). Ambas baseiam-se no fato de que os sinais do sistema que se deseja modelar são conhecidos somente em um intervalo de tempo contendo $N$ amostras. Veremos adiante as diferenças de cada uma destas técnicas, bem como suas vantagens e desvantagens na obtenção dos parâmetros de um modelo.

\section{Método da autocorrelação}

No método da autocorrelação, o valor do sinal fora do intervalo $[0, N-1]$ é considerado como sendo igual a zero. Esta proposição tem efeitos diretos no somatório utilizado para o cálculo da função de autocorrelação. Supondo por exemplo o caso de um sistema do tipo só-polo, estimado pelo método de Prony, a função de autocorrelação dada pela Equação 3.31 torna-se

$$
r_{y y}(m, k)=\sum_{n=0}^{N+p-1} y(n-k) y(n-m) .
$$

Note que para satisfazer o sistema definido em (3.30), o somatório de $r_{y y}(m, k)$ utiliza amostras do sinal $y(n)$ no intervalo $[-p, N+p-1]$. De acordo com o método da autocorrelação, esta soma é possível, pois as amostras nos intervalos $[-p,-1]$ e $[N, N+p-1]$ são consideradas como tendo valor nulo. Como consequência, a função de autocorrelação passa a depender somente da diferença $m-k$, de forma que podemos reescrevê-la como

$$
r_{y y}(m, k)=\varrho_{y y}(m-k)=\sum_{n=0}^{N+p-1} y(n) y(n-m+k)
$$

O sistema de equações normais é então dado por

$$
\sum_{k=1}^{p} a_{k} \varrho_{y y}(m-k)=\varrho_{y y}(m) \quad m=1,2, \ldots, p
$$

que também é conhecido como equações de Yule-Walker (OPPENHEIM; SCHAFER, 2009, cap. 11). Esse resultado é importante, pois implica em que a matriz de autocorrelação $\mathbf{R}_{y y}$ será uma matriz de Toeplitz. Isso possibilita uma série de soluções alternativas para 
o cálculo de sua inversa, de menor complexidade computacional que o caso geral, como por exemplo o algoritmo de Levinson-Durbin (BELLANGER, 1989). Como desvantagem, a adição de zeros à série de amostras pode influenciar o processo de modelagem, e resultar na obtenção de parâmetros não realistas, principalmente se os valores reais do sinal fora do intervalo $[0, N-1]$ forem muito diferentes de zero.

\section{Método da covariância}

O método da covariância, por sua vez, não depende dos valores do sinal fora do intervalo $[0, N-1]$. Neste método, o somatório da função de autocorrelação é feito somente sobre as amostras disponíveis, e é dado por

$$
r_{y y}(m, k)=\sum_{n=p}^{N-1} y(n-k) y(n-m) .
$$

Ao contrário do método da autocorrelação, aqui esta função não dependerá apenas da diferença $m-k$, e portanto deve ser calculada para todos valores de $m$ e $k$ que forem necessários. Este método produz estimativas mais próximas a realidade do sinal em questão, uma vez que não assume que seus valores são zero fora do intervalo de amostras. Se o sistema a ser modelado possuir exatamente a mesma estrutura do modelo proposto, o erro de estimação em $[p, N-1]$ pode inclusive ser igual a zero. Porém, perde-se a estrutura de Toeplitz da matriz de autocorrelação, o que inviabiliza o uso de métodos de reduzido custo computacional para estimar os coeficientes ótimos. Além disso, menos amostras são consideradas no cálculo, uma vez que o somatório se dá apenas em um subconjunto das amostras disponíveis.

\subsection{Conclusões}

Os conceitos apresentados neste capítulo formam a fundamentação teórica do processo de modelagem do sinal neuronal proposto neste trabalho. A teoria de identificação de sistemas é aplicada em etapas conforme a abordagem apresentada na Seção 3.2, uma vez definidos os objetivos e os requisitos do modelo idealizado. De início, são apresentadas as possíveis estruturas e os parâmetros envolvidos, na forma de funções de transferência e relações entrada-saída. Em seguida, diferentes técnicas de estimação de parâmetros, derivadas da minimização da energia do erro, são empregadas a fim de obter os coeficientes de cada modelo. 
O problema prático de aplicar as técnicas de estimação, no entanto, passa por utilizar algum método de cálculo das funções de autocorrelação. Essas questões são discutidas em detalhes nos capítulos a seguir, dentro do contexto do trabalho. Os resultados da estimação permitem simular o sinal de saída do modelo, e comparar os resultados com sinais reais. Na etapa de validação, estes resultados são analisados para decidir se o modelo encontrado satisfaz os objetivos propostos.

O conhecimento das ferramentas que compõem o processo de modelagem mostrou-se de grande importância para o desenvolvimento do trabalho. Na concepção da abordagem proposta, estas ferramentas são exploradas de forma conveniente para o problema de modelagem do sinal neuronal. Ressalta-se que a teoria aqui discutida é apenas um subconjunto pequeno dentro da área de identificação de sistemas, e que diversas outras possibilidades ainda podem ser estudadas para uma aplicação no tipo de problema aqui levantado (LJUNG, 1999; AGUIRRE, 2007). 


\section{A modelagem proposta}

O modelo para a função $H(z)$ da Figura 1.2 é desenvolvido em etapas, partindo de condições específicas até ser expandido para o caso geral desejado. Em uma etapa preliminar, iremos considerar o sistema composto por somente um neurônio ativo e um único eletrodo como saída (ou seja, $K=1$ e $L=1$ ). Como na prática a leitura obtida no meio externo é realizada simultaneamente por múltiplos eletrodos, veremos também que a estrutura pode ser estendida para mais de um canal extracelular, produzindo um sistema com múltiplas saídas, de forma que $K>1$. Estes modelos são inicialmente considerados para a parametrização de um disparo isolado do neurônio, produzindo um conjunto de parâmetros representativo do sinal dentro de uma janela fixa de tempo. Em cada caso, são discutidos os modelos empregados e as técnicas de estimação de parâmetros correspondentes, com base no que foi exposto no Capítulo 3.

Posteriormente, veremos que é possível vislumbrar um modelo representativo da atividade de mais de um neurônio na mesma região, ou seja, com $L>1$ entradas. A principal dificuldade, neste caso, é a ausência de informações sobre o sinal intracelular de todos os neurônios que compõem o sinal extracelular observado, o que impede a realização da etapa de estimação de parâmetros, e consequentemente a validação de resultados práticos. A estrutura formada por um arranjo de sistemas lineares, no entanto, pode ser sugerida com base nos resultados dos modelos de apenas uma entrada. A formalização dessa estrutura irá contribuir para o objetivo de encontrar um sistema inverso que considere diversos neurônios ativos.

\subsection{Modelo para um único neurônio}

Este modelo é responsável por representar o disparo de um único neurônio, utilizando uma estrutura do tipo polo-zero cuja entrada é um sinal de excitação pontual. Sua representação é dividida em dois subsistemas associados em série, conforme indicado na Figura 4.1. Cada um dos subsistemas possui um conjunto de coeficientes capaz de 
representar o sinal neuronal durante o intervalo de tempo de um disparo isolado, produzindo em sua saída uma forma de onda de acordo com o local de aquisição do sinal neuronal, conforme apresentado na Figura 2.2. Neste caso, teremos que a função de transferência do sistema inteiro será dada pela convolução dos seus subsistemas, ou seja, $H(z)=F(z) G(z)$.

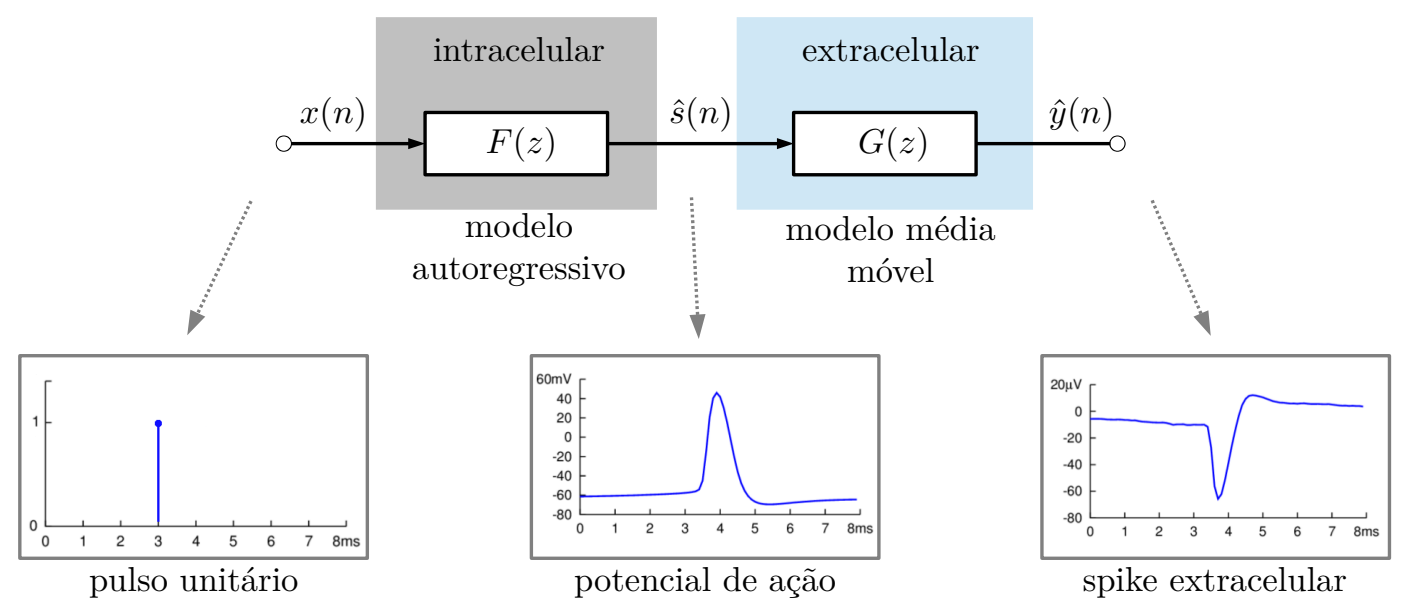

Figura 4.1: Modelo proposto para o disparo de um único neurônio.

A entrada $x(n)$ do modelo é um impulso unitário, deslocado no tempo para o exato momento em que o disparo é iniciado. Este impulso representa de forma abstrata o efeito que um estímulo pontual teria quando aplicado na célula nervosa. Como discutido na Seção 2.1, sabe-se que um neurônio irá disparar quando o potencial elétrico em sua membrana for acima de um determinado valor, chamado de potencial limiar (BEAR; CONNORS; PARADISO, 2006, cap. 4). Para representar esse fenômeno, consideramos que se o estímulo recebido pelo neurônio for abaixo do potencial limiar teórico, o sinal de entrada é considerado nulo; se for acima, o valor da entrada é tido como igual a unidade, o que faz a célula disparar. Esta premissa é comum em redes neurais artificiais, em que a saída do neurônio artificial é normalmente uma variável binária, tipicamente 0 ou 1 (HAYKIN, 2009). Portanto, pode-se representar matematicamente o sinal de entrada pela relação

$$
x(n)=\delta(n-\Delta)= \begin{cases}1, & n=\Delta \\ 0, & n \neq \Delta\end{cases}
$$

em que $n=\Delta$ é o instante de início do disparo, em que ocorre a formação do potencial de ação.

O subsistema $F(z)$ está associado com o potencial de ação produzido na membrana celular, e portanto irá representar características inerentes de cada neurônio. O problema de identificar esse sistema consiste em encontrar um modelo cuja saída $\hat{s}(n)$ seja uma boa 
estimativa do sinal original $s(n)$. Consequentemente, se o sinal intracelular $s(n)$ puder ser representado completamente pela função de sistema $F(z)$, teremos que $\hat{s}(n)=s(n)$.

O subsistema $G(z)$ representa o meio entre a célula e o eletrodo de leitura, e funciona como um canal de comunicação pelo qual o sinal intracelular é propagado até um determinado local externo. O sinal produzido em sua saída está associado ao spike extracelular, cujas características dependem não somente do neurônio gerador do disparo, mas também do ambiente no qual a célula está inserida. Nesse caso, a saída $\hat{y}(n)$ será uma estimativa do sinal real extracelular $y(n)$.

Iremos inicialmente utilizar um sistema autoregressivo do tipo só-polo para o subsistema $F(z)$. Da mesma forma, como ponto de partida para o subsistema $G(z)$, será utilizado um modelo do tipo média móvel, representado por um filtro transversal, também chamado de filtro FIR (Finite Impulse Response). A partir desses modelos, algumas estruturas alternativas são exploradas e validadas. A divisão resultante entre representações só-polo e média-móvel não é imediata, mas fica evidente quando analisadas as simulações de modelos contendo polos e zeros para cada subsistema, como será apresentado no Capítulo 5.

Por fim, deseja-se que a saída do sistema completo, formado pela concatenação em série de $F(z)$ com $G(z)$, forneça uma estimativa do sinal $y(n)$, ao ser alimentado com um impulso unitário na entrada. Esse modelo representará a parte determinista do sinal extracelular que está sendo modelado, ou seja, a parte capaz de ser parametrizada a partir de uma entrada determinista. Uma vez que esse modelo possui apenas uma entrada e uma saída, será do tipo SISO (Single Input Single Output).

\subsubsection{Modelo só-polo para o potencial de ação}

Nesta etapa será utilizado inicialmente um sistema autoregressivo do tipo só-polo para representar o sinal intracelular dentro de uma janela de tempo de um disparo. Dessa forma, vamos considerar que o valor do potencial de ação em um determinado instante é dado pela relação

$$
\hat{s}(n)=g_{f} x(n)+\sum_{k=1}^{K_{i}} a_{k} \hat{s}(n-k)
$$

em que $x(n)$ é a entrada do sistema, $g_{f}$ um fator de ganho geral, e $\hat{s}(n)$ a saída do modelo, de acordo com a estrutura ilustrada na Figura 4.1. Este modelo baseia-se na premissa de que, no curto intervalo de tempo em que ocorre um único potencial de ação, o potencial elétrico gerado pode ser previsto a partir de seus valores anteriores. Aplicando a 
transformada Z, temos que

$$
\hat{S}(z)=g_{f} X(z)+\hat{S}(z) \sum_{k=1}^{K_{i}} a_{k} z^{-k}
$$

Logo, a função de transferência do modelo $F(z)$ pode ser escrita como

$$
F(z)=\frac{\hat{S}(z)}{X(z)}=\frac{g_{f}}{1-\sum_{k=1}^{K_{i}} a_{k} z^{-k}}=\frac{g_{f}}{A(z)}
$$

que representa um sistema autoregressivo de ordem $K_{i}$. Portanto, para produzir um modelo deste tipo, devemos encontrar os valores dos coeficientes $a_{k}$ e do ganho $g_{f}$.

Como apresentado na Seção 3.4.1 os coeficientes do modelo autoregressivo podem ser obtidos utilizando-se o método de Prony. O primeiro passo, portanto, é encontrar o conjunto de coeficientes ótimos para o sistema dado por $A(z)$, a partir da solução do problema de predição progressiva. Nesse caso, considera-se como o sinal desejado o sinal intracelular $s(n)$, e a solução segundo o método dos mínimos quadrados é dada a partir da Equação 3.33, aqui reescrita como

$$
\mathbf{a}=\mathbf{R}_{s s}^{-1} \mathbf{r}_{s s}
$$

A matriz quadrada $\mathbf{R}_{s s}$ e o vetor $\mathbf{r}_{s s}$ possuem dimensões $\left(K_{i} \times K_{i}\right)$ e $\left(K_{i} \times 1\right)$, respectivamente, e são estimados com base no sinal $s(n)$, por meio das amostras obtidas experimentalmente.

Os coeficientes estimados com a solução da Equação 4.5 nos permitem encontrar o denominador da função de transferência $F(z)$. Resta, portanto, encontrar o valor do ganho $g_{f}$ mais adequado. Este ganho deve ser tal que a energia do sinal desejado seja igual a energia do sinal estimado no intervalo de tempo em questão. Dessa forma, se considerarmos que o sistema sem o efeito do ganho produz uma saída denotada por $\check{s}(n)$, podemos escrever

$$
g_{f}=\sqrt{\frac{\sum_{n=0}^{N-1}|s(n)|^{2}}{\sum_{n=0}^{N-1}|\check{s}(n)|^{2}}}
$$

e, portanto, a estimativa que iremos utilizar para o sinal será $\hat{s}(n)=g_{f} \check{s}(n)$. A função de transferência assim obtida representa a primeira parte do modelo. 


\subsubsection{Estendendo o modelo intracelular}

A modelagem do tipo só-polo possui a vantagem de utilizar um processo relativamente simples para obter um modelo autoregressivo para o potencial de ação. No entanto, este modelo pode ser melhorado com a adição de um termo do tipo média móvel, representado por $F_{\beta}(z)$, como ilustrado na Figura 4.2. Ao utilizarmos este novo termo associado ao modelo só-polo já encontrado, poderemos ter um sistema mais completo capaz de representar o potencial de ação com maior precisão.

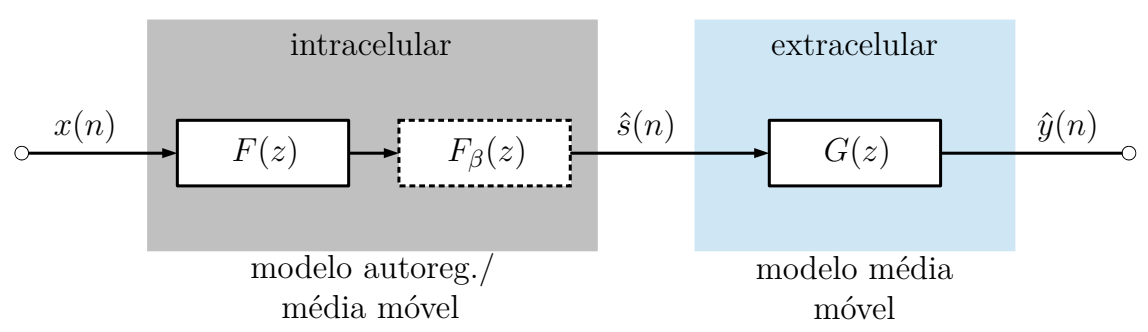

Figura 4.2: Modelo para o disparo neuronal com inclusão de uma função do tipo média móvel para o sinal intracelular $F_{\beta}(z)$.

O sistema a ser adicionado é um filtro do tipo FIR (Finite Impulse Response) de ordem $K_{\beta}$, cuja entrada é a saída do modelo só-polo, e a saída é o nova estimativa do potencial de ação. Dessa forma, a função de transferência associada ao numerador é dada por

$$
F_{\beta}(z)=\sum_{k=0}^{K_{\beta}} b_{k} z^{-k}
$$

em que $b_{k}$ são os coeficientes do sistema média móvel. Esse termo é associado à função $F(z)$ para produzir uma melhor estimativa do sinal $s(n)$. Como resultado, teremos um modelo alternativo para o potencial de ação, representado pela função $F_{p z}(z)$, de forma que

$$
F_{p z}(z)=F(z) F_{\beta}(z)=\frac{g_{f} \sum_{k=0}^{K_{\beta}} b_{k} z^{-k}}{1-\sum_{k=1}^{K_{i}} a_{k} z^{-k}} .
$$

Para o cálculo das estimativas dos parâmetros $a_{k}$ e $b_{k}$, iremos utilizar o método de Shanks, apresentado na Seção 3.4.2. Neste método, os coeficientes $a_{k}$ e o ganho $g_{f}$ são estimados por meio do método de Prony, a partir das Equações 4.5 e 4.6. Inicialmente é obtido um modelo só-polo, cuja saída será considerada um sinal intermediário, denotado 
como

$$
g(n)=g_{f} \check{s}(n) .
$$

A saída deste modelo é considerada como sinal de entrada em uma configuração de identificação de sistemas, cuja saída desejada é novamente $s(n)$. Essa configuração é utilizada para então encontrar os coeficientes $b_{k}$ de um filtro do tipo média móvel, por meio do sistema indicado na Equação 3.39. Dessa forma, o conjunto de coeficientes do numerador de (4.8) é dado pela relação

$$
\mathbf{b}=\mathbf{R}_{g g}^{-1} \mathbf{r}_{g s}
$$

Nessa equação, a solução depende da matriz de autocorrelação do sinal de saída do modelo intracelular só-polo, representada por $\mathbf{R}_{g g}$, e do vetor de correlação cruzada entre o sinal de saída do modelo só-polo e o sinal intracelular $s(n)$, dado por $\mathbf{r}_{g s}$. Vale reforçar que esses vetores e matrizes são estimados a partir do respectivos sinais em um intervalo de tempo de um único potencial de ação.

\subsubsection{Modelo média móvel para o sinal extracelular}

O segundo subsistema, denotado como $G(z)$, representa a transmissão do sinal no meio extracelular por meio de um sistema do tipo média móvel. Portanto, iremos modelar efeito do caminho que o sinal neuronal percorre entre a membrana celular e o eletrodo posicionado externamente à célula. A função de sistema proposta para esse caso é dada pela equação

$$
G(z)=\sum_{k=0}^{K_{e}} w_{k} z^{-k} .
$$

Assim, a saída produzida pelo modelo é calculada como

$$
\hat{y}(n)=\sum_{k=0}^{K_{e}} w_{k} \hat{s}(n-k)
$$

em que coeficientes $w_{k}$ do modelo são obtidos usando uma configuração de identificação de sistemas (HAYKIN, 1996; SAYED, 2008). Nessa configuração, a entrada do sistema desconhecido é o sinal intracelular; o sinal extracelular é a saída do modelo e também a resposta desejada.

Os coeficientes procurados podem ser obtidos pela solução dos mínimos quadrados para o problema de estimação supervisionada. Esse problema é um caso particular da estimativa ARX apresentada na Seção 3.4.3, em que as componentes autoregressivas são descartadas e somente a entrada é utilizada para a regressão. Em outras palavras, aplica-se 
a Equação 3.41, para o caso em que não existem coeficientes $a_{k}$, ou seja, a saída não depende de seus valores passados, com os valores $q=K_{e}$, e $u(n)=s(n)$. Detalhes da solução geral do problema de estimação são apresentados no Apêndice B.

Para calcular a solução desse sistema, iremos novamente estimar a matriz de autocorrelação procurada a partir dos dados experimentais. O sinal de entrada será o sinal intracelular $s(n)$, e o sinal desejado será o sinal extracelular $y(n)$ observado no eletrodo que será representado pelo modelo. Note que a ordem matriz de autocorrelação do sinal intracelular será nesse caso igual a $\left(K_{e}+1\right)$; a estimativa do vetor de correlação cruzada é dada por

$$
\mathbf{p}_{s y}=\sum_{n=0}^{N-1} \mathbf{s}(n) y(n)
$$

Teremos então uma estimativa dos coeficientes a partir da solução do sistema dado pela equação

$$
\mathbf{w}=\mathbf{R}_{s s}^{-1} \mathbf{p}_{s y}
$$

A concatenação do modelo extracelular média móvel com o modelo intracelular só-polo, proposto na Seção 4.1.1, permite propor a função de sistema $H(z)$ do modelo para o spike de um neurônio :

$$
H(z)=F(z) G(z)=\frac{g_{f} \sum_{k=0}^{K_{e}} w_{k} z^{-k}}{1-\sum_{k=1}^{K_{i}} a_{k} z^{-k}}
$$

que é um sistema ARMA, ou polo-zero.

\subsubsection{Modelo do disparo como um sistema ARX}

Uma maneira alternativa de estimar os coeficientes da estrutura apresentada pela Figura 4.1, é extrapolar o uso da técnica para modelos ARX (modelo autoregressivo de entradas exógenas) apresentada na Seção 3.4.3. Neste caso, o sinal de entada não é mais visto como um simples distúrbio do sistema, e sim como uma entrada determinista qualquer. Esta diferença supõe que o sinal de entrada carrega algum tipo de informação relacionada com a saída do modelo. Apesar de na prática o sinal de entrada continuar a ser o impulso unitário, veremos que esta suposição pode produzir resultados interessantes, e também pode ser considerada para estimar os parâmetros procurados. 


\section{Modelo ARX para o sinal intracelular}

Se considerarmos o modelo intracelular estendido definido na Equação 4.8 com ganho unitário, podemos aplicar a técnica de identificação ARX para encontrar os coeficientes $a_{k}$ e $b_{k}$ em um único passo. De acordo com a Equação 3.42, definimos os vetores de parâmetros e vetores de dados como sendo

$$
\begin{aligned}
\boldsymbol{\theta}_{i} & =\left[\begin{array}{llllllll}
a_{1} & a_{2} & \ldots & a_{K_{i}} & b_{0} & b_{1} & \ldots & b_{K_{\beta}}
\end{array}\right]^{T} \\
\phi_{i}(n) & =\left[\begin{array}{lllllllll}
s(n-1) & s(n-2) & \ldots & s\left(n-K_{i}\right) & x(n) & x(n-1) & \ldots & x\left(n-K_{\beta}\right)
\end{array}\right]^{T} .
\end{aligned}
$$

A solução é então dada pela equação a partir da Equação 3.46, aqui reescrita como

$$
\boldsymbol{\theta}_{i}=\mathbf{R}_{\phi_{i} \phi_{i}}^{-1} \boldsymbol{r}_{\phi_{i} s}
$$

Note que, apesar de produzir as estimativas de todos coeficientes em um só passo, a matriz de autocorrelação agora possui dimensão $\left(K_{i}+K_{\beta}+1\right)$.

\section{Modelo ARX para o sinal extracelular}

O mesmo procedimento pode ser aplicado utilizando o sinal extracelular $y(n)$ como referência. Os vetores neste caso são definidos como

$$
\begin{aligned}
\boldsymbol{\theta}_{e} & =\left[\begin{array}{lllllllll}
a_{1} & a_{2} & \ldots & a_{K_{i}} & w_{0} & w_{1} & \ldots & w_{K_{e}}
\end{array}\right]^{T} \\
\phi_{e}(n) & =\left[\begin{array}{llllllll}
y(n-1) & y(n-2) & \ldots & y\left(n-K_{i}\right) & x(n) & x(n-1) & \ldots & x\left(n-K_{e}\right)
\end{array}\right]^{T}
\end{aligned}
$$

A solução é então dada pela relação

$$
\boldsymbol{\theta}_{e}=\mathbf{R}_{\phi_{e} \phi_{e}}^{-1} \boldsymbol{r}_{\phi_{e} s}
$$

Aqui também temos a matriz de autocorrelação de maior dimensão, nesse caso igual a $\left(K_{i}+K_{e}+1\right)$. Outro fato importante é que teremos um sistema com polos e zeros para o sinal extracelular, cujos coeficientes são calculados em somente um passo de estimação. Idealmente, esse modelo deverá possuir parâmetros equivalentes aos encontrados em duas etapas (só-polo intracelular em cascata com média móvel extracelular).

\subsection{Modelo para múltiplos eletrodos}

Como discutido na Seção 1.3, a aquisição em laboratório do sinal extracelular é feita por meio de arranjos contendo de 4 a 6 eletrodos. Portanto, utilizando o processo de modelagem 
proposto, podemos considerar o caso do sinal produzido por um único neurônio durante seu disparo, observado simultaneamente por mais de um eletrodo. Como consequência, serão obtidas pelo menos 4 funções $G(z)$ para um mesmo spike. Na Figura 4.3 é ilustrada a estrutura de um modelo com 4 canais de saída, cada um deles associados a um eletrodo posicionado no meio externo à célula. Este modelo apresenta os subsistemas relativos ao sinal extracelular como canais de transmissão em paralelo, cujo sinal de entrada, produzido na célula nervosa, é o mesmo em todos canais. Espera-se que os valores estimados para cada função $G_{i}(z)$ reflitam a diferença de posicionamento de cada eletrodo em relação ao neurônio gerador do potencial de ação. Essas diferenças acrescentam diversidade espacial à captação do sinal extracelular, e portanto, podem auxiliar no processo de identificação do spike. O modelo dessa forma será do tipo SIMO (Single Input Multiple Output).

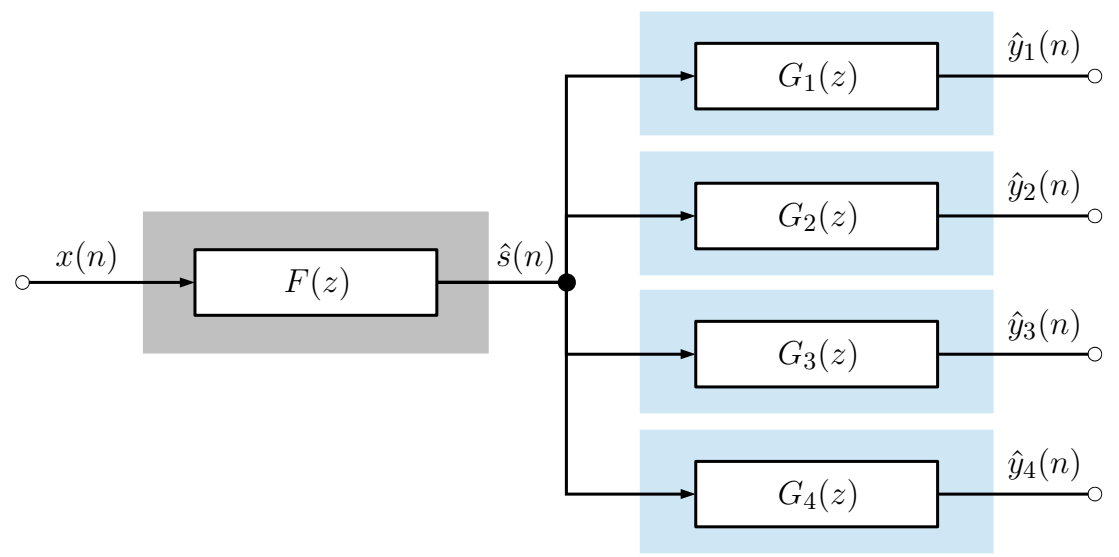

Figura 4.3: Estrutura do modelo de múltiplas saídas utilizando $K=4$ canais no modelo extracelular.

A equação para as saídas do sistema extracelular pode ser escrita na forma matricial no tempo:

$$
\left[\begin{array}{c}
\hat{y}_{1}(n) \\
\hat{y}_{2}(n) \\
\hat{y}_{3}(n) \\
\vdots \\
\hat{y}_{K}(n)
\end{array}\right]=\left[\begin{array}{ccccc}
w_{0}^{1} & w_{1}^{1} & w_{2}^{1} & \ldots & w_{K_{e}}^{1} \\
w_{0}^{2} & w_{1}^{2} & w_{2}^{2} & \ldots & w_{K_{e}}^{2} \\
w_{0}^{3} & w_{1}^{3} & w_{2}^{3} & \ldots & w_{K_{e}}^{3} \\
\vdots & \vdots & \vdots & \ddots & \vdots \\
w_{0}^{K} & w_{1}^{K} & w_{2}^{K} & \ldots & w_{K_{e}}^{K}
\end{array}\right] \cdot\left[\begin{array}{c}
\hat{s}(n) \\
\hat{s}(n-1) \\
\hat{s}(n-2) \\
\vdots \\
\hat{s}\left(n-K_{e}\right)
\end{array}\right]
$$

em que $w_{k}^{i}$ é o $k$-ésimo coeficiente da função $G_{i}(z)$, seguindo a mesma representação do tipo média móvel dada pela Equação 4.11. Note que essa matriz de coeficientes é análoga 
a uma matriz de mistura convolutiva para uma fonte única e múltiplas antenas (ATTUX et al., 2007a).

\subsection{Modelo para múltiplos neurônios ativos}

Os resultados apresentados até o momento possibilitam a obtenção da função de transferência $H(z)$ para o caso em que existe apenas um neurônio ativo, e a saída do sistema é observada por um ou mais eletrodos externos. Esse cenário possui uma modelagem simplificada, conforme ilustrado pela Figura 4.1. No entanto, na grande maioria dos casos, teremos mais de um neurônio ativo em uma dada região cerebral sendo observada. Devemos, portanto, estender o modelo para levar em consideração a atividade de múltiplas células neuronais ao mesmo tempo. Para tal, iremos considerar que o sinal que chega a um dado eletrodo é composto pela mistura de várias componentes, cada qual contendo os potenciais de ação de um neurônio ativo nas proximidades. O sinal obtido no eletrodo em uma região com $L$ neurônios ativos será então dado pela relação

$$
\hat{y}_{i}(n)=\sum_{j=1}^{L} \hat{y}_{i, j}(n)
$$

em que $\hat{y}_{i, j}(n)$ representa a componente produzida pelo neurônio $j$ no sinal captado por um eletrodo $i$. Note que, neste caso, estamos assumindo que o sinal final é uma sobreposição dos sinais extracelulares de cada neurônio ativo. Na Figura 4.4 apresenta-se a estrutura básica do modelo, com as componentes intracelulares e extracelulares exibidas separadamente. Neste modelo, temos $L$ entradas para somente uma saída, e portanto ele será do tipo MISO (Multiple Input Single Output).

Assim como no modelo de um neurônio único, a estrutura do modelo para o disparo de uma ou mais células neuronais é dividida em duas partes. Na primeira parte, temos subsistemas em paralelo que produzem em cada saída um potencial de ação quando a entrada correspondente receber um impulso unitário. Essa etapa, portanto, está associada exclusivamente às entradas $x_{j}(n)$ do sistema e irá representar o conjunto de neurônios responsáveis por originar os potenciais de ação.

Na segunda parte, temos subsistemas que produzem spikes com as mesmas características do sinal extracelular, a partir dos potenciais de ação dos neurônios representados pelo modelo intracelular. Portanto, suas entradas estão conectadas às saídas do modelo da etapa anterior. Como visto, pode-se dizer que o modelo desta etapa representa o caminho entre o neurônio e cada um dos eletrodos. As saídas então são somadas para formar uma 
mistura de spikes em um mesmo sinal. Analiticamente, esta relação pode ser descrita como

$$
\hat{Y}_{i}(z)=\sum_{j=1}^{L} F_{j}(z) G_{i, j}(z) X_{j}(z)
$$

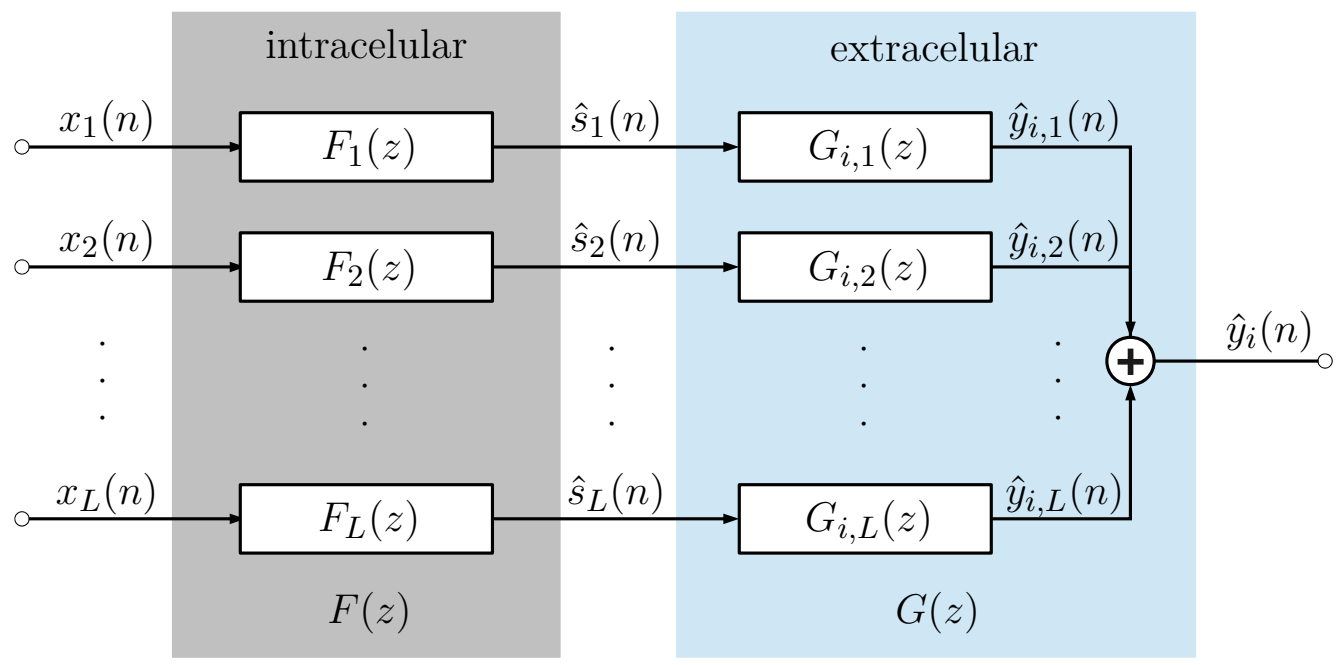

Figura 4.4: Modelo para o sistema formado por $L$ neurônios ativos observados por um único eletrodo externo.

Conforme visto na Seção 4.2, eletrodos podem estar dispostos em arranjos com diversos elementos em paralelo, obtendo mais de uma leitura da região em um mesmo intervalo de tempo, analogamente à um sistema de múltiplas antenas. Dessa forma, teremos na realidade que $i=1, \ldots, K$, em que $K$ é o número de eletrodos no arranjo, e o sistema completo será de múltiplas entradas e múltiplas saídas, ou MIMO (Multiple Input Multiple Output). Um exemplo com $L$ neurônios e $K=2$ saídas é representado na Figura 4.5.

Como os subsistemas $F_{j}(z)$ são funções racionais, podemos simplificar a formulação escrevendo as equações matriciais do sistema completo no domínio da frequência. Sejam seguintes vetores

$$
\begin{aligned}
\mathbf{X}(z) & =\left[\begin{array}{llll}
X_{1}(z) & X_{2}(z) & \ldots & X_{L}(z)
\end{array}\right]^{T} \\
\hat{\mathbf{S}}(z) & =\left[\begin{array}{llll}
\hat{S}_{1}(z) & \hat{S}_{2}(z) & \ldots & \hat{S}_{L}(z)
\end{array}\right]^{T}
\end{aligned}
$$

respectivamente, o vetor cujos elementos são os sinais de entrada do sistema, e o vetor cujos elementos representam os sinais obtido em cada saída do modelo intracelular. A 


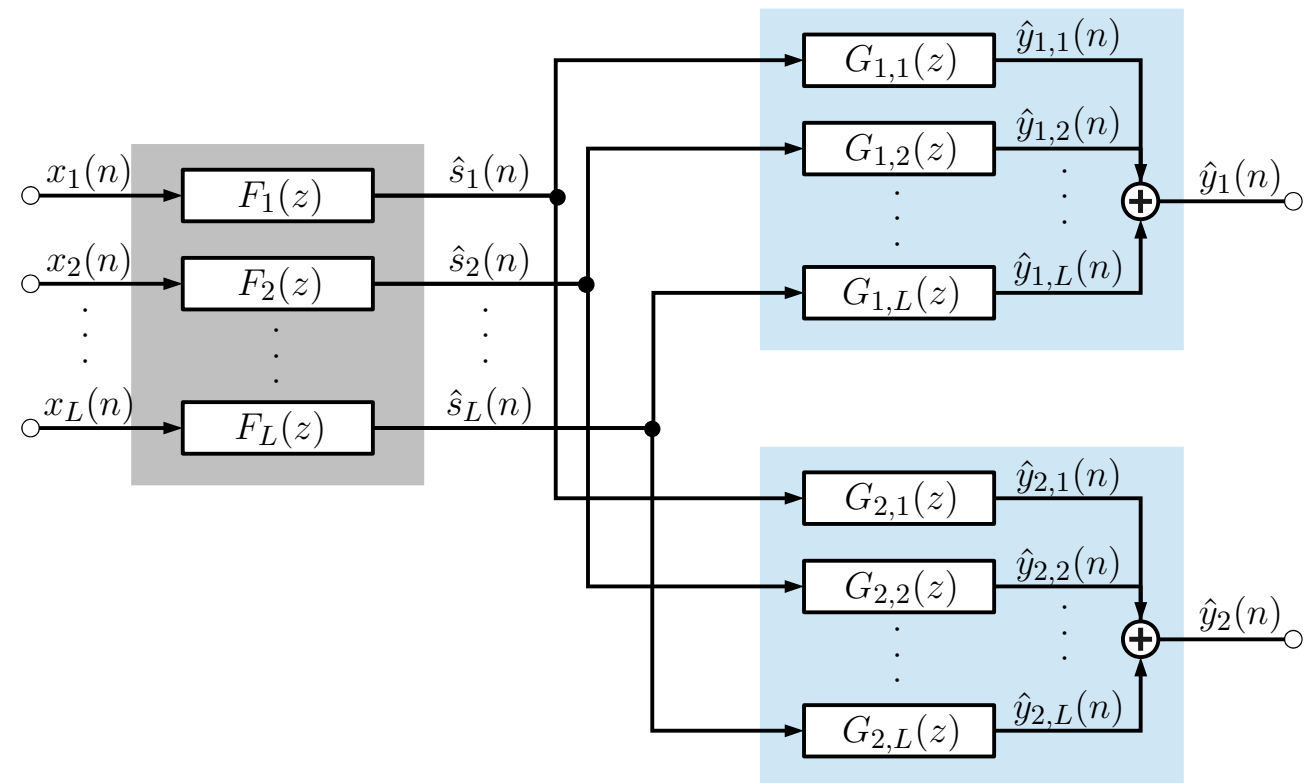

Figura 4.5: Sistema MIMO com $L$ neurônios e $K=2$ eletrodos na saída.

relação entre esses sinais será dada por

$$
\left[\begin{array}{c}
\hat{S}_{1}(z) \\
\hat{S}_{2}(z) \\
\hat{S}_{3}(z) \\
\vdots \\
\hat{S}_{L}(z)
\end{array}\right]=\left[\begin{array}{ccccc}
F_{1}(z) & 0 & 0 & \ldots & 0 \\
0 & F_{2}(z) & 0 & \ldots & 0 \\
0 & 0 & F_{3}(z) & \ldots & 0 \\
\vdots & \vdots & \vdots & \ddots & \vdots \\
0 & 0 & 0 & \ldots & F_{L}(z)
\end{array}\right] \cdot\left[\begin{array}{c}
X_{1}(z) \\
X_{2}(z) \\
X_{3}(z) \\
\vdots \\
X_{L}(z)
\end{array}\right]
$$

Da mesma forma, o vetor cujos elementos são as saídas do sistema extracelular pode ser escrito como sendo

$$
\hat{\mathbf{Y}}(z)=\left[\begin{array}{llll}
\hat{Y}_{1}(z) & \hat{Y}_{2}(z) & \ldots & \hat{Y}_{K}(z)
\end{array}\right]^{T}
$$

de forma que a relação entre o sinal intracelular e o sinal extracelular é dada por

$$
\left[\begin{array}{c}
\hat{Y}_{1}(z) \\
\hat{Y}_{2}(z) \\
\hat{Y}_{3}(z) \\
\vdots \\
\hat{Y}_{K}(z)
\end{array}\right]=\left[\begin{array}{ccccc}
G_{1,1}(z) & G_{1,2}(z) & G_{1,3}(z) & \ldots & G_{1, L}(z) \\
G_{2,1}(z) & G_{2,2}(z) & G_{2,3}(z) & \ldots & G_{2, L}(z) \\
G_{3,1}(z) & G_{3,2}(z) & G_{3,3}(z) & \ldots & G_{3, L}(z) \\
\vdots & \vdots & \vdots & \ddots & \vdots \\
G_{K, 1}(z) & G_{K, 2}(z) & G_{K, 3}(z) & \ldots & G_{K, L}(z)
\end{array}\right] \cdot\left[\begin{array}{c}
\hat{S}_{1}(z) \\
\hat{S}_{2}(z) \\
\hat{S}_{3}(z) \\
\vdots \\
\hat{S}_{L}(z)
\end{array}\right]
$$

Substituindo (4.21) em (4.22), pode-se encontrar a relação entrada-saída do sistema 
completo:

$$
\left[\begin{array}{c}
\hat{Y}_{1}(z) \\
\hat{Y}_{2}(z) \\
\vdots \\
\hat{Y}_{K}(z)
\end{array}\right]=\left[\begin{array}{cccc}
G_{1,1}(z) F_{1}(z) & G_{1,2}(z) F_{2}(z) & \ldots & G_{1, L}(z) F_{L}(z) \\
G_{2,1}(z) F_{1}(z) & G_{2,2}(z) F_{2}(z) & \ldots & G_{2, L}(z) F_{L}(z) \\
\vdots & \vdots & \ddots & \vdots \\
G_{K, 1}(z) F_{1}(z) & G_{K, 2}(z) F_{2}(z) & \ldots & G_{K, L}(z) F_{L}(z)
\end{array}\right] \cdot\left[\begin{array}{c}
X_{1}(z) \\
X_{2}(z) \\
\vdots \\
X_{L}(z)
\end{array}\right]
$$

De acordo com as definições dos vetores de entrada e saída, podemos escrever a Equação 4.23 como

$$
\hat{\mathbf{Y}}(z)=\mathbf{H}(z) \mathbf{X}(z)
$$

sendo $\mathbf{H}(z)$ a matriz polinomial contendo as funções de transferência do sistema completo. Essa matriz terá dimensões $K \times L$, e seus elementos representam a função de transferência pela qual cada sinal de entrada passa para produzir uma componente no sinal de saída.

\subsection{Conclusões}

Apresentamos a modelagem do sinal neuronal partindo de um modelo mais simples, representativo do sinal produzido por um neurônio isolado, em uma janela de tempo fixa em torno de um único disparo. Esse modelo foi considerado como sendo a associação em série de dois subsistemas, intracelular e extracelular. O primeiro, com características predominantemente de um sistema autoregressivo; o segundo, de um sistema do tipo média móvel. A associação em série destes dois modelos obtidos de forma independente visa a reproduzir o spike por meio de um conjunto limitado de parâmetros, a partir de um impulso unitário na entrada, representando um estímulo responsável pela ativação do neurônio.

Os parâmetros dos modelos lineares propostos podem ser obtidos por meio de técnicas de estimação conhecidas, discutidas em detalhe no Capítulo 3. Esse modelo será validado no próximo capítulo, utilizando dados experimentais reais dos sinais intracelular e extracelular. Por meio de observações simultâneas de eletrodos dispostos em arranjos, também é possível construir um modelo de múltiplas saídas. Dessa forma, o modelo poderá representar a atividade de um único neurônio observada por $K$ eletrodos (com $K=1, \ldots, 4$, no caso de um tetrodo) posicionados no meio extracelular. Esse modelo reproduz a diversidade espacial comumente encontrada em leituras experimentais.

A estrutura dos modelos permite sugerir um sistema mais geral, de múltiplas entradas e múltiplas saídas, contendo a atividade de várias células de uma mesma região cerebral. 
Como vimos, encontrar os parâmetros desse modelo dependerá da disponibilidade de sinais de mais de um neurônio. Porém, é possível imaginar a estrutura teórica da matriz do sistema e algumas de suas propriedades. Essa abordagem poderá ter aplicações úteis na busca pelo sistema inverso, uma vez validados os sistemas mais simples. Um ponto para maior investigação é entender a capacidade dos parâmetros encontrados para identificar e diferenciar spikes produzidos por neurônios distintos. 


\section{A validação do modelo proposto}

Este capítulo apresenta os resultados da aplicação do processo de modelagem proposto utilizando dados experimentais para estimação dos parâmetros e validação dos modelos obtidos. Antes de serem utilizados, no entanto, os dados experimentais passam por uma etapa prévia de processamento de forma a garantir que somente as componentes de interesse de cada sinal sejam consideradas na modelagem. Essa etapa é discutida em detalhes no começo do capítulo.

O processo de simulação e validação inicia-se com a determinação da ordem dos modelos de cada subsistema, e consequentemente da dimensão dos vetores e matrizes definidos no Capítulo 4, utilizados no cálculo dos coeficientes. Inicialmente é validado o modelo neuronal SISO para um disparo isolado, em seus subsistemas intracelular e extracelular. A estimação de coeficientes é então estendida ao caso em que a leitura é feita por mais de um eletrodo, repetindo-se o processo para cada canal do sinal extracelular.

Os resultados são apresentados para cada subsistema isoladamente, comparando-se a saída dos modelos obtidos e os sinais reais, de acordo com a técnica de estimação dos parâmetros empregada. Este processo é aplicado em um único disparo selecionado, definindo-se uma janela de tempo em torno do potencial de ação e do respectivo spike. As amostras dos sinais dentro dessa janela são consideradas para estimar um conjunto de parâmetros associado ao disparo em questão. Em uma etapa posterior, esse procedimento é replicado para cada disparo de uma sequência, o que permite a análise da variação dos valores dos coeficientes de um mesmo neurônio ao longo do tempo. O capítulo termina com discussões adicionais que complementam o processo de modelagem.

\subsection{Considerações sobre os dados experimentais}

O processo de validação baseia-se na utilização de medições in vivo do potencial elétrico produzido pela atividade neuronal, registradas em séries temporais disponíveis no site do CRCNS (HENZE et al., 2000b). Essas medições foram feitas utilizando-se 
uma micropipeta posicionada no corpo celular, capaz de registrar o sinal intracelular, e um arranjo de quatro a seis eletrodos posicionados no meio externo à célula. As leituras passam por um processo de filtragem e amplificação, e são posteriormente digitalizadas em arquivos binários contendo um canal para cada leitura (um para o sinal intracelular e 4 a 6 para o sinal extracelular). Mais detalhes sobre o processamento empregado nos dados antes de serem disponibilizados são apresentados na Seção 1.3. Na forma como são fornecidos, no entanto, os dados digitalizados ainda requerem um refinamento para serem utilizados no processo de modelagem em particular. Neste trabalho, realizamos duas etapas de processamento sobre o sinal disponibilizado, detalhadas a seguir. Após este processamento, é evidenciada a forma de onda do sinal durante o intervalo de disparo, e suas variações no espaço e no tempo.

\subsubsection{Ajustes de escala dos dados}

Devido ao processo de amplificação e filtragem na fonte durante a captura, os valores absolutos dos sinais intracelular e extracelular não representam realisticamente o fenômeno fisiológico, e estão dissociados do potencial elétrico que se espera como resultado da atividade neuronal. Portanto, um primeiro passo é efetuar um ajuste de escala sobre todas as leituras. Esse ajuste é feito por meio de uma transformação que resulta no sinal com a amplitude correta, a partir de parâmetros que dependem do experimento e do equipamento utilizado. Resumidamente, leva-se em consideração os número de bits utilizado para a quantização $\left(b_{\text {quant }}\right)$, uma constante acrescentada ao sinal antes da gravação $\left(v_{\text {off set }}\right)$, o ganho da amplificação na fonte $\left(g_{s r c}\right)$, e os valores máximos de escala do equipamento de leitura $\left(v_{\max }\right)$. Esses parâmetros são fornecidos junto com os dados de cada experimento. O sinal intracelular $s(n)$ ajustado é calculado então na forma

$$
s(n)=\frac{\left[s_{\text {orig }}(n)-v_{\text {offset }}\right] v_{\max }}{g_{\text {src }} 2^{\left(b_{\text {quant }}-1\right)}} .
$$

em que $s_{\text {orig }}(n)$ é o sinal bruto antes do ajuste. A mesma operação é realizada sobre cada canal do sinal extracelular.

\subsubsection{Filtragem preliminar}

Antes de serem utilizados no processo de modelagem, é desejável eliminar dos sinais as componentes que não terão sua representação no modelo proposto. No caso do sinal extracelular, por exemplo, devemos retirar as partes relacionadas ao LFP, para obter uma 
série que contenha somente a sequência de spikes produzida pelos neurônios próximos aos eletrodos. Dessa forma, cada canal extracelular passa por um filtro do tipo passa-altas, com frequência de corte em $300 \mathrm{~Hz}$, antes de ser utilizado no processo de modelagem. Somado ao fato de que o sinal fora filtrado na fonte por meio de um passa-baixas com frequência de corte em $3000 \mathrm{~Hz}$, o sinal resultante irá apresentar somente componentes no intervalo de 300-3000Hz. Na Figura 5.1a é apresentado o sinal experimental obtido originalmente pelo eletrodo extracelular, enquanto que na Figura 5.1b observa-se o mesmo sinal após passar pelo filtro passa-altas. Note que ao removermos as componentes de baixa frequência, os spikes do trecho em questão são naturalmente realçados. Percebe-se que o sinal filtrado apresenta os spikes perceptivelmente visíveis.

a)

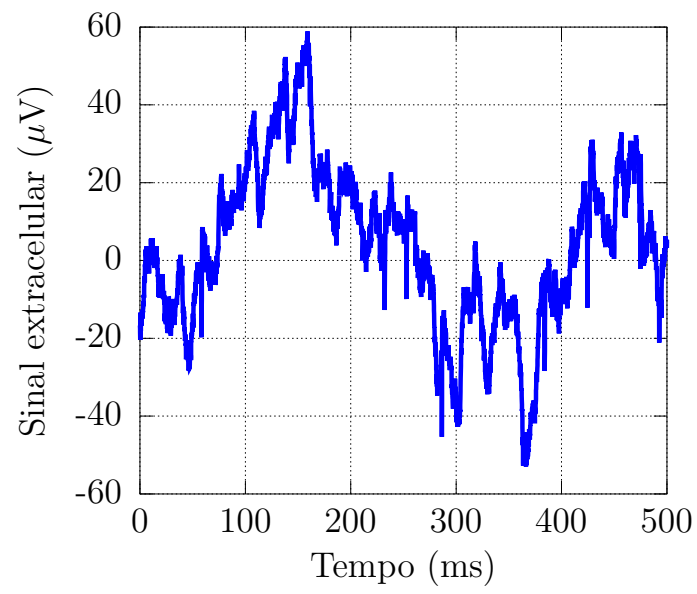

b)

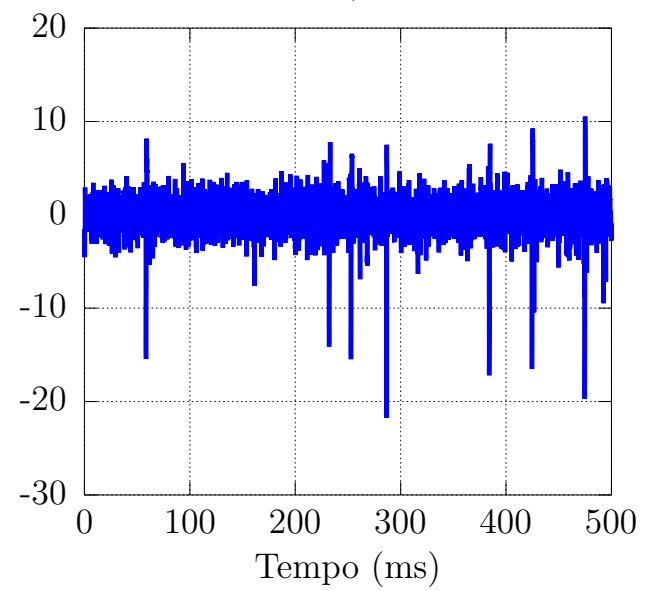

Figura 5.1: a) sinal extracelular originalmente obtido in vivo e b) mesmo sinal após passar por um filtro passa-altas.

Da mesma forma, o sinal intracelular passa por um filtro passa-altas, com frequência de corte em $50 \mathrm{~Hz}$, com a função principal de remover componentes contínuas. A Figura 5.2 ilustra o mesmo trecho do sinal intracelular antes e após esta filtragem. Após esta etapa, ambos os sinais (intracelular e extracelular) apresentam seu valor de repouso próximo de zero.

A partir dos sinais filtrados, conseguimos estabelecer uma correspondência entre as séries temporais intracelular e extracelular. Na Figura 5.3 são apresentados os sinais obtidos em um mesmo intervalo de tempo, destacando os spikes gerados pelo mesmo neurônio ativo na série intracelular. Note que boa parte dos spikes que compõem a série não está relacionada com o neurônio em questão. 
a)

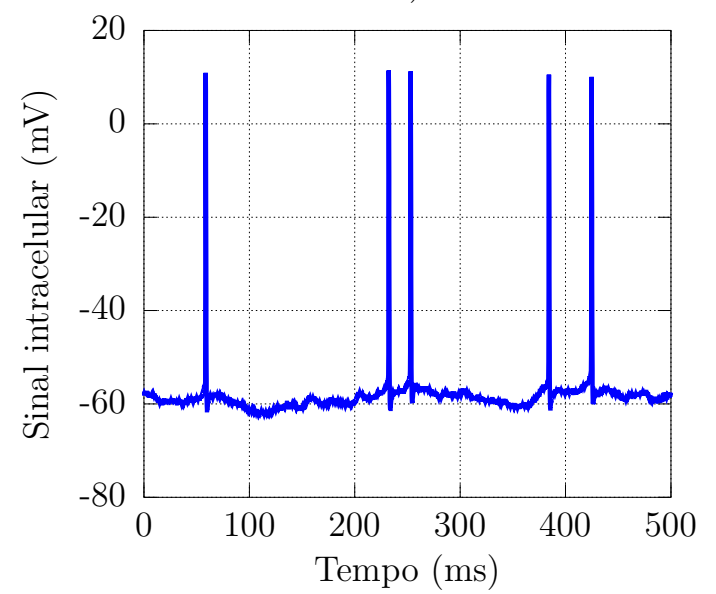

b)

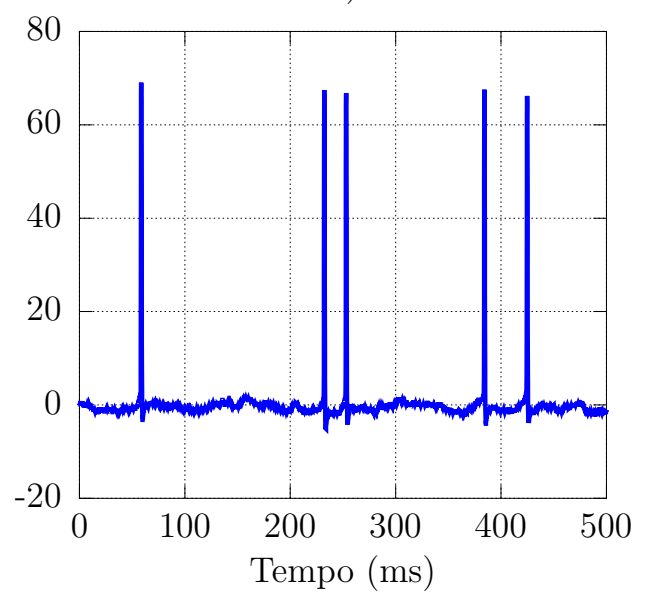

Figura 5.2: a) sinal intracelular original e b) mesmo sinal com valor de repouso em zero, após remoção de componentes contínuas.

a)
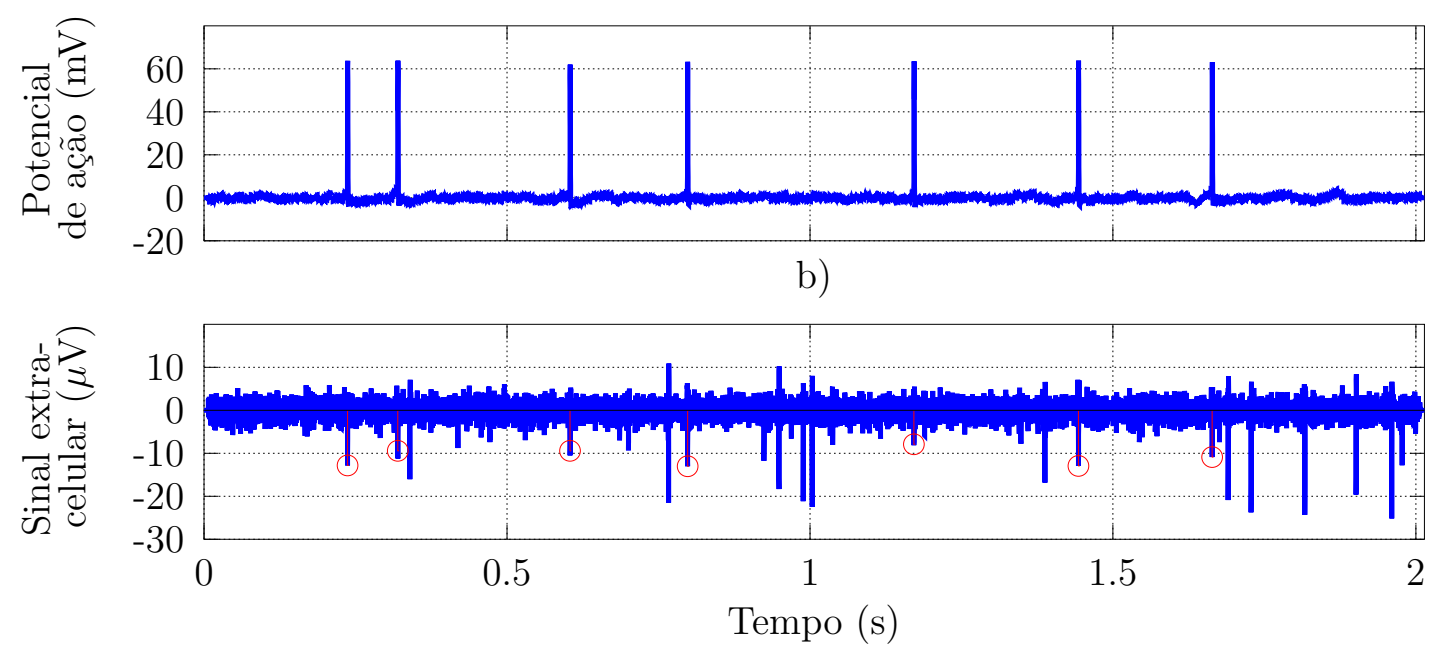

Figura 5.3: a) sinal intracelular e b) sinal extracelular, destacando os spikes que correspondem aos potenciais de ação gerado pelo neurônio observado.

\subsubsection{Variações na forma de onda do disparo}

É possível observar a variação do potencial de ação produzido pelo neurônio, sobrepondose todos os potenciais de ação por ele produzidos em um dado intervalo de tempo. Na Figura 5.4 são mostrados o valor da curva média e os limites estabelecidos pelo desvio padrão, para um conjunto de 86 potenciais de ação observados em sequência. Essa curva é obtida alinhando-se o valor máximo de cada potencial de ação da série em uma mesma janela de 14 ms. Da mesma forma, podemos calcular a curva média e o desvio padrão para o spike extracelular, encontrando o resultado apresentado na Figura 5.5. Pode-se observar visualmente o efeito de uma pior relação sinal-ruído no caso do sinal extracelular, comumente encontrado em leituras deste tipo. 


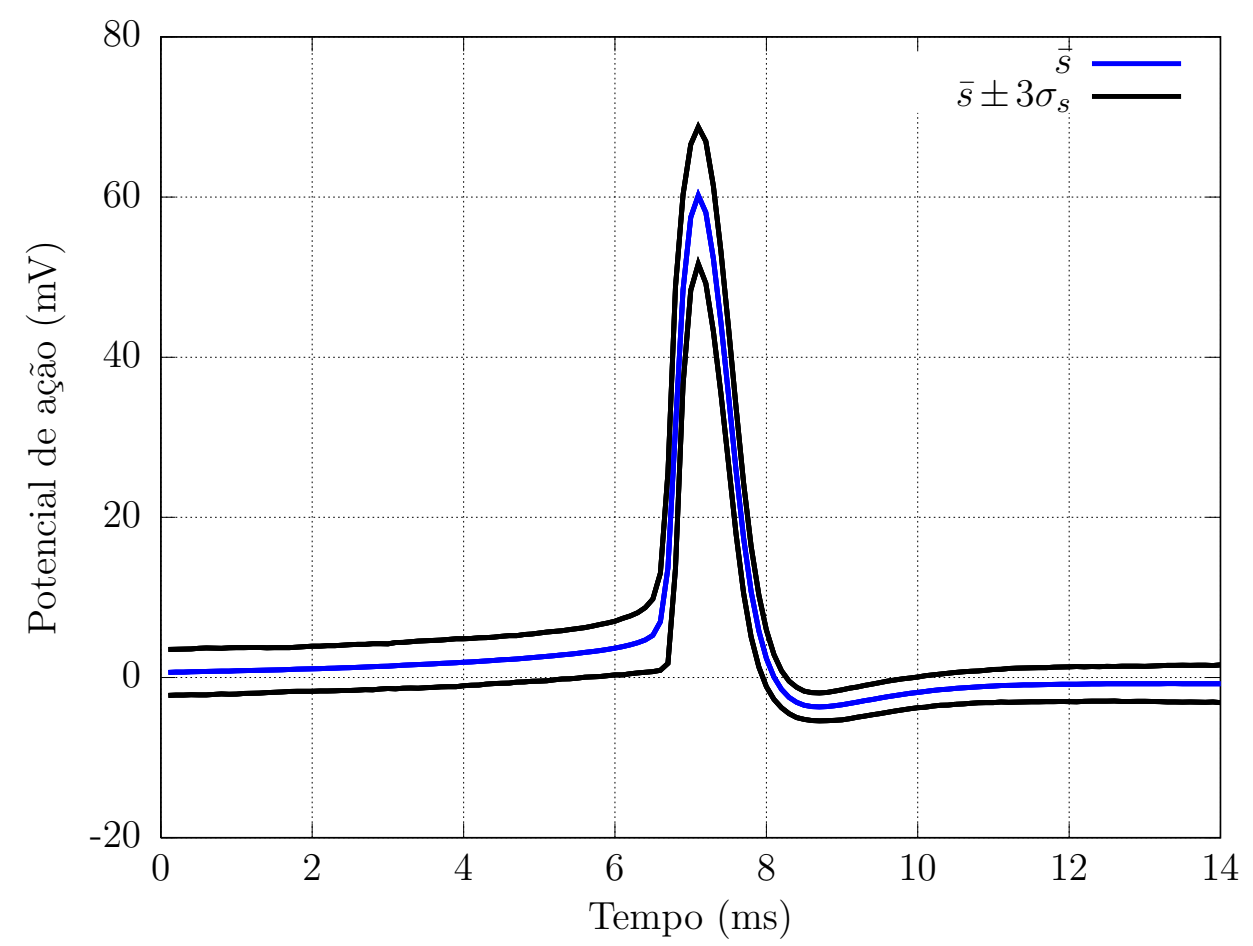

Figura 5.4: Valor médio dos potenciais de ação $(\bar{s})$ observados em sequência em um mesmo intervalo de tempo e limites definidos a partir do desvio padrão calculado $\left(\sigma_{s}\right)$.

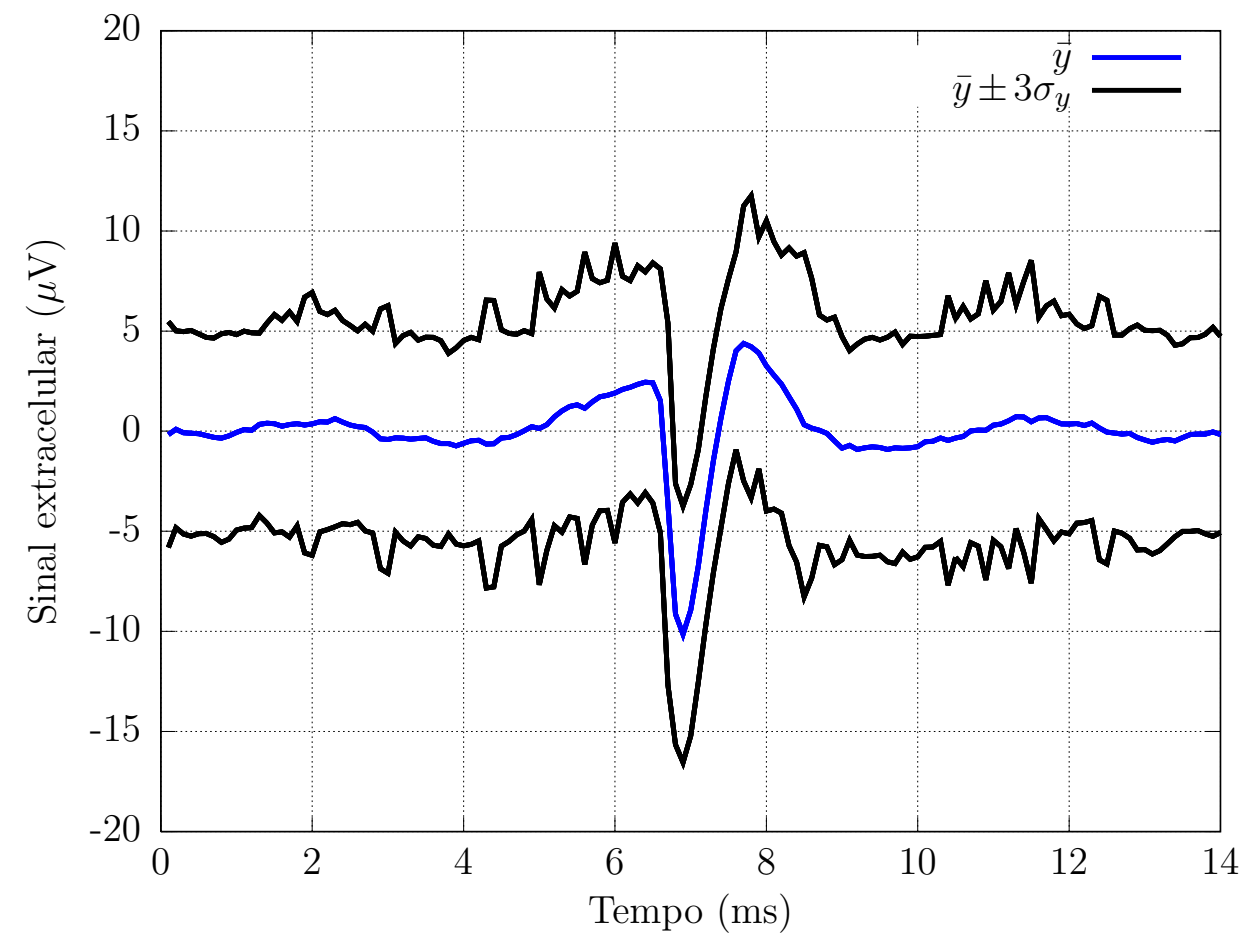

Figura 5.5: Valor médio dos spikes $(\bar{y})$ de um mesmo neurônio observados em sequência em um mesmo intervalo de tempo, e limites definidos a partir do desvio padrão calculado $\left(\sigma_{y}\right)$.

As diferenças entre o sinal extracelular observado em um disparo também são perceptíveis entre as leituras de cada eletrodo, pois estes encontram-se em posições distintas em 
relação à célula. Na Figura 5.6 é apresentado um mesmo spike observado simultaneamente em quatro eletrodos independentes. Dessa forma, espera-se que os parâmetros do modelo variem não somente a cada disparo, mas também entre os eletrodos em que o sinal é observado.

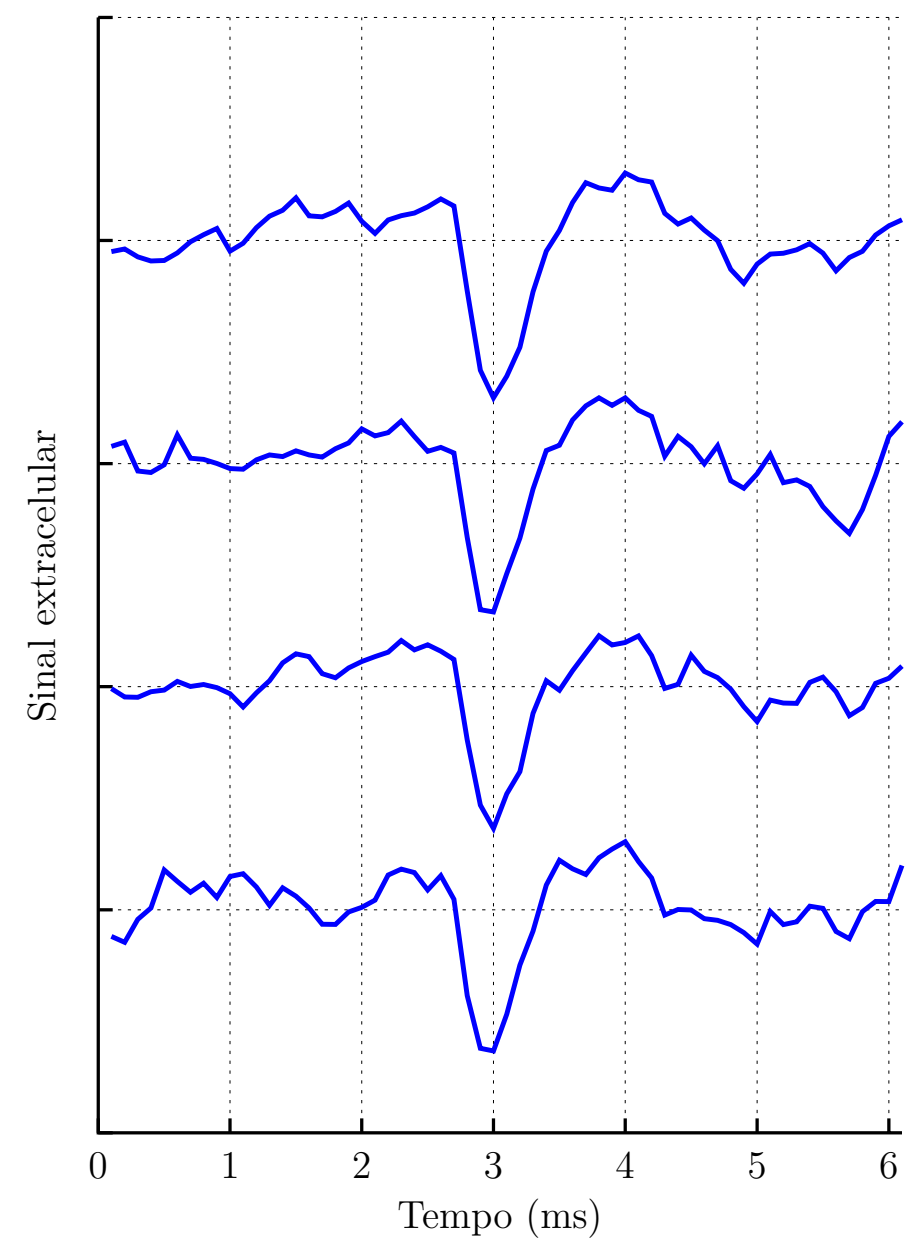

Figura 5.6: Leitura de um mesmo spike por quatro eletrodos extracelulares.

\subsection{A ordem dos modelos}

Em cada subsistema que compõe o modelo para o caso SISO, é necessário definir o número mínimo de coeficientes que permite que o modelo seja capaz de reproduzir o sinal neuronal com razoável assertividade. Em outras palavras, deve-se encontrar os menores inteiros $K_{i}$ e $K_{e}$, utilizados nas Equações 4.2 e 4.12, que sejam suficientes para produzir modelos adequados. Note que esta definição afeta diretamente a complexidade dos cálculos envolvidos na estimação dos parâmetros de cada subsistema, pois irá determinar as dimensões das matrizes de autocorrelação utilizadas.

Diversas abordagens podem ser empregadas para se estimar a ordem de um modelo 
paramétrico (LJUNG, 1999, cap. 16). As abordagens mais conhecidas em geral baseiam-se em critérios de informação (STOICA; SELÉN, 2004; BEHESHTI; DAHLEH, 2003), ou derivam de medidas da correlação entre as variáveis envolvidas. No caso do modelo só-polo, uma boa indicação do número de coeficientes do denominador é dada a partir da função de autocorrelação parcial do sinal $s(n)$. Em um modelo autoregressivo de ordem $p$, espera-se que o valor da autocorrelação parcial para o atraso $p+1$ ou maior seja igual ou próximo a zero. Na prática, define-se um intervalo de confiança baseado no erro padrão SE (Standard Error) da função, dentro do qual a função é considerada como tendo um valor desprezível (BOX; JENKINS; REINSEL, 2008, cap. 3). Na Figura 5.7 mostra-se a função de autocorrelação parcial média calculada com os disparos da série intracelular em questão, e o intervalo de confiança de $95 \%$ baseado no erro padrão.

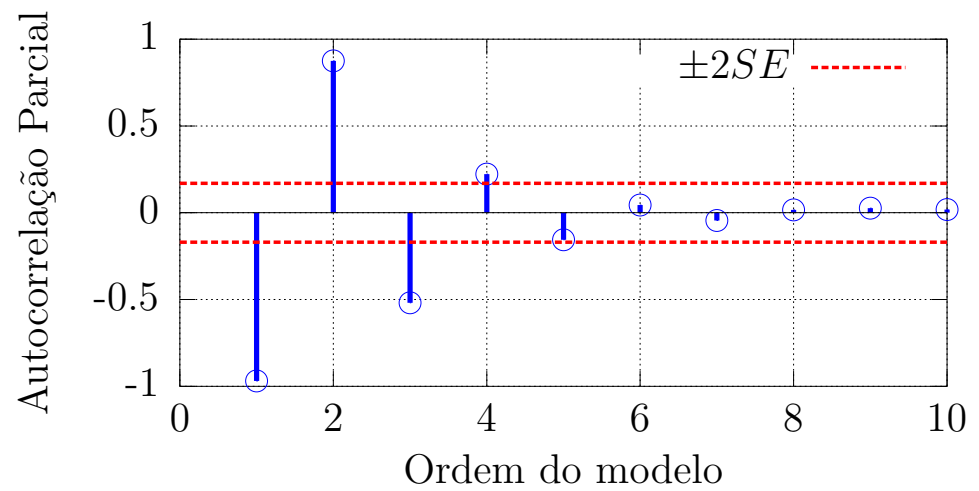

Figura 5.7: Função de autocorrelação parcial para o sinal intracelular, com intervalo de confiança para definição da ordem baseando-se no erro padrão (SE).

Como alternativa para ambos subsistemas, também é possível inferir a ordem necessária calculando-se a energia normalizada do erro de estimação entre a saída do sistema e o sinal observado (OPPENHEIM; SCHAFER, 2009, cap. 11) em função da ordem do modelo. Esta análise parte dos erros de estimação dados pelas equações

$$
\begin{aligned}
& e_{s}(n)=s(n)-\hat{s}(n) \\
& e_{y}(n)=y(n)-\hat{y}(n)
\end{aligned}
$$

em que $e_{s}(n)$ é o erro de estimação do sinal intracelular, e $e_{y}(n)$ o erro de estimação do sinal extracelular. A energia normalizada do erro é dada pela relação entre a energia do erro de estimação e a energia do sinal que se está modelando, resultando em

$$
\xi_{s}=\frac{\sum_{n=0}^{N-1}\left|e_{s}(n)\right|^{2}}{\sum_{n=0}^{N-1}|s(n)|^{2}}
$$


no caso do modelo intracelular. Analogamente, no modelo extracelular é dada por

$$
\xi_{y}=\frac{\sum_{n=0}^{N-1}\left|e_{y}(n)\right|^{2}}{\sum_{n=0}^{N-1}|y(n)|^{2}}
$$

em que $N$ é o número de amostras em uma janela de tempo de um disparo. Quando esse erro se aproximar de um patamar constante, há indicação de que a adição de coeficientes não é mais relevante. Na Figura 5.8 mostra-se a energia normalizada do erro dos sinais intracelular e extracelular de um mesmo neurônio, de acordo com a ordem do modelo. Junto com a Figura 5.7, é um bom indicativo de que devemos utilizar pelo menos $K_{i}=4$ coeficientes no modelo intracelular e $K_{e}=3$ coeficientes no modelo extracelular. Para as simulações a seguir, no entanto, utilizaremos modelos de ordem ligeiramente superiores a estas, a fim de garantir uma aproximação mais precisa, mas ainda assim buscando uma quantidade de parâmetros bem menor que o número de amostras do sinal na janela de tempo selecionada.

a)

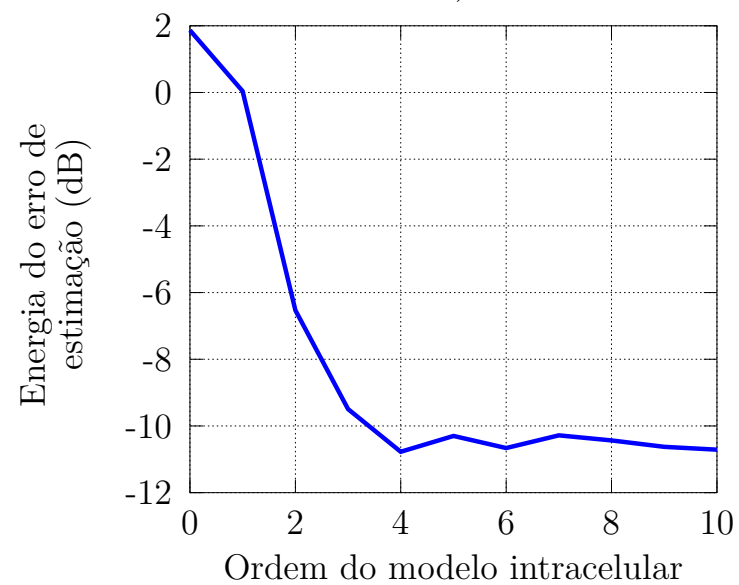

b)

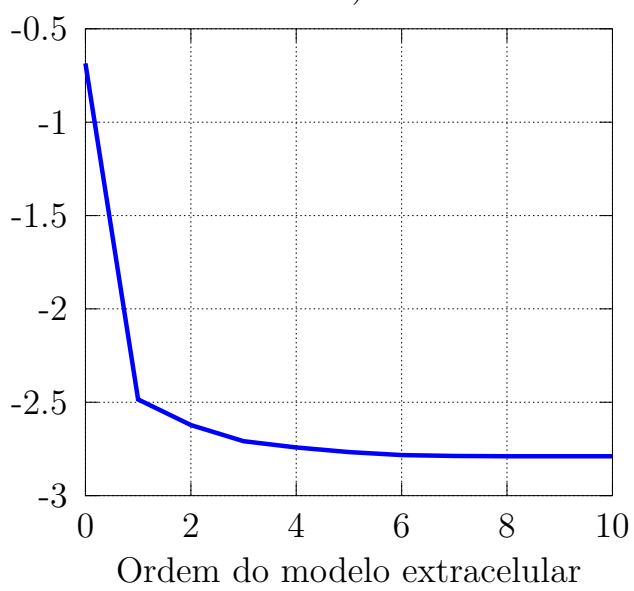

Figura 5.8: Energia normalizada do erro de estimação vs. ordem do modelo. a) modelo autoregressivo intracelular; b) modelo média móvel extracelular. Valores médios para 86 disparos de um mesmo neurônio.

\subsection{Modelo de um disparo isolado}

Após estabelecer as ordens de cada subsistema, pode-se aplicar as técnicas de estimação de parâmetros apropriadas para a estrutura escolhida para o modelo. Cada técnica utilizada produz um conjunto diferente de parâmetros, o que permite o cálculo do sinal de saída produzido pelo modelo, e a comparação deste com o sinal experimental de referência. Inicialmente, um único disparo é selecionado para ser modelado, definindo-se uma janela 
de 14 ms em torno do valor máximo do potencial de ação. Ambos os sinais intracelular e extracelular deste disparo são então utilizados no processo de estimação de parâmetros e servem como referência para avaliar a saída produzida do modelo. Os valores dos coeficientes estimados utilizados para a reprodução dos resultados apresentados podem ser encontrados no final desta seção.

\subsubsection{Modelo só-polo intracelular}

O primeiro modelo analisado é o obtido para o sinal intracelular por meio de um sistema do tipo só-polo em $F(z)$. Neste caso, os parâmetros do sistema são estimados utilizando-se o método de Prony para o caso só-polo, como detalhado na Seção 4.1.1. Na Figura 5.9 é ilustrada uma comparação entre o sinal neuronal original e o sinal obtido na saída do sistema produzido nesta etapa. Pode-se observar, no intervalo em questão, as fases do potencial de ação nas quais a saída do modelo está mais próxima do sinal real. O desvio em relação ao sinal original ocorre principalmente na fase de hiperpolarização do potencial de ação, e no instante em que o sinal descola do potencial de repouso.

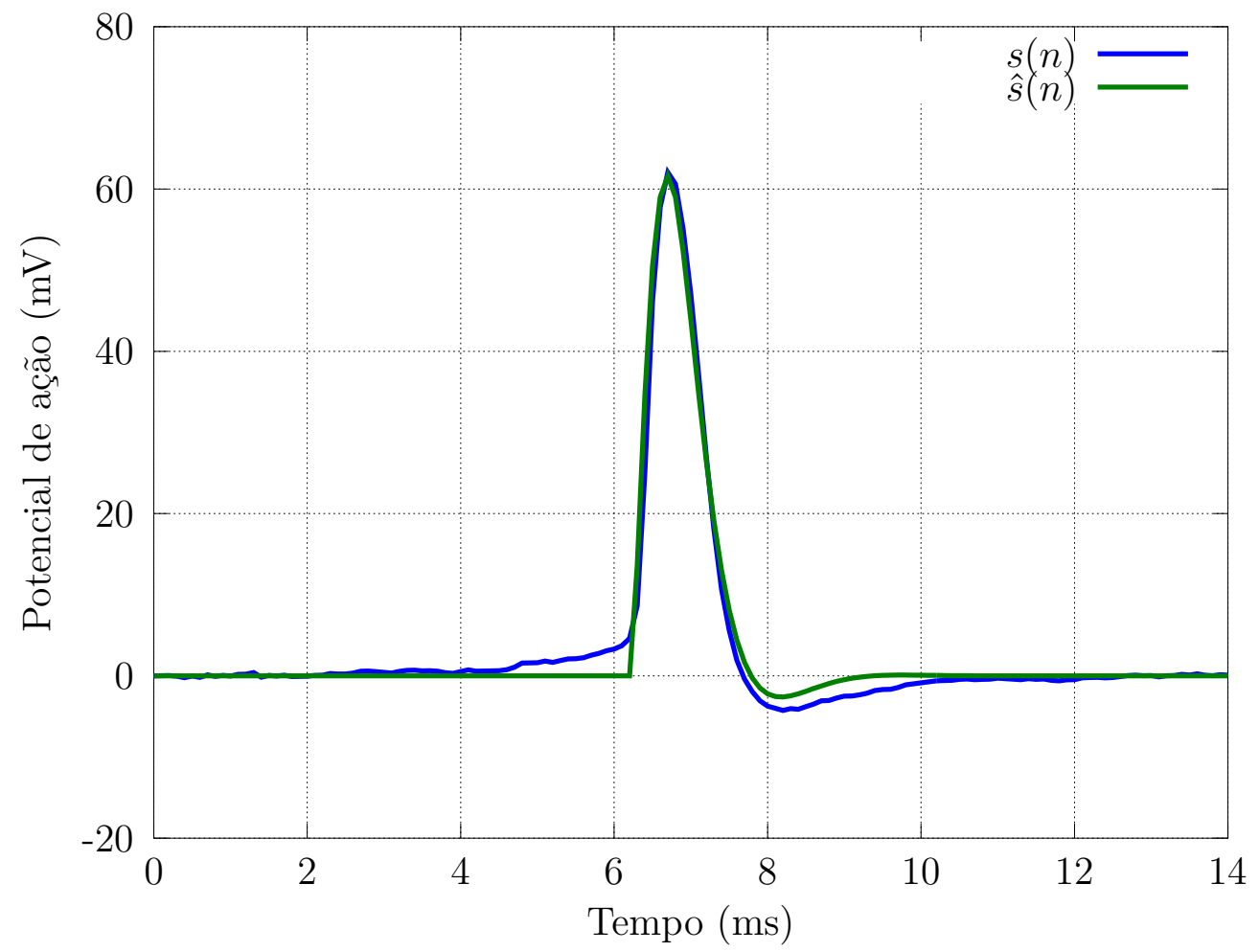

Figura 5.9: Potencial de ação real $s(n)$ e saída do filtro $\hat{s}(n)$ após solução das equações do sistema para $K_{i}=6$. 


\subsubsection{Modelo polo-zero intracelular}

A modelagem do potencial de ação pode ser estendida utilizando-se um sistema do tipo polo-zero para representar $F(z)$. Nesse caso, o método de Shanks é utilizado para se obter os coeficientes do numerador, que será acrescentado ao modelo só-polo produzido anteriormente por meio do método de Prony. O método de Shanks foi abordado em mais detalhes na Seção 4.1.2.

A adição do numerador aumenta o número de parâmetros utilizados, mas visa a representar as componentes do sinal intracelular que eventualmente não se encaixem em um modelo puramente autoregressivo. Na Figura 5.10 é ilustrado o resultado da adição do sistema média móvel em série com o modelo intracelular original, para um modelo com $K_{i}=6$ (número de coeficientes do termo autoregressivo) e $K_{\beta}=6$ (número de coeficientes do modelo média móvel). Podemos perceber que o potencial de ação produzido pelo modelo polo-zero apresenta um comportamento levemente diferente na etapa de hiperpolarização do potencial de ação, onde torna-se mais próximo ao sinal observado em laboratório.

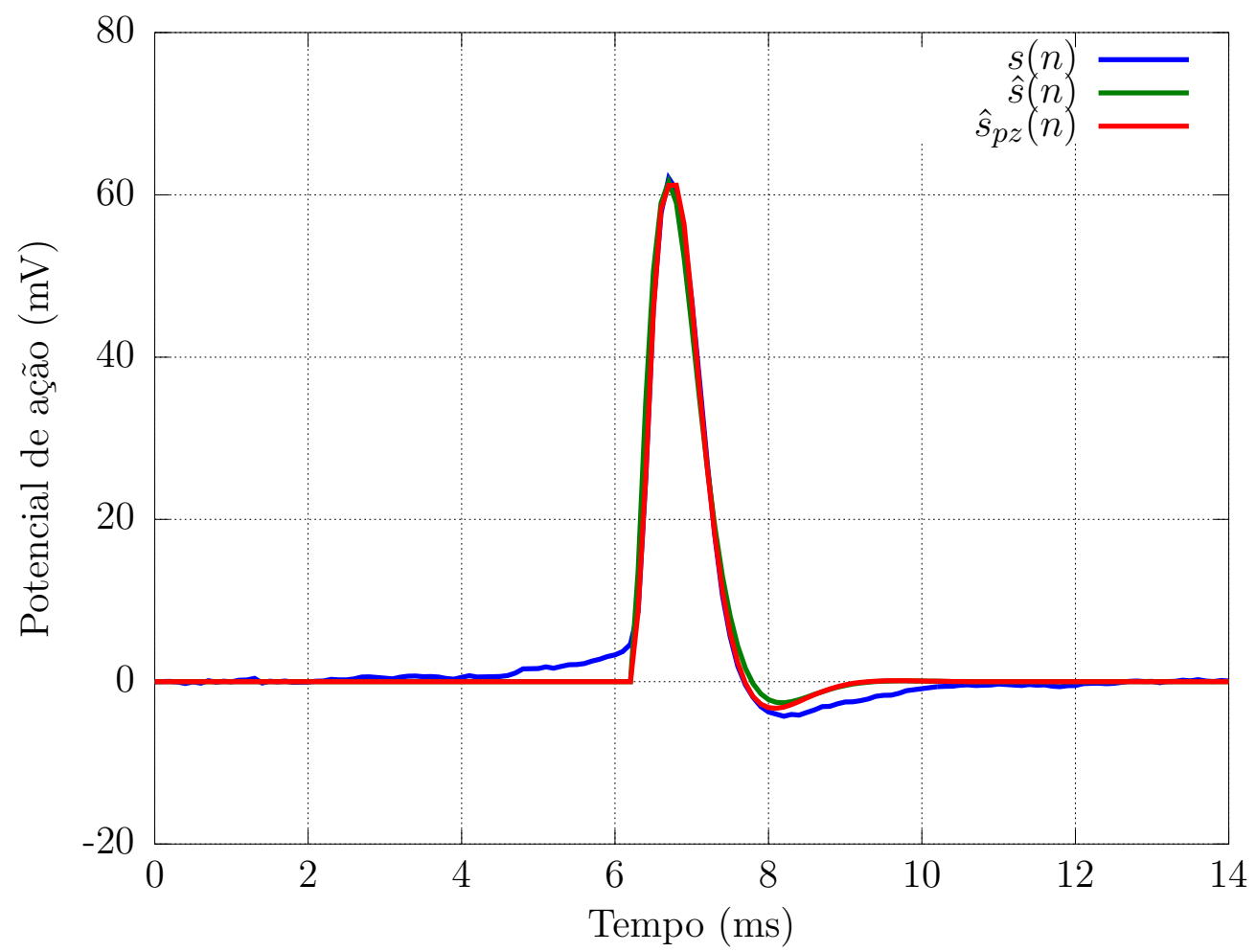

Figura 5.10: Comparação da saída do modelo polo-zero $\hat{s}_{p z}(n)$, com a saída do modelo só-polo $\hat{s}(n)$ e com o sinal observado em laboratório $s(n)$.

Apesar de ser um elemento que resulta em uma maior precisão na estimativa do potencial de ação, iremos abrir mão desta etapa na construção do sistema SISO. Veremos mais adiante que, uma vez sendo o objetivo produzir um sinal semelhante ao sinal observado 
no meio extracelular, utilizar um modelo só-polo nesta etapa é suficiente na construção do modelo que irá produzir o spike final.

\subsubsection{Modelo média móvel extracelular}

Utilizando uma configuração de identificação de sistemas, podemos estimar os coeficientes do modelo média móvel $G(z)$ para o sinal extracelular, como discutido na Seção 4.1.3. Este modelo, ao ser associado em série com o modelo intracelular, será capaz de reproduzir spike resultante do potencial de ação do neurônio. Na Figura 5.11 é apresentada uma comparação entre sinal produzido pelo modelo obtido nesta etapa e o sinal original da leitura experimental de um único eletrodo extracelular. Nota-se que este modelo não representa o ruído do sinal extracelular, que pode ser entendido como um ruído aditivo sobre a saída do subsistema extracelular.

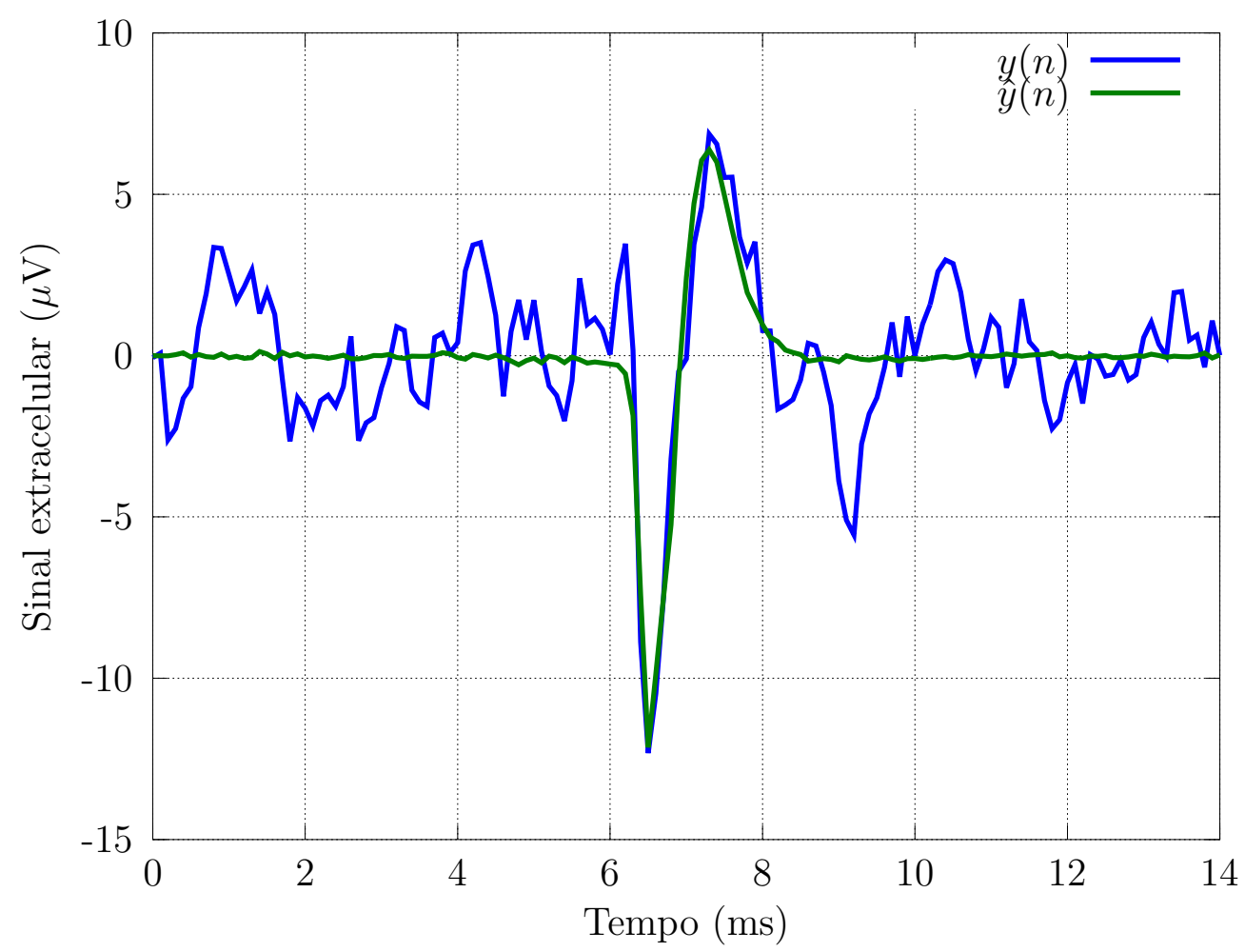

Figura 5.11: Sinal extracelular obtido em laboratório $y(n)$ e saída do filtro $\hat{y}(n)$ após solução das equações do sistema para $K_{e}=4$.

Nessa simulação, procura-se analisar somente o modelo média móvel, sem influência do modelo intracelular. Dessa forma, o sinal de entrada do modelo simulado é o sinal intracelular real $s(n)$, com as mesmas amostras que foram utilizadas como sinal desejado no modelo intracelular. É possível utilizar em sua entrada o sinal produzido pelo modelo 
intracelular, produzindo um spike a partir do impulso unitário aplicado na entrada do sistema como um todo.

\subsubsection{Concatenação dos subsistemas}

A modelagem do sistema SISO resulta na parametrização de duas funções de transferência, que associadas em série constituem um modelo polo-zero para o spike. Dessa forma, o sistema é representado pela função de transferência dada por:

$$
H(z)=F(z) G(z)=\frac{g_{f} \sum_{k=0}^{K_{e}} w_{k} z^{-k}}{1-\sum_{k=1}^{K_{i}} a_{k} z^{-k}}
$$

Esse modelo pode ser construído com os coeficientes obtidos independentemente para os

estimadores das funções $F(z)$ e $G(z)$. Nas seções anteriores, os modelos para estas funções foram validados em etapas separadas.

Resta, portanto, validar o modelo composto pela associação dos subsistemas até agora analisados. Na Figura 5.12 é apresentado o sinal de saída produzido pela concatenação do modelo intracelular só-polo com o modelo extracelular média móvel. Pode-se perceber que esse modelo se aproxima do sinal original, desconsiderando-se o efeito do ruído. O modelo assim obtido contém uma parametrização do spike por completo, considerando-se que a entrada do sistema é o impulso unitário. 


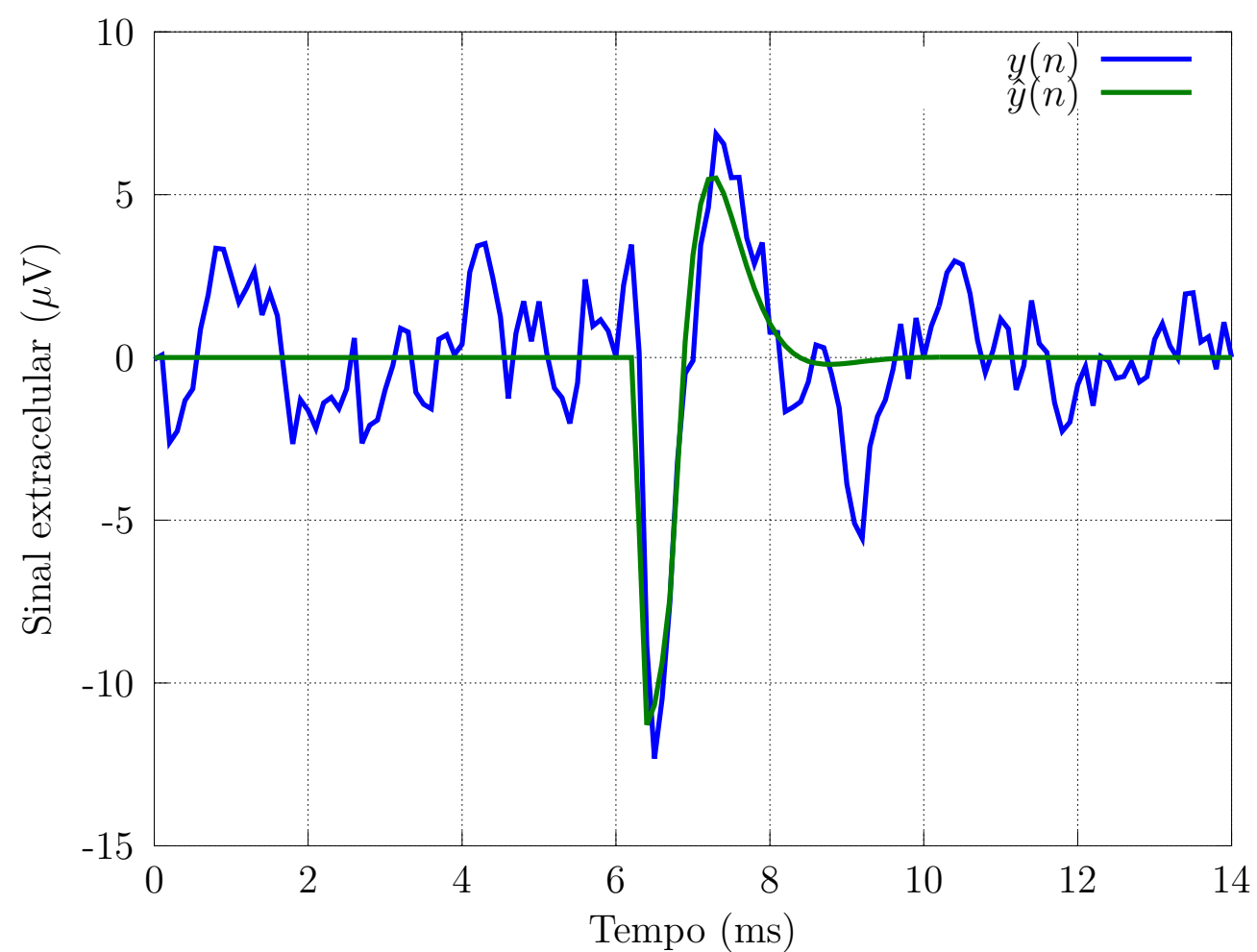

Figura 5.12: Saída do modelo obtido pela concatenação dos subsistemas $F(z)$ e $G(z)$, com impulso unitário na entrada.

\subsubsection{Resultados da modelagem ARX}

Um processo alternativo para modelagem dos sistemas intracelular e extracelular é por meio de um modelo ARX. Este processo permite obter uma estimativa para todos os coeficientes de um modelo contendo polos e zeros, em uma única etapa. Para isso, utiliza-se o sinal de entrada na construção das matrizes de autocorrelação, como apresentado na Seção 4.1.4.

\section{Modelo intracelular ARX}

Neste caso, o sistema polo-zero para o potencial de ação é entendido como um sistema ARX, e a respectiva técnica de estimação dos coeficientes é aplicada. Na Figura 5.13 ilustra-se a saída do modelo ARX em comparação com o sinal intracelular original, por meio das mesmas amostras dentro da janela de $14 \mathrm{~ms}$ utilizadas anteriormente. Pode-se perceber que aqui também os maiores desvios em relação ao sinal original ocorrem nas fases de hiperpolarização e de início do disparo. 


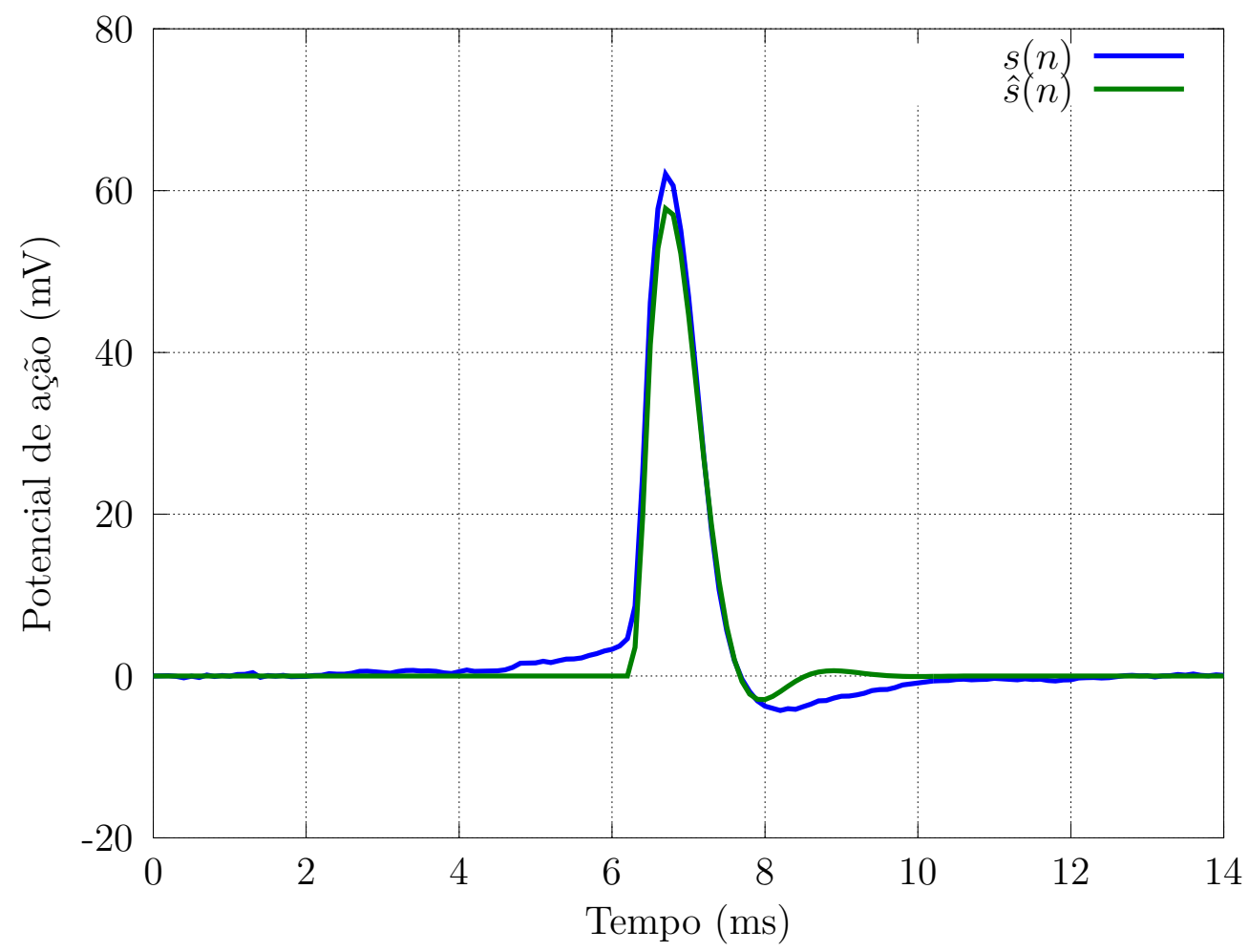

Figura 5.13: Simulação do modelo ARX intracelular para $K_{i}=6$ e $K_{\beta}=6$ coeficientes.

\section{Modelo extracelular ARX}

O mesmo processo de modelagem ARX pode ser utilizado para encontrar em uma única etapa os coeficientes do numerador e do denominador do sistema polo-zero completo, como ilustrado na Figura 4.1. Neste caso, a entrada do sistema dada por $x(n)$ é um impulso unitário e a saída é a estimativa do spike, denotada por $\hat{y}(n)$. Na Figura 5.14 é ilustrada a saída do modelo em comparação com o spike observado experimentalmente. Nota-se que, apesar de utilizar o mesmo número de coeficientes, este processo produz um resultado ligeiramente diferente ao observado para a modelagem em duas etapas. No entanto, com esta abordagem, não é necessário utilizar as amostras do sinal intracelular para obter as estimativas dos coeficientes do modelo. Consequentemente, é possível modelar qualquer spike detectado em uma série, inclusive de células diferentes, uma vez determinado o seu instante de disparo. 


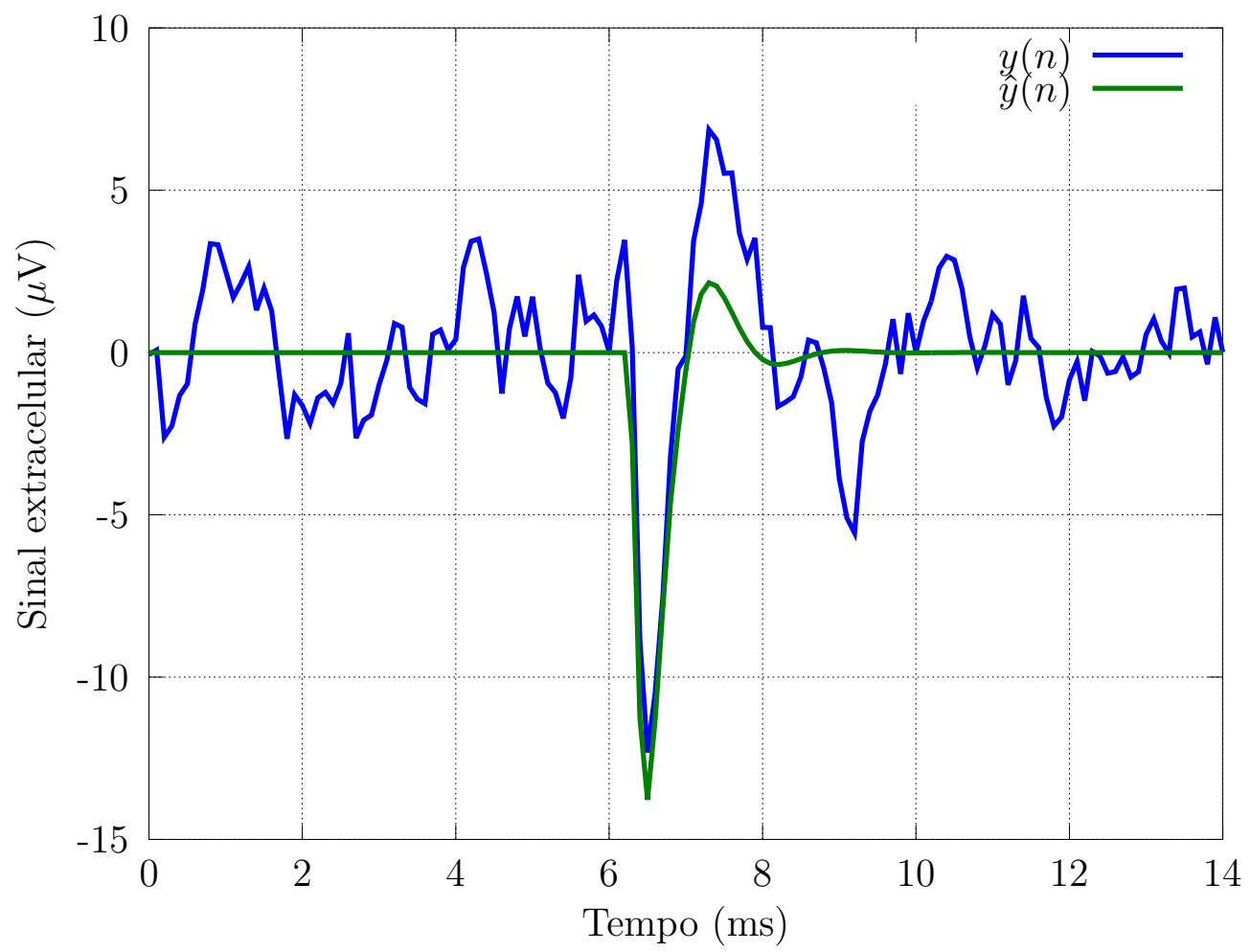

Figura 5.14: Simulação do modelo ARX extracelular para $K_{i}=6$ e $K_{e}=4$ coeficientes.

\subsubsection{Valores estimados dos coeficientes}

Os resultados apresentados para o disparo de um neurônio isolado podem ser diretamente reproduzidos substituindo-se os valores estimados para os coeficientes nas Equações 4.2, 4.8 e 4.12. Na Tabela 5.1 são apresentados os valores calculados para cada coeficiente, de acordo com o processo de estimação utilizado. Estes valores foram utilizados para a simulação da saída dos modelos do potencial de ação e do spike avaliados nesta seção. Pode-se perceber que mesmo modelos que compartilham a mesma estrutura (e.g. modelo intracelular polo-zero e modelo intracelular ARX) apresentam coeficientes com valores distintos. 
Tabela 5.1: Coeficientes estimados para um único disparo isolado.

\begin{tabular}{|c|c|c|c|c|c|}
\hline & I-SP & I-PZ & E-MM & I-ARX & E-ARX \\
\hline$g_{f}$ & 13.5750 & 13.5750 & - & - & - \\
\hline$a_{0}$ & 1.0000 & 1.0000 & - & 1.0000 & 1.0000 \\
\hline$a_{1}$ & 2.5463 & 2.5463 & - & 1.6221 & 0.9102 \\
\hline$a_{2}$ & -2.7596 & -2.7596 & - & -0.3311 & -0.0568 \\
\hline$a_{3}$ & 1.8910 & 1.8910 & - & -0.6248 & -0.0415 \\
\hline$a_{4}$ & -1.0660 & -1.0660 & - & 0.3494 & -0.1488 \\
\hline$a_{5}$ & 0.4562 & 0.4562 & - & -0.1111 & 0.1252 \\
\hline$a_{6}$ & -0.0972 & -0.0972 & - & 0.0502 & -0.0977 \\
\hline$b_{0}$ & - & 0.6371 & - & 3.5495 & - \\
\hline$b_{1}$ & - & 0.2427 & - & 13.9494 & - \\
\hline$b_{2}$ & - & 0.3803 & - & 10.1784 & - \\
\hline$b_{3}$ & - & -0.3522 & - & -4.8486 & - \\
\hline$b_{4}$ & - & 0.0399 & - & -3.3290 & - \\
\hline$b_{5}$ & - & 0.1940 & - & -0.1003 & - \\
\hline$b_{6}$ & - & -0.1929 & - & -0.4154 & - \\
\hline$w_{0}$ & - & - & -0.3860 & - & -2.7983 \\
\hline$w_{1}$ & - & - & 0.1515 & - & -8.7134 \\
\hline$w_{2}$ & - & - & 0.2653 & - & -3.6880 \\
\hline$w_{3}$ & - & - & -0.2530 & - & 0.4813 \\
\hline$w_{4}$ & - & - & 0.2042 & - & 0.7431 \\
\hline
\end{tabular}

I-SP: modelo intracelular só-polo; I-PZ: modelo intracelular polo-zero; E-MM: modelo extracelular média móvel; I-ARX: modelo intracelular ARX; E-ARX: modelo extracelular ARX.

\subsection{Representação de uma sequência de disparos}

O processo de modelagem pode ser aplicado para qualquer disparo produzido pelo neurônio. Considerando-se a mesma série de 86 disparos utilizada na discussão da Seção 5.1.3, é possível produzir um conjunto de coeficientes para cada um dos disparos observados. O resultado permite observar o comportamento estatístico dos coeficientes, e suas variações ao longo do tempo. Dessa forma, podemos vislumbrar o modelo contendo coeficientes que variam a cada disparo, e cujos valores refletem as mudanças na forma de onda do sinal produzido pelo neurônio. 


\subsubsection{Modelo intracelular}

Com a Figura 5.15, é possível observar os coeficientes estimados para cada disparo dentro de uma sequência de potenciais de ação. Para obter esta perspectiva, foram calculados os coeficientes do modelo autoregressivo utilizando a modelagem só-polo, de forma independente para cada um dos potenciais de ação da série. O processo de modelagem é repetido em cada disparo, sempre dentro de uma janela de tempo de $14 \mathrm{~ms}$ em torno de cada máximo do potencial de ação, de forma a encontrar os parâmetros que melhor estimam o modelo autoregressivo do neurônio nesta janela. Nota-se que os valores dos coeficientes concentram-se em torno de determinados valores ao longo do tempo.

a)

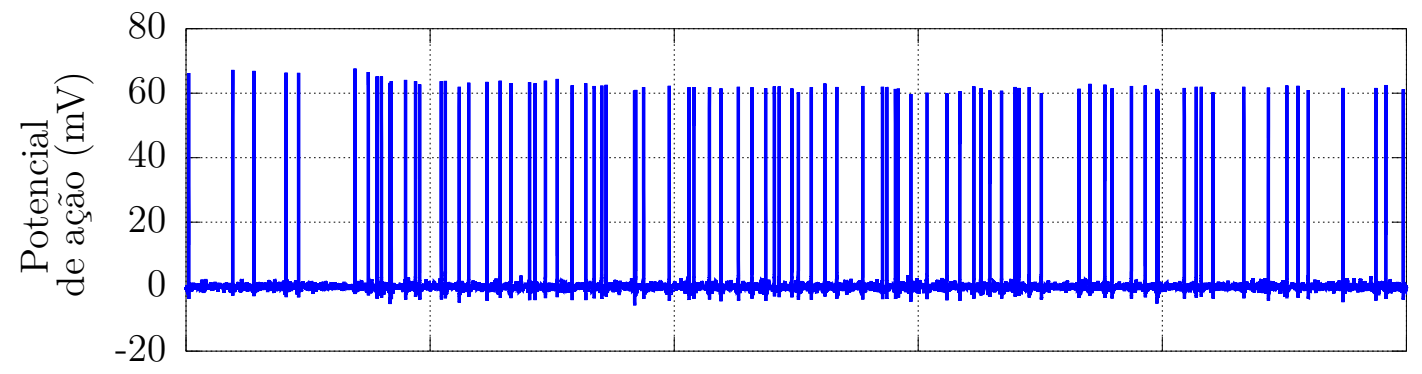

b)

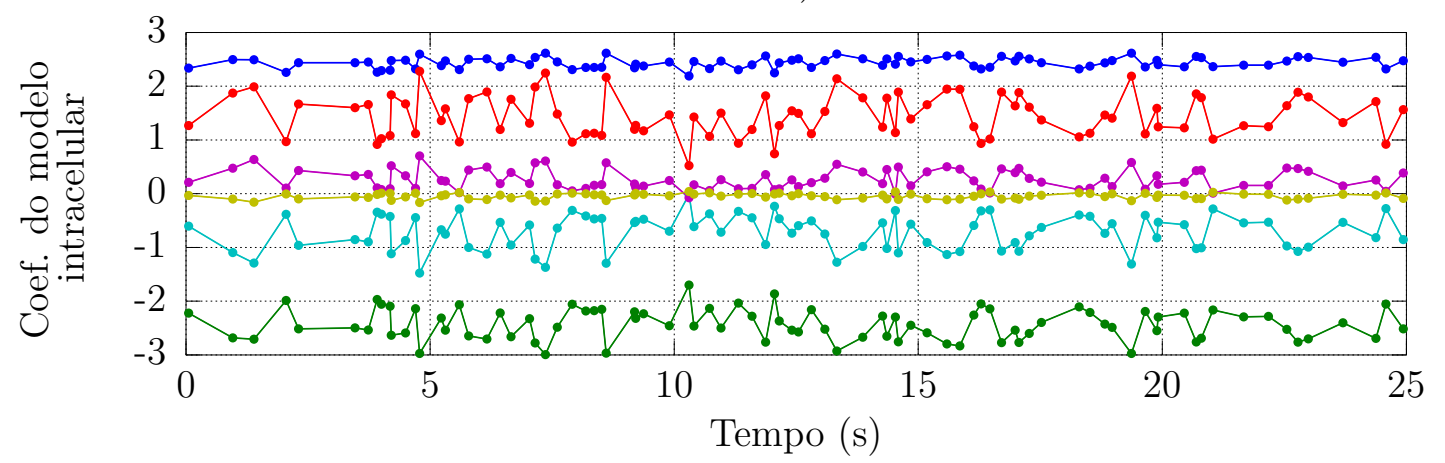

Figura 5.15: Modelagem de disparos em uma série de potenciais de ação: a) potenciais de ação observados; b) coeficientes estimados do modelo autoregressivo intracelular, com $K_{i}=6$.

A variação observada nos valores dos coeficientes é resultado das mudanças na forma de onda do potencial de ação ao longo do tempo, mesmo que este seja originado do mesmo neurônio, como discutido anteriormente na Seção 5.1. Esta variação pode ser observada na distribuição de cada coeficiente da mesma sequência de potenciais de ação. A Figura 5.16 apresenta o histograma de cada coeficiente para o modelo só-polo intracelular, e o valor médio correspondente. 

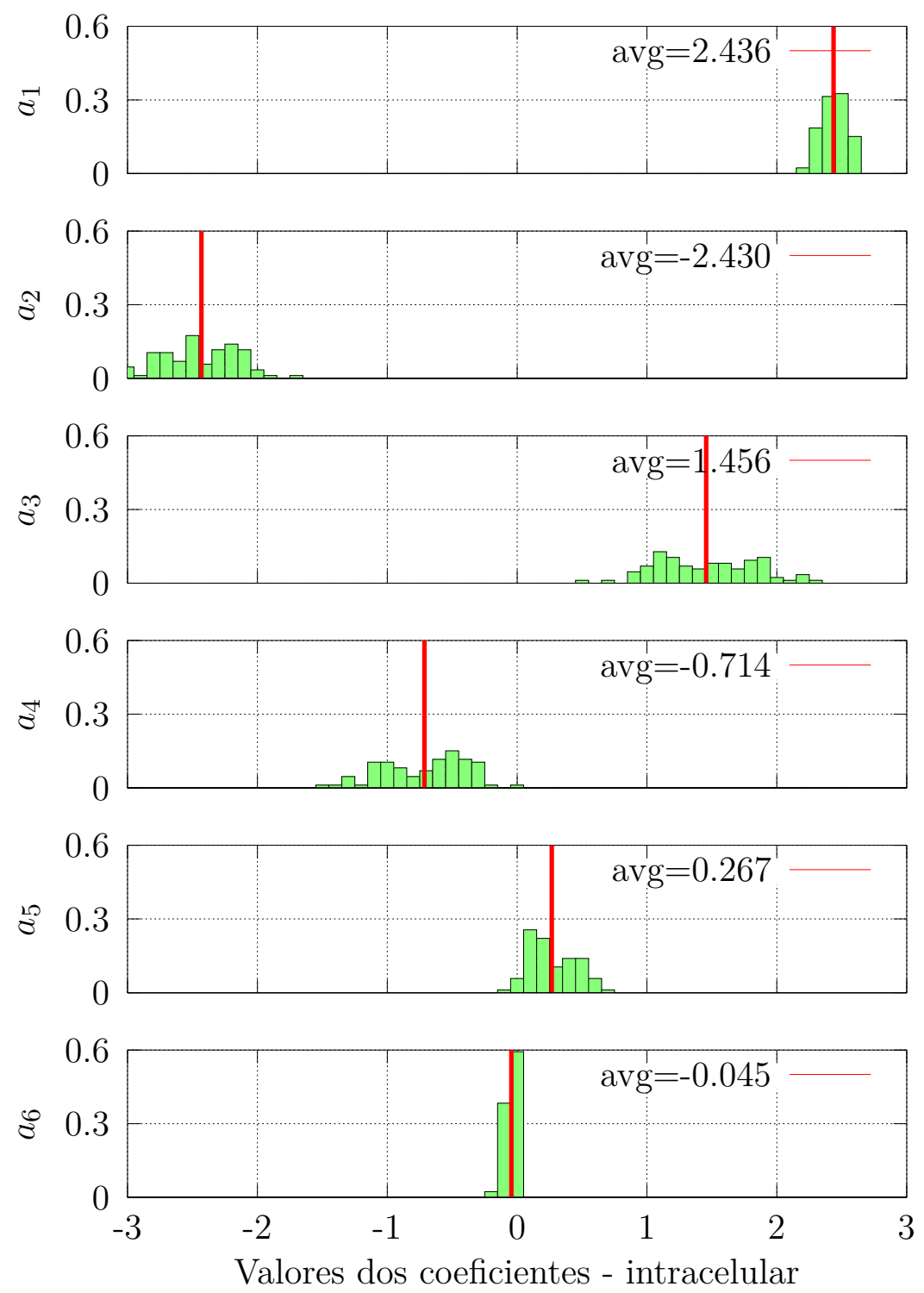

Figura 5.16: Distribuição dos parâmetros do modelo só-polo intracelular, considerando $K_{i}=6$ coeficientes.

\subsubsection{Modelo extracelular}

Também é possível repetir o processo de modelagem para todos os spikes de um intervalo maior de observação. Na Figura 5.17 são apresentados os sinais intracelular, contendo uma sequência de potenciais de ação; o sinal extracelular, contendo uma mistura de spikes de diversas células; e os coeficientes calculados para o modelo média móvel de cada spike produzidos pela célula observada. Como podemos notar, estes coeficientes também se mantêm em torno de valores médios durante o intervalo de tempo escolhido, 
mais próximos entre si que no caso do modelo intracelular.

a)

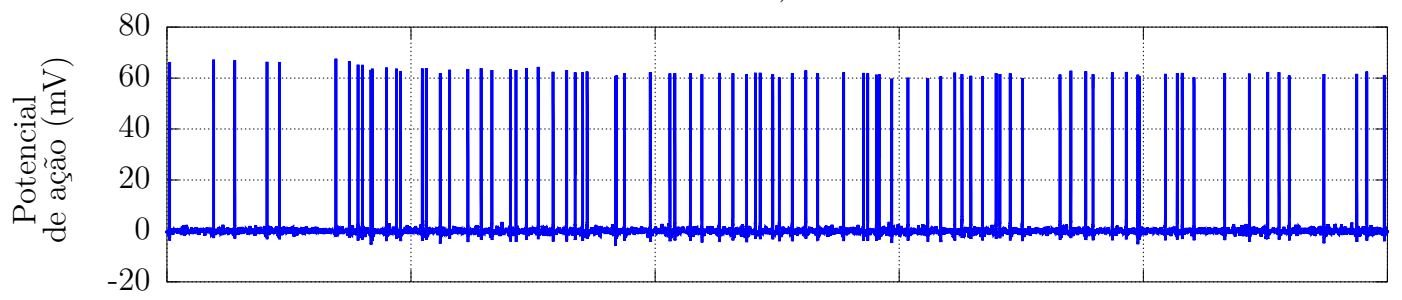

b)

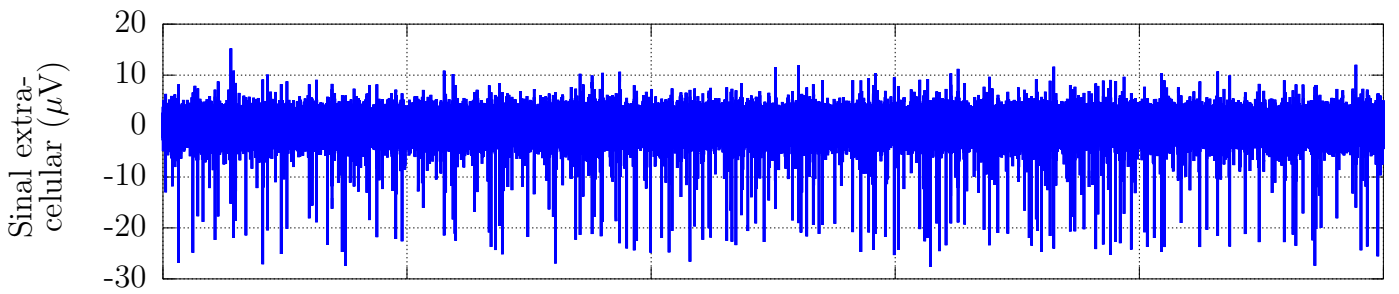

c)

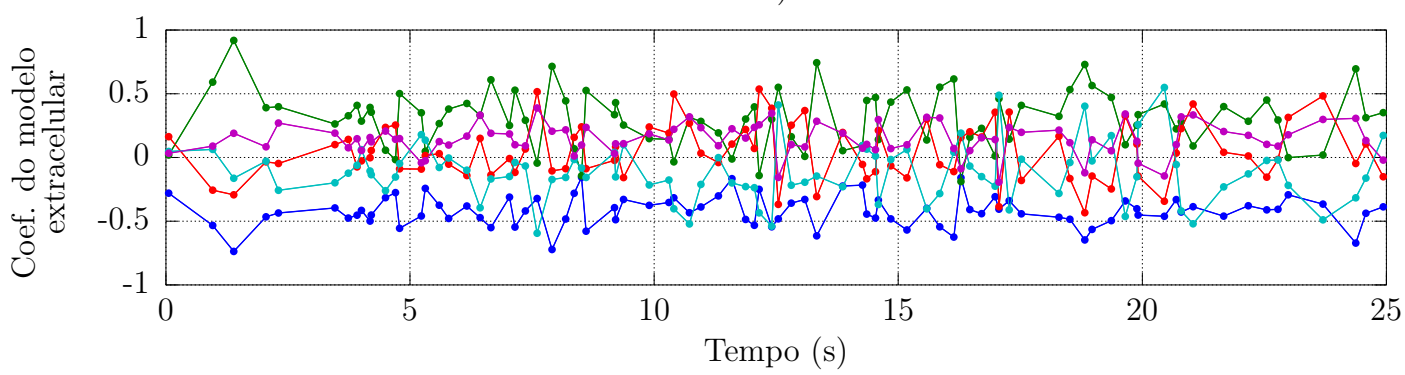

Figura 5.17: Resultados do processo de modelagem para o sistema extracelular: a) potencial de ação observado no intervalo considerado; b) sinal extracelular adquirido por eletrodos; c) evolução dos coeficientes do modelo média móvel calculados para cada spike de um dado neurônio.

Essas variações nos coeficientes do modelo extracelular devem-se a diferenças na forma de onda observadas também entre spikes de um mesmo neurônio, como discutido na Seção 5.1. No caso do sinal extracelular, há ainda que se considerar o efeito do ruído e do sinal de outros neurônios nas proximidades, que pode influenciar o resultado obtido com o modelo. Na Figura 5.18 é ilustrada a distribuição dos coeficientes do modelo média móvel extracelular, e seus respectivos valores médios. 

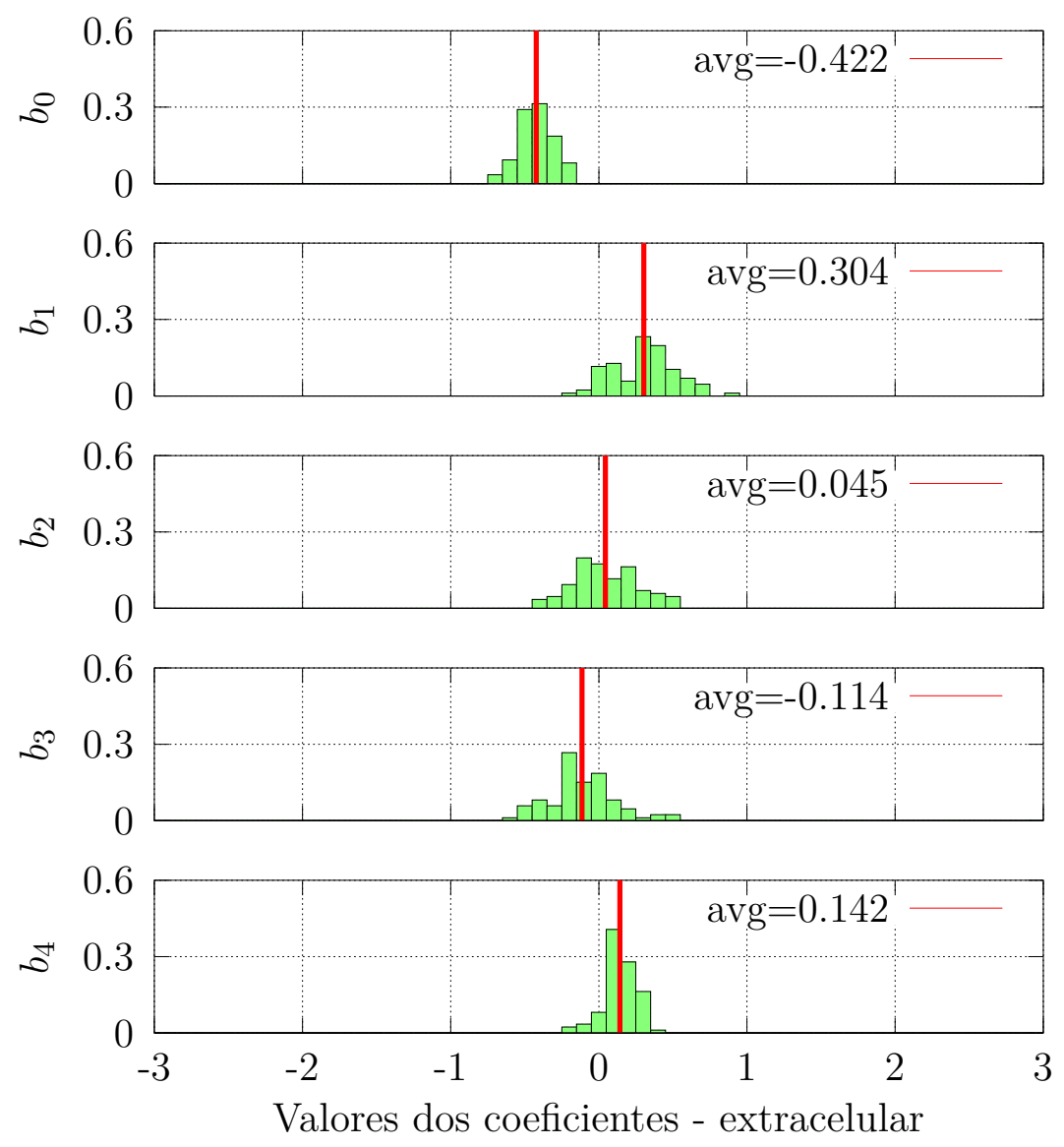

Figura 5.18: Distribuição dos coeficientes do modelo média móvel extracelular

\subsubsection{Valores médios dos coeficientes}

A modelagem de um conjunto de disparos permite encontrar coeficientes médios para cada modelo, que irão representar as formas de ondas do neurônio durante o intervalo de observação. Assim como no caso do disparo isolado, cada técnica de estimação irá produzir um conjunto de parâmetros definidos pela estrutura escolhida para o modelo. Na Tabela 5.2 são apresentados os valores médios de cada coeficiente de acordo com o método de estimação empregado. Estes valores foram calculados com os disparos da mesma sequência analisada nesta seção. Nota-se que mesmo modelos com estruturas semelhantes apresentam coeficientes com valores diferentes, dependendo da técnica de estimação de parâmetros utilizada. 
Tabela 5.2: Valores médios dos coeficientes para um mesmo neurônio.

\begin{tabular}{|c|c|c|c|c|c|}
\hline & I-SP & I-PZ & E-MM & I-ARX & E-ARX \\
\hline$g_{f}$ & 14.6220 & 14.6220 & - & - & - \\
\hline$a_{0}$ & 1.0000 & 1.0000 & - & 1.0000 & 1.0000 \\
\hline$a_{1}$ & 2.4365 & 2.4365 & - & 1.5536 & 0.9026 \\
\hline$a_{2}$ & -2.4302 & -2.4302 & - & -0.3442 & -0.2125 \\
\hline$a_{3}$ & 1.4556 & 1.4556 & - & -0.2171 & 0.0408 \\
\hline$a_{4}$ & -0.7137 & -0.7137 & - & -0.1424 & -0.0373 \\
\hline$a_{5}$ & 0.2666 & 0.2666 & - & 0.0499 & 0.0176 \\
\hline$a_{6}$ & -0.0445 & -0.0445 & - & 0.0601 & -0.0897 \\
\hline$b_{0}$ & - & 0.8217 & - & 5.6858 & - \\
\hline$b_{1}$ & - & 0.1183 & - & 15.0086 & - \\
\hline$b_{2}$ & - & 0.2140 & - & 7.4220 & - \\
\hline$b_{3}$ & - & -0.1776 & - & -4.0748 & - \\
\hline$b_{4}$ & - & -0.1022 & - & -4.9457 & - \\
\hline$b_{5}$ & - & 0.3176 & - & -1.9692 & - \\
\hline$b_{6}$ & - & -0.2609 & - & -0.1686 & - \\
\hline$w_{0}$ & - & - & -0.4221 & - & -4.3822 \\
\hline$w_{1}$ & - & - & 0.3039 & - & -6.3563 \\
\hline$w_{2}$ & - & - & 0.0449 & - & -2.5715 \\
\hline$w_{3}$ & - & - & -0.1136 & - & -1.5210 \\
\hline$w_{4}$ & - & - & 0.1424 & - & -0.3631 \\
\hline
\end{tabular}

I-SP: modelo intracelular só-polo; I-PZ: modelo intracelular polo-zero; E-MM: modelo extracelular média móvel; I-ARX: modelo intracelular ARX; E-ARX: modelo extracelular ARX.

\subsection{Múltiplos eletrodos de leitura}

A partir do modelo SIMO apresentado na Seção 4.2, é possível estimar um conjunto de coeficientes do modelo extracelular média móvel para cada eletrodo de leitura. Estes coeficientes irão fornecer informações sobre a diversidade espacial do sinal do spike modelado. Dessa forma, cada canal do sinal extracelular é utilizado para estimar um conjunto de coeficientes, que estará associado ao eletrodo em questão. Os coeficientes médios das funções $G_{i}(z)$ obtidos na mesma sequência de spikes até aqui utilizada são listados na Tabela 5.3. Como estes valores representam os disparos de um mesmo neurônio visto por 
eletrodos diferentes, as diferenças observadas entres as funções $G_{i}(z)$ refletem basicamente a diferença de posicionamento de cada eletrodo, em relação à célula geradora do sinal.

Tabela 5.3: Valores médios dos coeficientes do modelo extracelular SIMO.

\begin{tabular}{rrrrr}
\hline & $G_{1}$ & $G_{2}$ & \multicolumn{1}{c}{$G_{3}$} & \multicolumn{1}{c}{$G_{4}$} \\
\hline$w_{0}$ & -0.4221 & -0.5161 & -0.4547 & -0.5950 \\
$w_{1}$ & 0.3039 & 0.4492 & 0.3496 & 0.6418 \\
$w_{2}$ & 0.0449 & -0.0164 & 0.0277 & -0.1588 \\
$w_{3}$ & -0.1136 & -0.1037 & -0.1053 & -0.0294 \\
$w_{4}$ & 0.1424 & 0.1463 & 0.1395 & 0.1053
\end{tabular}

\subsection{Demais discussões relevantes}

Apresentamos nesta seção um pequeno conjunto de análises que irá complementar o processo de validação do modelo. O primeiro ponto importante é a definição exata do sinal de entrada, que não é obrigatório para a parametrização da forma de onda do sinal, porém é necessário para a representação do instante correto de disparo do neurônio. Também relevante é a discussão do erro residual das diferentes técnicas de estimação utilizadas. Por fim, apresentaremos a utilização de filtros adaptativos sobre os dados experimentais para realizar a modelagem de forma dinâmica, aproveitando a estrutura linear do modelo.

\subsubsection{Instante do disparo e sinal de entrada}

O instante exato em que o impulso unitário de entrada ocorre é definido empiricamente após o cálculo das estimativas dos coeficientes do modelo. O sinal de entrada, definido como $x(n)=\delta(n-\Delta)$, depende do valor de $\Delta$ para resultar em um disparo no instante desejado. Esse valor é estabelecido comparando-se o pico produzido na saída do modelo, mantendo a entrada igual a um impulso unitário na origem (e portanto $x(n)=\delta(n)$ na entrada), com o valor de pico do potencial de ação real. O atraso entre estes picos é calculado diretamente, uma vez que só existe um máximo para cada sinal no intervalo considerado, e será utilizado como o valor de $\Delta$ para alinhar a saída do modelo com o sinal real. Na Figura 5.19 é ilustrado o sinal do modelo intracelular quando sua entrada é um impulso na origem, em comparação com o potencial de ação observado, destacando o número de amostras entre os dois máximos. O valor da saída do modelo no instante $n=\Delta$ pode ser entendido como o início do potencial de ação, momento no qual o estímulo resulta em um disparo da célula neuronal. 


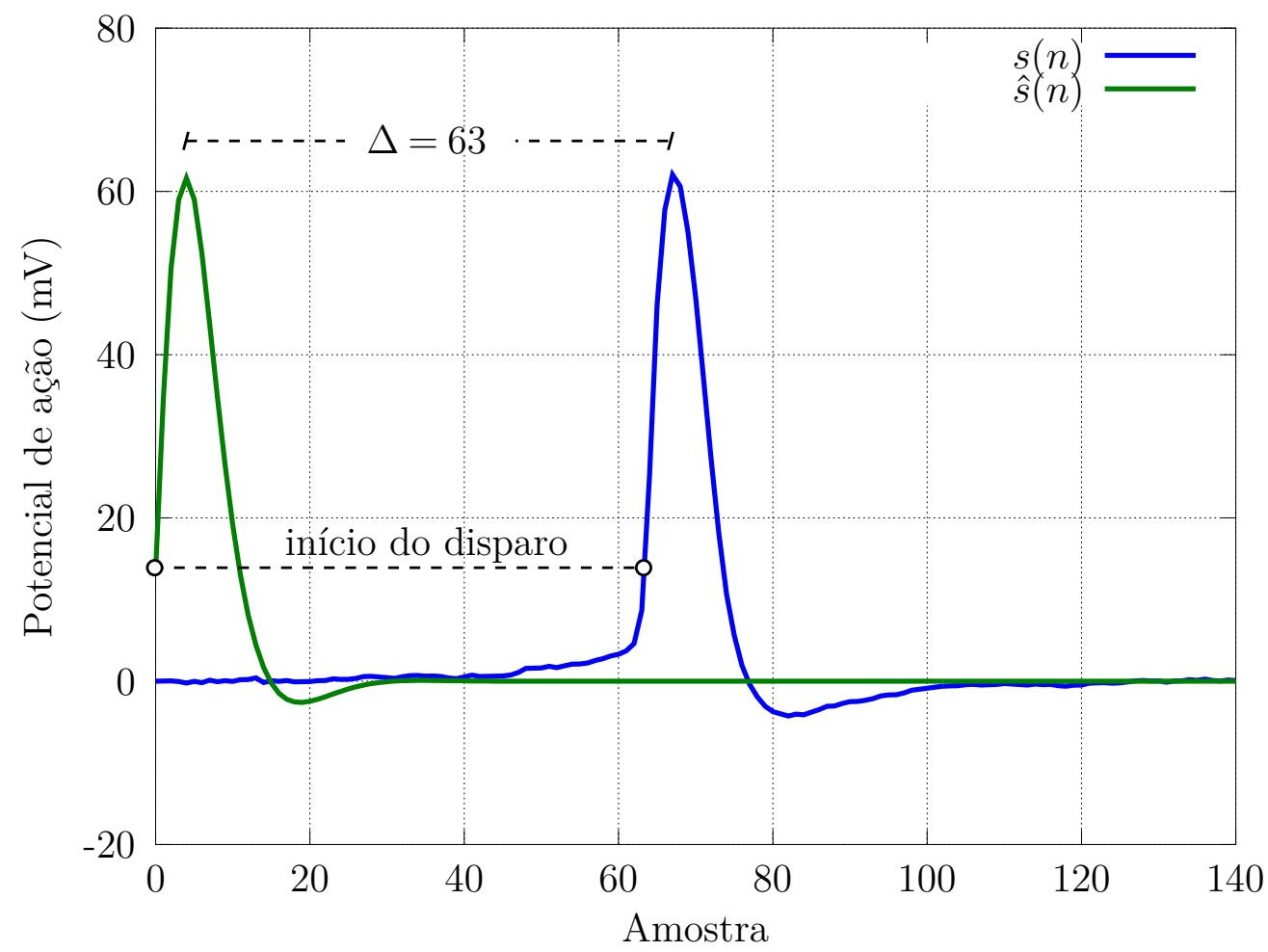

Figura 5.19: Saída do modelo $\hat{s}(n)$ para entrada com impulso unitário na origem em comparação com sinal intracelular real $s(n)$, com $K_{i}=6$ e $x(n)=\delta(n)$.

Esse atraso foi utilizado para posicionar no tempo os sinais dos gráficos na Seção 5.3, de forma a alinhar a saída do modelo intracelular. Para o potencial de ação em questão, o disparo ocorre em $n=63$, e o valor potencial elétrico observado é de aproximadamente $13.6 \mathrm{mV}$. Percebe-se que valores do potencial de ação anteriores a este ponto de início não são reproduzidos pelo modelo. Esses valores podem ser entendidos como parâmetros temporais do sinal modelado, e sugerem uma investigação mais profunda sobre o seu papel na parametrização do spike, especialmente sob o ponto de vista de identificar a célula geradora.

\subsubsection{Erro residual}

Nas Seções 5.3 e 5.4 observamos que existem diferenças entre a saída produzida em cada subsistema e o sinal real do neurônio. A magnitude destas diferenças são indícios da qualidade do modelo e do processo de estimação utilizado, e são analisadas em cada modelo como erro de estimação, também chamado de erro residual de modelagem (LJUNG, 1999, cap. 16). Os erros residuais foram definidos formalmente nas Equações 5.2 e 5.3, para o sinal intracelular e extracelular, respectivamente. Na Figura 5.20 são apresentados os erros residuais dos modelos só-polo intracelular e média móvel extracelular, para o 
mesmo disparo isolado modelado nas seções anteriores. Nota-se que o este erro possui características próprias em cada subsistema.

a)

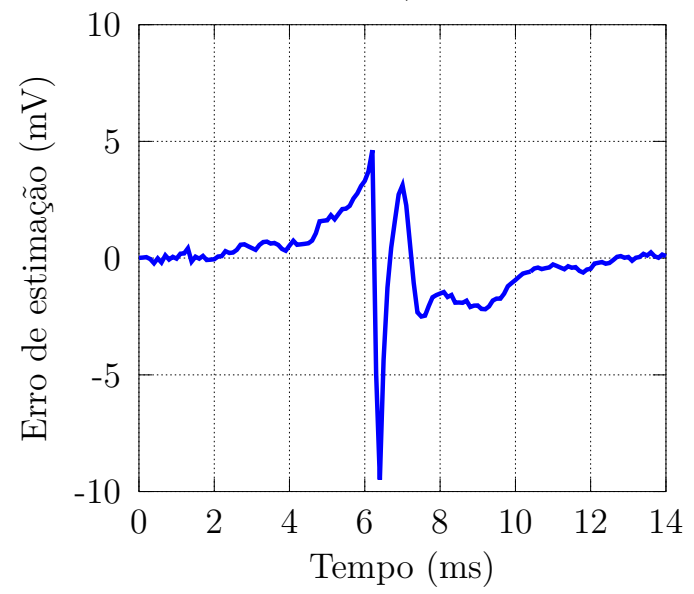

b)

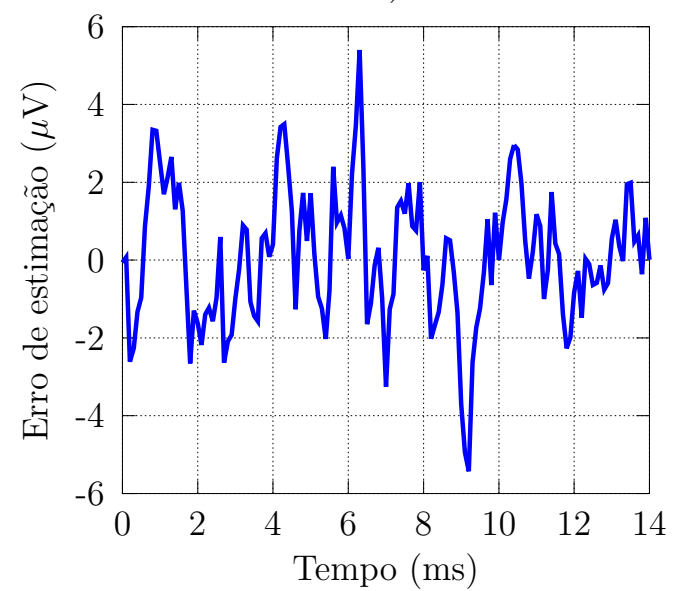

Figura 5.20: Erro residual entre o sinal real e a saída do modelo, para a) modelo intracelular só-polo e b) modelo extracelular média móvel.

O erro no caso do sistema intracelular deve-se a diferenças na fase de despolarização, especialmente logo antes do início do disparo, e na fase de hiperpolarização. São aspectos do sinal não representados pelo modelo autoregressivo utilizado. Por outro lado, o erro observado no sistema extracelular está principalmente associado ao ruído encontrado nas leituras do sinal real. Esse ruído é usualmente parte do sinal extracelular, cuja aquisição é feita em um meio compartilhado por diversas células ativas ao mesmo tempo, e cuja potência é consideravelmente menor que a do sinal intracelular. Um modelo para o disparo isolado que leve em conta este efeito irá considerar a adição de um ruído à saída do sistema, como ilustrado na Figura 5.21.

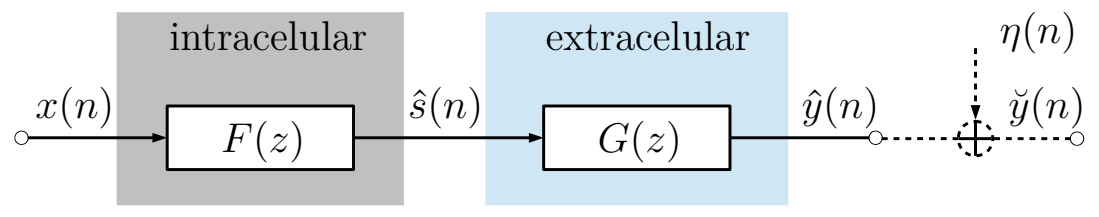

Figura 5.21: Representação do modelo para um disparo isolado considerando componente de ruído $\eta(n)$.

Este ruído em geral é considerado como sendo gaussiano, e decorre da adição de fatores biológicos, instrumentais e da própria ação das células da região (ASSIS, 2011). No modelo proposto, não é considerada qualquer informação sobre o spike que possa resultar do 
processamento deste ruído, e não supõe-se que esteja associado a alguma característica do neurônio que efetuou o disparo (BEAR; CONNORS; PARADISO, 2006, cap. 4).

\section{Gaussianidade do erro residual}

A seguir faremos uma breve análise da gaussianidade do erro residual do modelo extracelular apresentada na Figura 5.20b. Para tal, vamos verificar se a seguinte relação segue uma distribuição $\chi^{2}$ (chi-quadrado) (MADISETTI, 2009; LJUNG, 1999):

$$
\zeta_{N, M}=\frac{N}{\left[\hat{r}_{e_{y} e_{y}}(0)\right]^{2}} \sum_{k=1}^{M_{l}}\left[\hat{r}_{e_{y} e_{y}}(k)\right]^{2}
$$

em que $M$ é o número de graus de liberdade (número de possíveis atrasos a serem modelados), e

$$
\hat{r}_{e_{y} e_{y}}(k)=\frac{1}{N} \sum_{k=0}^{N-1} e_{y}(n) e_{y}(n-k)
$$

representa a função de autocorrelação estimada para o erro residual extracelular $e_{y}(n)$, definido pela Equação 5.3. Para o caso de uma distribuição não-gaussiana, espera-se que $\zeta_{N, M}$ seja maior que o valor $\chi_{\alpha}^{2}$ de erro do tipo I (falso positivo para aceitar a hipótese de que o erro não é gaussiano com significância de $\alpha$ ) da distribuição $\chi^{2}$. Na Tabela 5.4 são apresentados os valores obtidos com o erro residual do spike extracelular modelado pelo sistema polo-zero, para alguns graus de liberdade possíveis. Em todos os casos, podemos ver que $\zeta_{N, M}$ mantém-se acima de valores tabelados de $\chi_{5 \%}^{2}(\mathrm{NETO}, 1977)$.

Tabela 5.4: Fator de distribuição $\chi^{2}$ do erro residual para diferentes graus de liberdade.

\begin{tabular}{l|l}
\hline$M_{l}$ & $\zeta_{N, M}$ \\
\hline 2 & 101.6 \\
3 & 109.2 \\
4 & 111.0 \\
5 & 111.9 \\
10 & 124.0 \\
15 & 156.4 \\
20 & 161.1
\end{tabular}

Esse fato invalida inicialmente a gaussianidade do erro residual, indicando que ainda há possibilidade de construir uma função de sistema que atue sobre a componente do erro, e consequentemente este modelo terá uma estrutura Box-Jenkins parecida com a da 
Figura 3.3. A modelagem do sistema responsável pela geração deste ruído e sua relação com os parâmetros da onda do spike pode ser explorado em trabalhos futuros.

\section{Comparação entre técnicas de estimação}

A técnica de estimação dos parâmetros utilizada também influenciará o valor do erro residual. Como vimos na Seção 5.3, cada técnica produz um modelo com coeficientes diferentes, e consequentemente resulta em um sinal de saída diferente para o mesmo subsistema. Na Figura 5.22 é apresentada uma comparação da energia normalizada do erro de estimação, para todos os disparos da sequência utilizada na Seção 5.4, de acordo com a definição do cálculo da energia normalizada do erro dada pelas Equações 5.4 e 5.5. Quanto menor este valor, mais próximo é o sinal gerado pelo modelo do sinal real, o que torna mais evidente o fato de que o erro residual é mais relevante no sinal extracelular, segundo esse critério.

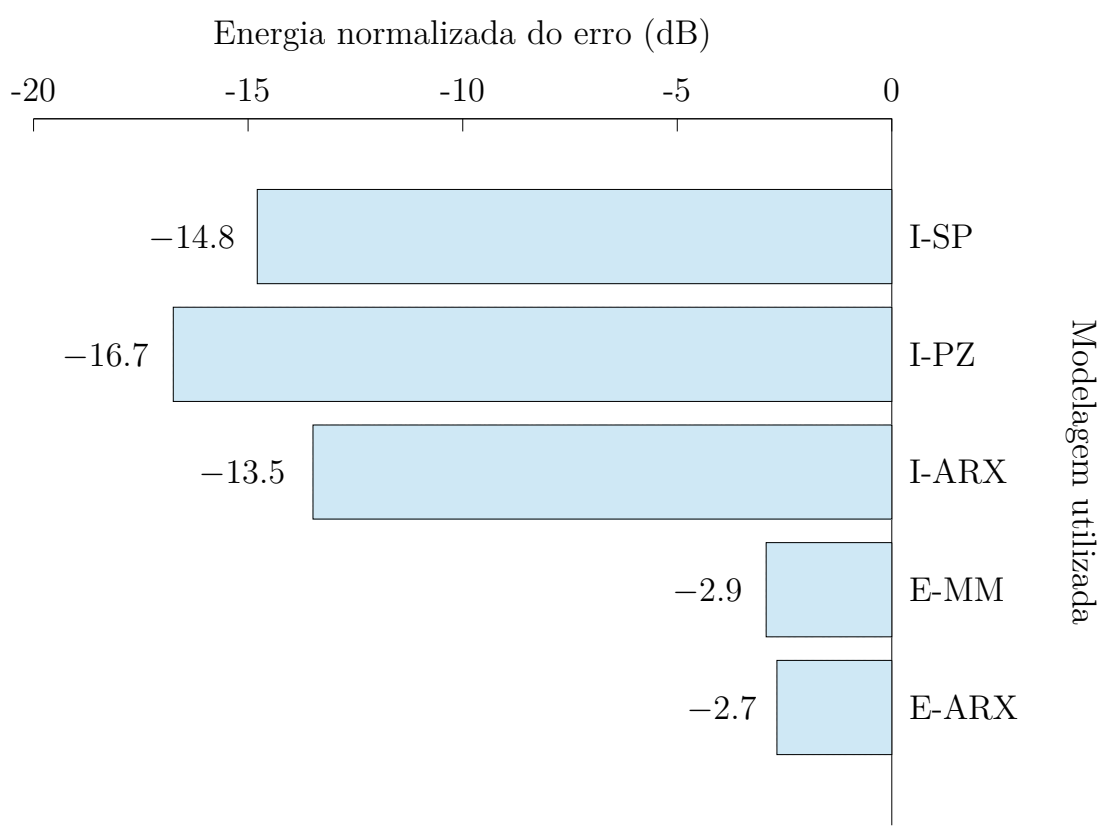

Figura 5.22: Energia normalizada do erro de estimação resultante de cada técnica de modelagem. I-SP: modelo intracelular só-polo; I-PZ: modelo intracelular polo-zero; E-MM: modelo extracelular média móvel; I-ARX: modelo intracelular ARX; E-ARX: modelo extracelular ARX.

\subsubsection{Modelagem dinâmica adaptativa}

A estrutura linear proposta pelos modelo permite explorar soluções usualmente aplicadas em processamento de sinais de comunicações. Os resultados das simulações demonstram que para cada disparo neuronal existe um conjunto de parâmetros que segue a função de 
sistema da Equação 4.15. A solução das equações normais, como a dada pela Equação 4.5, feitas até aqui a partir das estimativas da matriz de autocorrelação e do vetor de correlação cruzada, podem ser encontradas também por meio de algoritmos recursivos, (LIU; WANG; DING, 2010), sem a necessidade de realizar explicitamente a operação de inversão de matriz, que possui certa complexidade computacional.

Algoritmos adaptativos são utilizados para atualizar os coeficientes de filtros lineares ao longo do tempo, através de amostras dos sinais envolvidos. Em geral permitem o cálculo em tempo real de estimativas dos coeficientes, acompanhando variações em algumas propriedades estatísticas dos sinais, e também evitando a operação de inversão de matrizes. Nesse sentido, foi simulada a utilização de filtros adaptativos para estimar dinamicamente os valores dos parâmetros dos modelos intracelular e extracelular ao longo do tempo, de forma supervisionada. Na Figura 5.23 é apresentado o resultado da simulação do modelo intracelular só-polo utilizando o algoritmo adaptativo RLS (Recursive Least Squares) para o cálculo dos coeficientes ao longo de uma sequência de disparos. O Apêndice C apresenta um breve resumo dos passos desse algoritmo.

Para utilizar o algoritmo RLS, é preciso definir o sinal de entrada $u(n)$ e o sinal desejado como resposta na saída do filtro, denotado $d(n)$. No caso do modelo intracelular, o algoritmo é simulado para um preditor linear progressivo, que, como demonstrado na Seção 3.4, é a estrutura por trás do modelo só-polo. Dessa forma, o sinal de entrada do filtro é o próprio potencial de ação, porem atrasado em uma amostra no tempo, de forma que o vetor de entrada é definido como

$$
\mathbf{u}_{i}(n)=\left[\begin{array}{llll}
s(n-1) & s(n-2) & \ldots & s\left(n-K_{i}\right)
\end{array}\right]^{T}
$$

e o sinal desejado é o próprio sinal intracelular, ou seja, $d(n)=s(n)$. 
a)

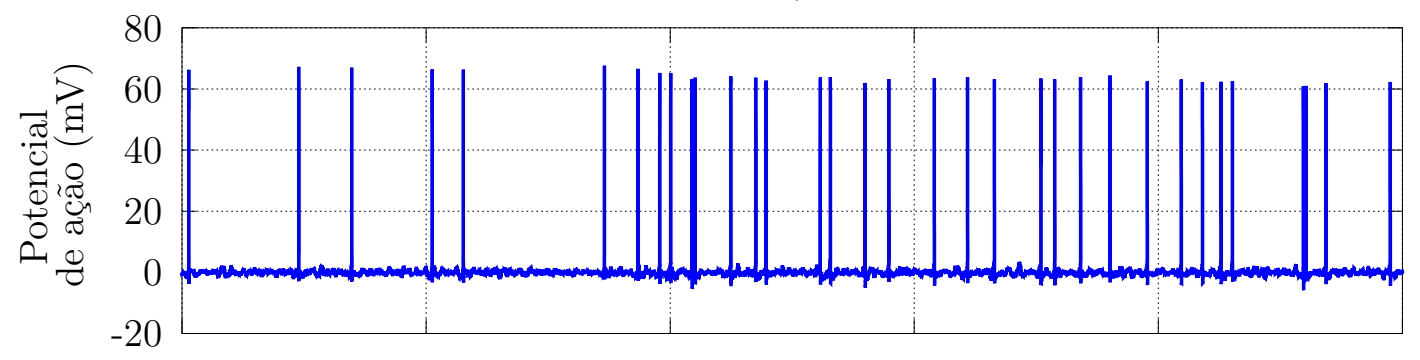

b)

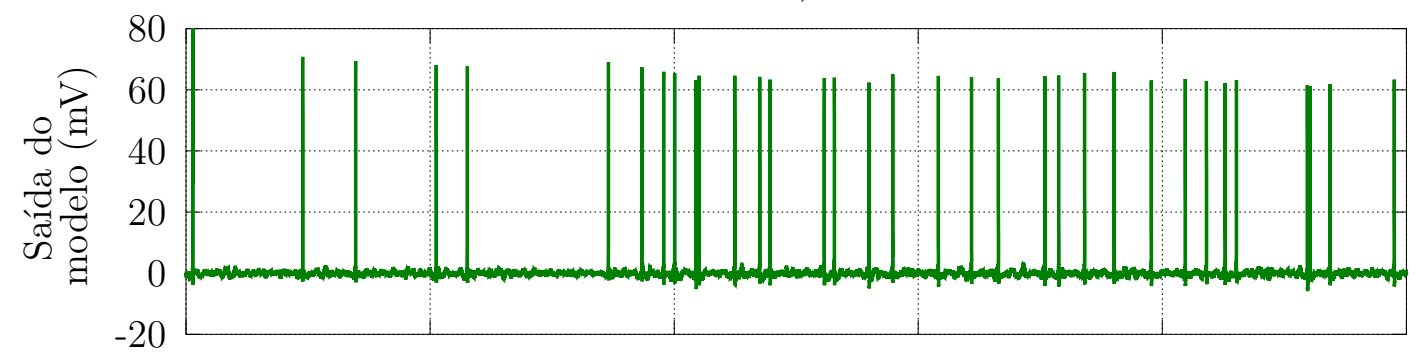

b)

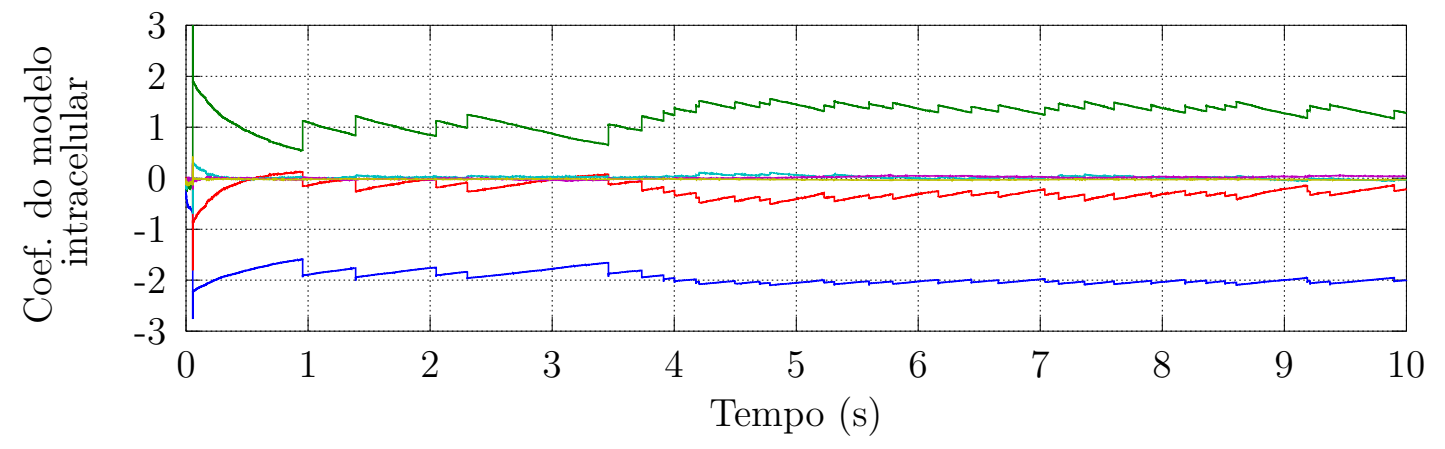

Figura 5.23: Resultados da modelagem do sinal intracelular por meio de filtro adaptativo RLS ( $\delta=1$ e $\lambda=0.9999)$ : a) sinal intracelular original, b) saída do preditor linear e c) evolução dos coeficientes do filtro $\left(K_{i}=6\right)$.

De forma análoga, na Figura 5.24, é apresentado o resultado da simulação do filtro adaptativo para atualizar os coeficientes do modelo extracelular média móvel. Neste caso, temos um filtro FIR simples, cuja entrada é o potencial de ação é dada por:

$$
\mathbf{u}_{e}(n)=\left[\begin{array}{llll}
s(n) & s(n-1) & \ldots & s\left(n-K_{e}\right)
\end{array}\right]^{T}
$$

e o sinal desejado o spike neuronal, ou seja, $d(n)=y(n)$. Note que somente os spikes do neurônio conhecido são modelados, pois o sinal $s(n)$ só contém os disparos desta célula. 
a)

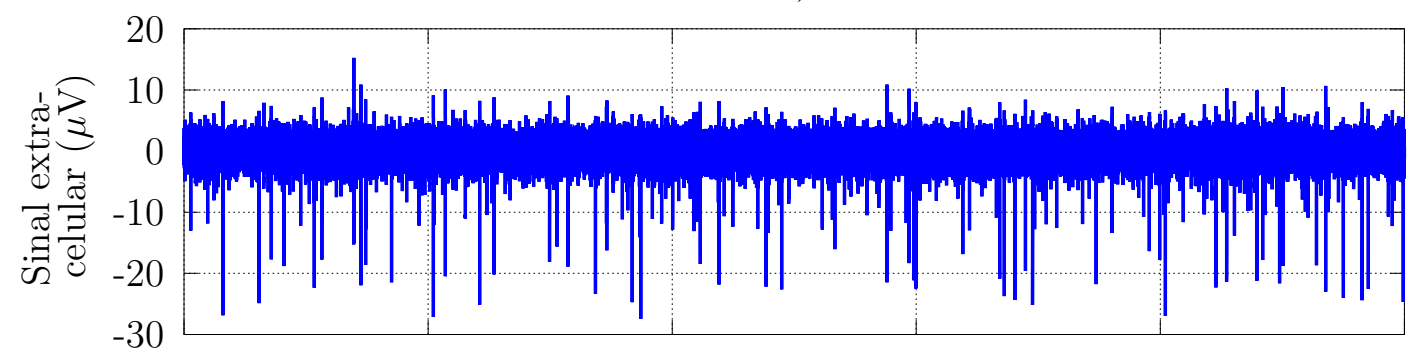

b)

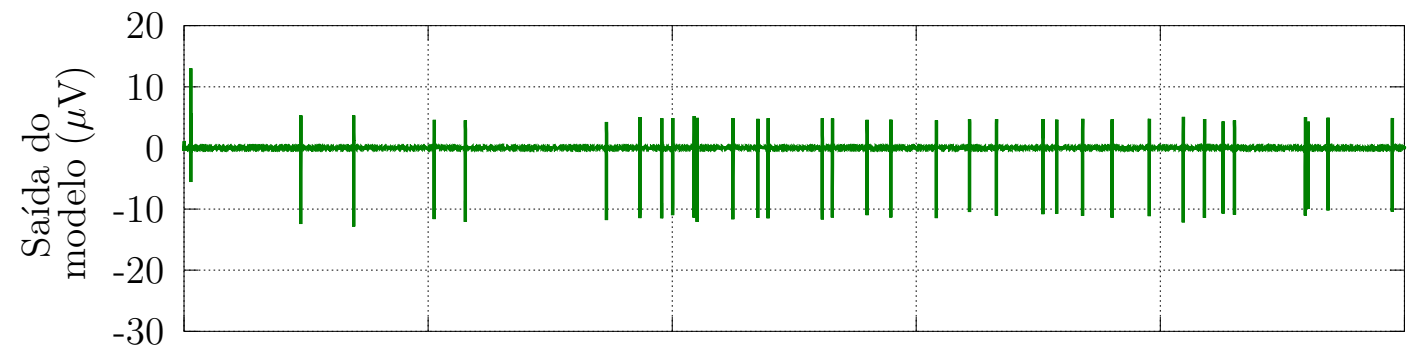

c)

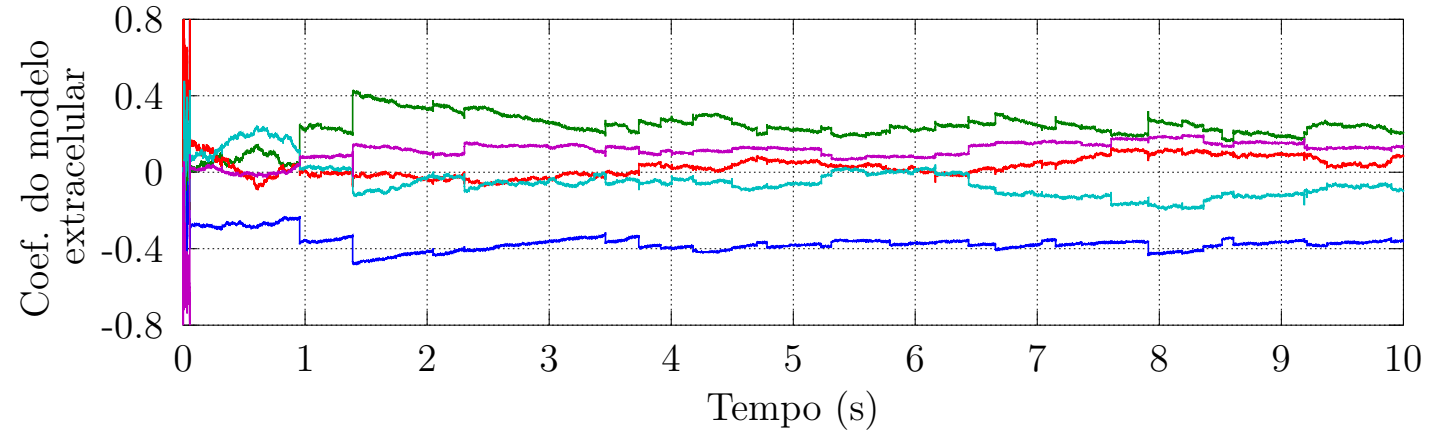

Figura 5.24: Resultados da modelagem do sinal extracelular por meio de filtro adaptativo RLS ( $\delta=1$ e $\lambda=0.9999)$ : a) sinal extracelular original, b) saída do filtro FIR adaptativo e c) evolução dos coeficientes do filtro $\left(K_{e}=4\right)$.

A modelagem por meio de filtros adaptativos apresenta resultados favoráveis nas condições encontradas. O algoritmo RLS aqui utilizado foi o que inicialmente mostrou-se adequado para o caso em questão, considerando os sinais envolvidos. Porém, outros algoritmos ainda devem ser explorados para investigar mais profundamente este tipo de solução. Todavia, a análise apresentada é um passo inicial no sentido de utilizar algoritmos on-line que permitam a parametrização em tempo real, com o objetivo maior de encontrar uma solução de baixa complexidade para o sistema inverso do modelo neuronal. 


\subsection{Conclusões}

Esse capítulo foi dedicado a apresentar a validação dos modelos obtidos através do processo apresentado ao longo do trabalho. De início, apresentou-se uma etapa de préprocessamento que permite encontrar as componentes mais apropriadas dos sinais para a modelagem a partir das séries temporais disponibilizadas na base de dados.

Devido às limitações dos dados experimentais utilizados, as simulações concentraram-se em modelos derivados da atividade de uma única célula neuronal ( $L=1$ na Figura 1.2). Dessa forma, a etapa de validação do modelo ficou restrita ao caso de um sistema com apenas uma entrada. A validação do modelo para múltiplas entradas é uma tarefa em aberto para trabalhos futuros, sujeito à disponibilidade de leituras neuronais mais completas. Já o caso de múltiplas saídas $(K>1)$ é diretamente simulado por meio dos demais canais do sinal extracelular, conferindo diversidade espacial aos parâmetros encontrados.

A simulação foi realizada inicialmente para um único disparo, e estendida para uma sequência de disparos de uma mesma série temporal. Assim, foi possível observar a variação dos parâmetros de acordo com a evolução das formas de onda do potencial de ação e do spike ao longo do tempo. Por meio de filtros adaptativos usando o algoritmo RLS, foi possível atualizar dinamicamente as estimativas dos parâmetros ao longo da sequência de disparos, de forma supervisionada. Esse resultado é positivo no sentido de encontrar soluções de tempo real, e um primeiro passo para uma parametrização cega do sinal.

Também foram apresentadas algumas discussões importantes para reproduzir e validar esses resultados. Sobre o sinal de entrada, pode-se perceber que sua função está relacionada com o instante exato de disparo, um parâmetro temporal do sinal. Além disso, uma análise do erro residual permitiu entender um pouco melhor as componentes não representadas pelo modelo, e cuja função ainda carece de maior investigação. Todavia, os resultados aqui expostos são oportunos para validar o modelo proposto, e prosseguir com a busca por um modelo inverso baseado nas estruturas sugeridas. 


\section{O modelo inverso}

Neste capítulo, são investigadas possíveis soluções para o sistema inverso sob a perspectiva estabelecida pelo modelo linear para o sinal neuronal. De início, o problema de encontrar o modelo inverso é caracterizado analiticamente a partir das equações matriciais do modelo no domínio da frequência. Duas abordagens principais são então analisadas, com o intuito de abrir caminho para futuras pesquisas que se aprofundem na visão proposta por este trabalho.

Em um primeiro momento, é discutido o tratamento do modelo inverso como um problema de separação de fontes multicanal. É apresentada uma formulação conceitual do problema, considerando-se a estrutura do modelo de múltiplos neurônios, e discutindo-se as restrições técnicas pra este tipo de abordagem. Essa formulação visa a criar uma primeira relação do problema com possíveis técnicas de separação de fontes que possam ser aplicáveis.

Em seguida, é estabelecida uma analogia entre a busca pelo sistema inverso e o problema de equalização de um canal de comunicações. Uma solução comum para este problema é a utilização de filtros adaptativos capazes de reconstruir o sinal de entrada a partir de amostras da saída do sistema. Dessa forma, será proposta uma solução baseada em filtros adaptativos transversais operando de forma supervisionada e sob condições restritas, que podem futuramente servir de base para situações mais realistas.

\subsection{A representação do modelo inverso}

O problema de separar os sinais dos spikes de diferentes neurônios contidos em uma mistura extracelular, identificando a célula responsável por cada disparo, caracteriza um problema inverso. A solução de um problema inverso consiste em encontrar causas de um fenômeno baseando-se na observação de seus efeitos. Considera-se um modelo $\mathcal{M}$ do tipo MIMO, tal que

$$
\mathbf{y}(n)=\mathcal{M}[\boldsymbol{\theta}, \mathbf{x}(n)]
$$


em que $\mathbf{y}(n)$ é o vetor de saída, $\mathbf{x}(n)$ o vetor de entrada, e $\boldsymbol{\theta}$ o vetor de parâmetros do modelo. O problema inverso consiste em determinar o valor dos sinais de entrada $\mathbf{x}(n)$, a partir de amostras dos sinais de saída $\mathbf{y}(n)$ (ASTER; BORCHERS; THURBER, 2012). No caso da mistura de spikes, sob o ponto de vista do modelo proposto para o sinal extracelular, o objetivo do problema inverso será o de encontrar os impulsos unitários associados a cada entrada do sistema, como ilustrado na Figura 1.3. Essa questão é de certa forma equivalente ao problema do spike sorting, conforme discutido na Seção 1.1.1.

Como ponto de partida, é necessário estabelecer formalmente o problema de encontrar o sistema inverso. Podemos formular matematicamente a função de sistema do modelo inverso no domínio da frequência, a partir da representação dada pela Equação 4.24. Assumindo que o modelo é suficientemente capaz de representar o sinal real, ou seja, que o erro de estimação é desprezível, pode-se considerar que $\mathbf{y}(n)=\hat{\mathbf{y}}(n)$, de forma que

$$
\mathbf{Y}(z)=\mathbf{H}(z) \mathbf{X}(z)
$$

Os valores dos elementos da matriz $\mathbf{H}(z)$ não são todos conhecidos, e portanto iremos procurar uma matriz $\mathbf{M}(z)$ tal que

$$
\mathbf{M}(z) \mathbf{H}(z)=\mathbf{I}(z)
$$

sendo $\mathbf{I}(z)$ uma matriz identidade. As Equações 6.2 e 6.3, resultam na expressão teórica para o sistema inverso:

$$
\mathbf{M}(z) \mathbf{Y}(z)=\mathbf{X}(z)
$$

O sistema $\mathbf{M}(z)$ portanto tem como entrada o sinal extracelular, e produz em suas saídas os impulsos unitários nos instantes de disparo associados a cada célula. Essa formulação teórica, no entanto, depende de diversas condições sobre os sinais envolvidos. Iremos investigar possíveis soluções para encontrar sistemas capazes de realizar, mesmo que de forma aproximada, a função de $\mathbf{M}(z)$, baseando-se na estrutura da matriz $\mathbf{H}(z)$, desenvolvida no processo de modelagem.

\subsection{Sistema inverso como um separador de fontes}

Neste caso, a ideia principal é encontrar uma matriz responsável pela mistura dos sinais de diferentes fontes, e por meio de técnicas de separação estimar uma matriz inversa. Esta solução dependerá principalmente de três condições: (i) a matriz a ser invertida não ser singular, (ii) as fontes possuírem distribuições de probabilidade não-gaussianas, e (iii) 
os sinais envolvidos possuírem um grau de independência suficiente para que possam ser separados (HYVÄRINEN; KARHUNEN; OJA, 2001).

No caso do modelo MIMO discutido na Seção 4.3, cuja representação resulta na Equação 6.2, encontrar um sistema inverso pode não ser uma tarefa trivial. Vale lembrar que o modelo para $\mathbf{H}(z)$ resulta em uma matriz polinomial, com elementos contendo funções de sistema do tipo polo-zero. O tratamento pode ser simplificado escrevendo-se as equações para as saídas do sistema em termos do sinal intermediário $\hat{s}(n)$, seguindo a estrutura apresentada na Figura 4.5:

$$
\left[\begin{array}{c}
\hat{y}_{1}(n) \\
\hat{y}_{2}(n) \\
\hat{y}_{3}(n) \\
\vdots \\
\hat{y}_{K}(n)
\end{array}\right]=\left[\begin{array}{ccccc}
\mathbf{w}_{1,1} & \mathbf{w}_{1,2} & \mathbf{w}_{1,3} & \ldots & \mathbf{w}_{1, L} \\
\mathbf{w}_{2,1} & \mathbf{w}_{2,2} & \mathbf{w}_{2,3} & \ldots & \mathbf{w}_{2, L} \\
\mathbf{w}_{3,1} & \mathbf{w}_{3,2} & \mathbf{w}_{3,3} & \ldots & \mathbf{w}_{3, L} \\
\vdots & \vdots & \vdots & \ddots & \vdots \\
\mathbf{w}_{K, 1} & \mathbf{w}_{K, 2} & \mathbf{w}_{K, 3} & \ldots & \mathbf{w}_{K, L}
\end{array}\right] \cdot\left[\begin{array}{c}
\hat{\mathbf{s}}_{1}(n) \\
\hat{\mathbf{s}}_{2}(n) \\
\hat{\mathbf{s}}_{3}(n) \\
\vdots \\
\hat{\mathbf{s}}_{L}(n)
\end{array}\right]
$$

em que $\hat{y}(n)$ são as saídas do modelo, que representam cada canal extracelular. Os vetores $\hat{\mathbf{s}}_{j}(n)$ contêm $K_{e}+1$ amostras atrasadas do sinal produzido pelo modelo intracelular correspondente ao neurônio $j$. Portanto,

$$
\hat{\mathbf{s}}_{j}(n)=\left[\begin{array}{llll}
\hat{s}_{j}(n) & \hat{s}_{j}(n-1) & \ldots & \hat{s}_{j}\left(n-K_{e}\right)
\end{array}\right]^{T} .
$$

Por sua vez, os vetores $\mathbf{w}_{i, j}$ são os coeficientes do sistema média móvel, obtidos para cada função $G_{i, j}(z)$ do modelo extracelular, ou seja

$$
\mathbf{w}_{i, j}=\left[\begin{array}{llll}
w_{0}^{i, j} & w_{1}^{i, j} & \ldots & w_{K_{e}}^{i, j}
\end{array}\right]
$$

Para simplificar a notação, podemos escrever a Equação 6.5 em forma puramente matricial:

$$
\hat{\mathbf{y}}(n)=\mathbf{W} \hat{\mathbf{s}}(n) .
$$

Vale notar que o vetor $\hat{\mathbf{y}}(n)$ terá dimensão $K \times 1$, a matriz $\mathbf{W}$ terá dimensão $K \times L\left(K_{e}+1\right)$, e o vetor $\widehat{\mathbf{s}}(n)$ terá dimensão $L\left(K_{e}+1\right) \times 1$.

Na grande maioria dos casos, a matriz W não será uma matriz quadrada. Leituras extracelulares em geral apresentam um número de eletrodos menor que o de neurônios, resultando em uma matriz com um número de linhas menor que o de colunas. Neste caso, temos um problema de separação submodelado, de forma que mesmo conhecendo seus elementos, não é possível inverter diretamente a matriz $\mathbf{W}$, e obter uma solução ótima.

Os spikes de diferentes células também não são necessariamente independentes entre si, 
eliminando também outra condição para solução trivial de separação de fontes. Entretanto, técnicas especializadas podem ser usadas para contornar estas restrições. Algumas delas baseiam-se na recuperação de fontes isoladamente (i.e. uma fonte por vez), sendo inclusive aplicadas com sucesso na separação de spikes gerados artificialmente (MAMLOUK et al., 2005).

\subsection{Solução adaptativa supervisionada}

O problema de separação de fontes possui uma ligação direta com o problema de equalização multiusuário (ATTUX et al., 2007a; ATTUX et al., 2007b). Portanto, pode-se interpretar a estrutura dos modelos ilustrados nas Figuras 4.4 e 4.5 como sendo análoga a um canal de transmissão cujos símbolos de entrada são zeros e uns. Nesse sentido, procurase encontrar uma solução capaz de restaurar o vetor dos sinais de entrada $\mathbf{x}(n)$, contendo os instantes de disparo dos neurônios originais, a partir de leituras do sinal extracelular, utilizando um filtro transversal adaptativo para realizar a função do sistema inverso. Será considerada a filtragem adaptativa sobre o sinal extracelular real, e posteriormente sobre uma mistura de spikes gerada artificialmente, a fim de permitir a simulação de disparos de múltiplas células. O objetivo deste estudo é estabelecer uma relação entre o problema de equalização multiusuário e o sistema inverso do modelo neuronal.

\subsubsection{Sistema inverso para um único neurônio}

Considera-se o caso em que o sinal de entrada do filtro adaptativo são os canais de leitura do sinal extracelular, representados pelo vetor $\mathbf{y}(n)$ cujos elementos $y_{k}(n)$ representam as séries temporais de cada eletrodo. Desta forma, para um filtro adaptativo de ordem $M$, teremos o vetor de entrada

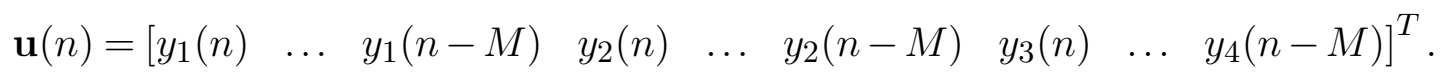

O sinal de resposta desejado será dado por $d(n)=x(n)$, contendo uma sequência de impulsos unitários de uma única célula durante o intervalo de observação. Note que este é um caso particular do sistema ilustrado pela Figura 1.3, com apenas uma única saída $(L=1)$. Na Figura 6.1 é apresentada a configuração utilizada, através da qual é possível implementar um algoritmo adaptativo multiusuário a fim de recuperar os instantes de disparo do neurônio em questão.

Assim como no processo de estimação do modelo, o sinal $x(n)$, contendo os impulsos 
unitários, é determinado pelos potenciais de ação do sinal intracelular da célula que foi observada no mesmo conjunto de dados. Como ilustrado na Figura 5.3, esta relação pode ser estabelecida alinhando-se os sinais intracelular e extracelular, de forma que os spikes associados à célula observada possam ser identificados. O filtro adaptativo irá reconstruir esta série de impulsos obtida a partir da sequência de spikes obtidas pelos eletrodos nas proximidades.

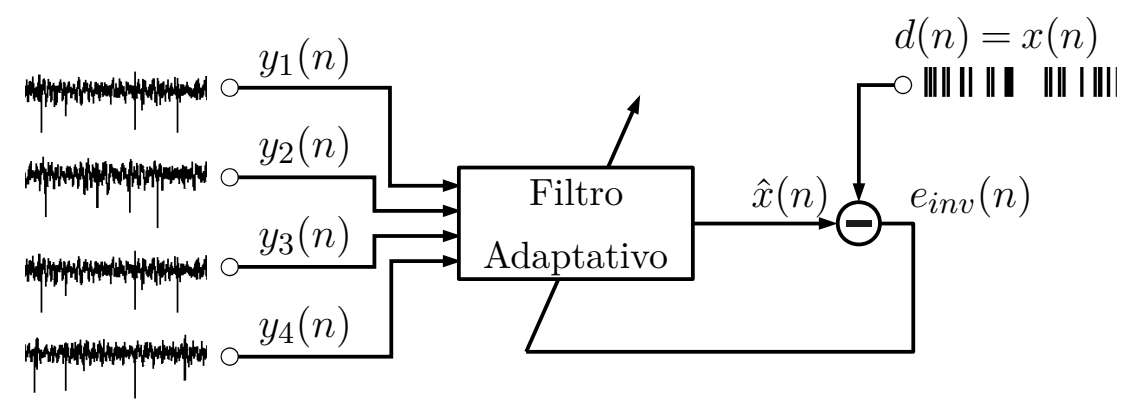

Figura 6.1: Configuração de modelagem inversa utilizando filtro adaptativo diretamente a partir dos sinais experimentais $\mathbf{y}(n)$, e a sequência de impulsos unitários de uma célula na região.

A fim de reconstruir a sequência de impulsos unitários, é utilizado um decisor por meio da função degrau, ou função de Heaviside, sobre a saída $\hat{x}(n)$ do filtro adaptativo. Dessa forma, uma estimativa mais precisa para o sinal procurado será dada por:

$$
U(\hat{x})= \begin{cases}1, & \hat{x} \geq x_{\text {min }} \\ 0, & \hat{x}<x_{\text {min }}\end{cases}
$$

em que $x_{\text {min }}$ é um patamar estabelecido empiricamente, acima do qual considera-se que o sinal de saída é um impulso unitário. Este patamar tem a função de auxiliar o reconhecimento do impulso, eliminando variações indesejadas do sinal de saída do filtro.

Foi avaliada a utilização do algoritmo adaptativo NLMS (Normalized Least Mean Squares) (HAYKIN; WIDROW, 2003), cujos passos são detalhados no Apêndice D, para testar esta configuração. Aqui o algoritmo NLMS mostrou-se mais apropriado, possivelmente devido a diferenças nas características estatísticas dos sinais envolvidos, em contraste com a análise do sistema direto, apresentada na Seção 5.6, em que foi empregado o algoritmo RLS.

O resultado da simulação desta configuração é apresentado na Figura 6.2. Nesta simulação, foi utilizado um filtro transversal com $M=20$ coeficientes como sistema inverso. 
O valor de patamar utilizado foi de $x_{\text {min }}=0.5$, e os parâmetros do algoritmo NLMS foram $\mu=1.0$ e $\delta=10^{-2}$ (respectivamente o passo de adaptação e o parâmetro de regularização). Nota-se que neste caso o filtro adaptativo é capaz de recuperar completamente a sequência de impulsos associada aos spikes da célula em questão, apesar de sua entrada conter spikes de diversas células, além da presença de ruído.

a)

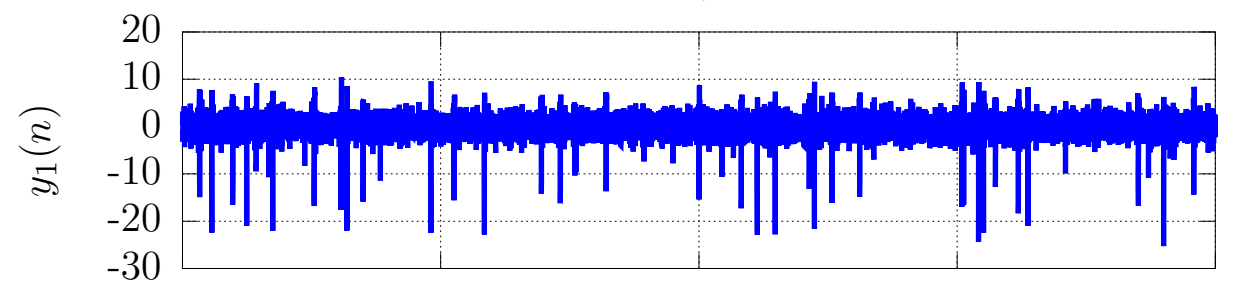

b)

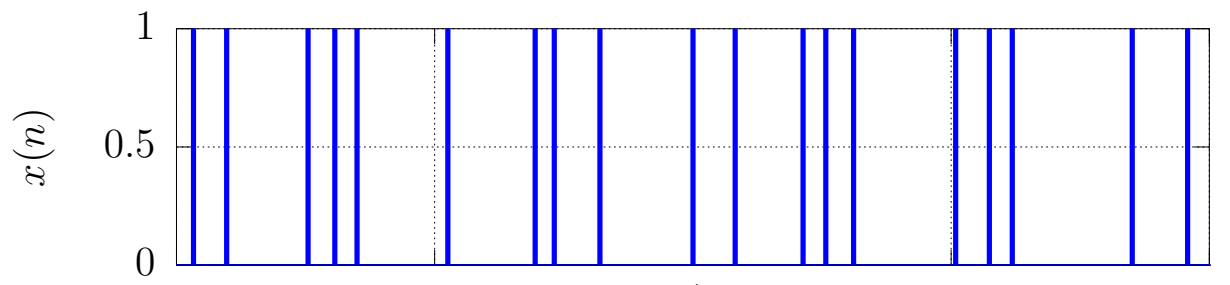

c)

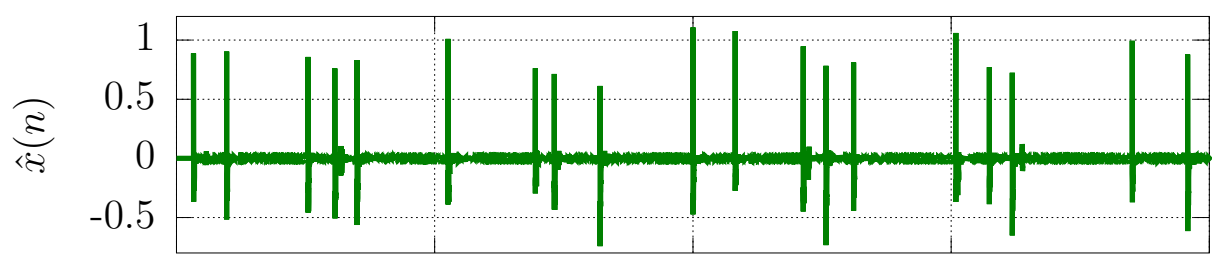

d)

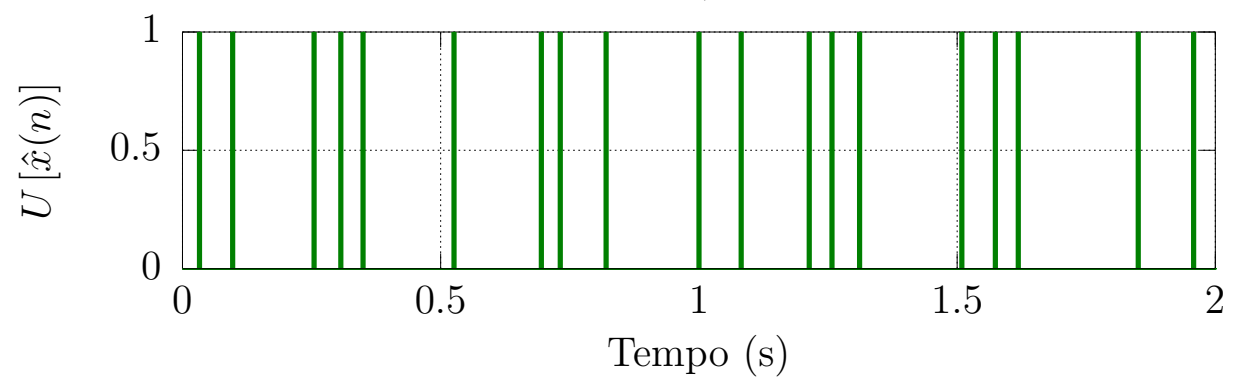

Figura 6.2: Resultados da simulação do algoritmo NLMS sobre o sinal extracelular: a) sinal extracelular real em um dos eletrodos; b) sequência de impulsos determinada pelo modelo correspondente; c) saída do filtro adaptativo; d) saída após passar pelo decisor.

Parâmetros de simulação: $x_{\min }=0.5 ; \mu=1.0 ; \delta=0.01 ; M=20$ coeficientes.

Apesar de encorajador, este resultado tem como propósito apenas ilustrar as possibilidades ainda a serem exploradas com essa abordagem. O resultado de uma simulação deste tipo é influenciado consideravelmente pelos parâmetros utilizados no algoritmo, não 
analisados de forma aprofundada neste trabalho, bem como outros algoritmos que possam apresentar melhores resultados. Além disso, vale lembrar que a solução encontrada não é diretamente útil em uma situação prática, pois considera um modelo de apenas uma entrada, ou seja, somente um neurônio ativo. Apesar disso, a estrutura em que o problema foi modelado e o resultado obtido sugerem maior investigação para uma solução análoga ao problema de equalização multiusuário.

\subsubsection{Sistema inverso para múltiplos neurônios}

Para aproximar-se de um cenário real, a simulação da modelagem inversa por meio de filtros adaptativos deveria considerar o caso de múltiplas células ativas. No caso da filtragem adaptativa supervisionada, isso só seria possível se estivessem disponíveis as entradas $x_{j}(n)$ de todas as células que dispararam durante o intervalo de tempo considerado. Como os dados utilizados contêm o sinal intracelular de apenas uma célula, foram geradas sequências de disparo para mais de uma célula utilizando o próprio modelo para o sinal extracelular. Após gerar uma sequência de spikes e os respectivos sinais de entrada, a simulação é feita com um algoritmo adaptativo para múltiplos sinais de saída.

\section{Síntese de uma mistura de spikes}

Para gerar uma sequência de spikes a partir de mais de um canal de entrada contendo impulsos unitários, o modelo obtido para o neurônio é implementado com coeficientes pré-definidos. Na Figura 6.3 é ilustrada a configuração do modelo utilizada para gerar a sequência de spikes observada por um eletrodo $i$ qualquer. Este esquema segue a mesma estrutura do modelo MISO apresentado na Figura 4.4. Neste caso, porém, os coeficientes são estimados inicialmente para um único neurônio, produzindo as funções de sistema $F(z)$ e $G_{i}(z)$. Os coeficientes do modelo extracelular são então ponderados por um fator multiplicador para se obter os modelos das demais células que se deseja adicionar na mesma mistura. 


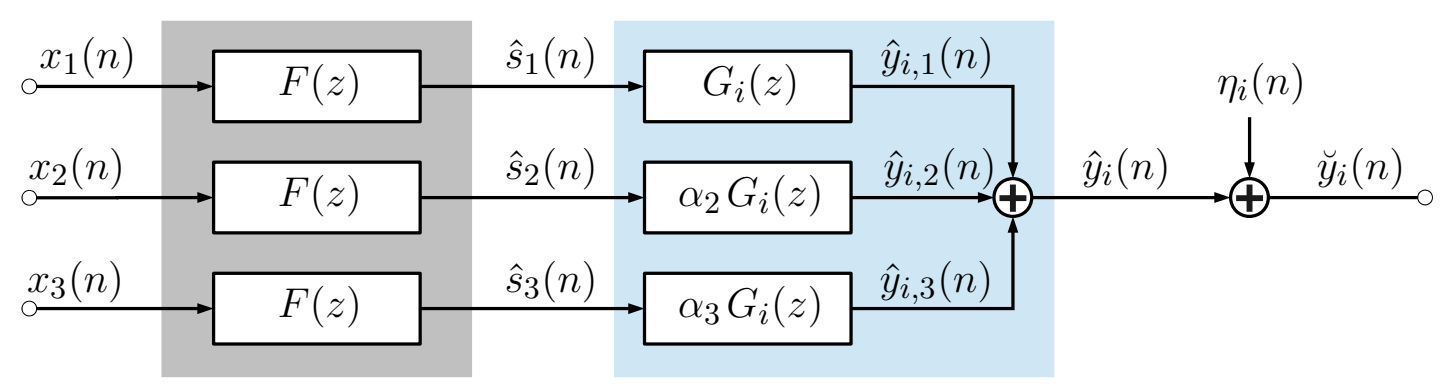

Figura 6.3: Configuração para geração de uma sequência artificial de spikes, a partir do modelo de um neurônio definido pelas funções $F(z)$ e $G_{i}(z)$.

É importante ressaltar que a configuração utilizada na Figura 6.3 assume as seguintes hipóteses simplificadoras:

i células distintas produzem um potencial de ação suficientemente similar, e por isso considera-se que todas as células produzem uma forma de onda a partir dos mesmos parâmetros definidos em $F(z)$;

ii os spikes sofrem o efeito de um fator de atenuação, representado pelos parâmetros $\alpha_{2}$ e $\alpha_{3}$, associados a cada neurônio ativo, de forma que as diferenças entre os spikes de células diferentes resumem-se principalmente a amplitudes de pico distintas;

iii cada célula dispara em um instante diferente das demais, logo cada entrada é definida como $x_{j}(n)=\delta\left(n-\Delta_{j}\right)$, com $\Delta_{j}$ o instante exato do início do potencial de ação a ser gerado em $\hat{s}_{j}(n)$. Em situações reais, células podem produzir spikes sobrepostos uns aos outros, com picos bem próximos no tempo.

Os sinais produzidos com a aplicação dessa configuração são ilustrados na Figura 6.4. Note que há a adição de um ruído para tornar a mistura mais próxima do caso real, como discutido na Seção 5.6. Nesta figura é possível observar que o sinal final gerado contém spikes das células ativas em uma mesma sequência. Este procedimento pode ser repetido com os coeficientes de outras funções média móvel $G_{i}(z)$, para qualquer eletrodo $i$. 
a)

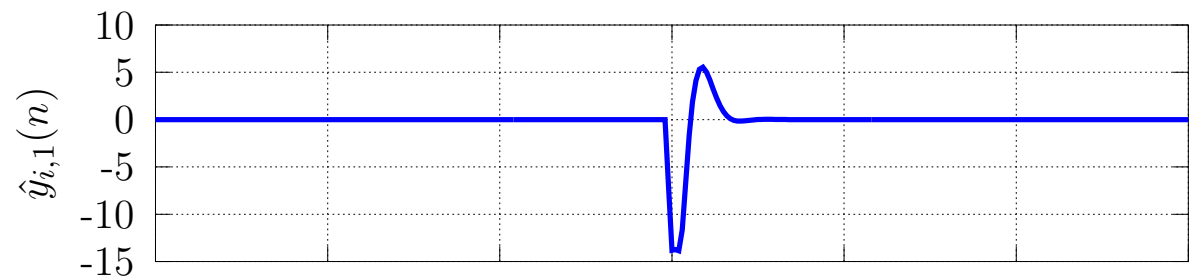

b)

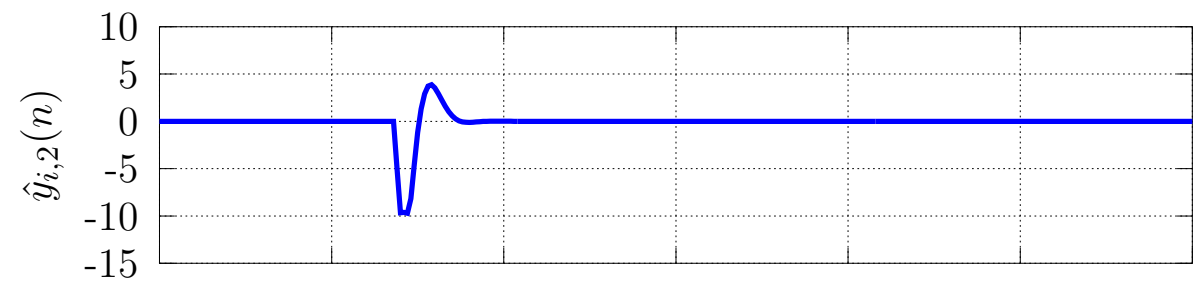

c)

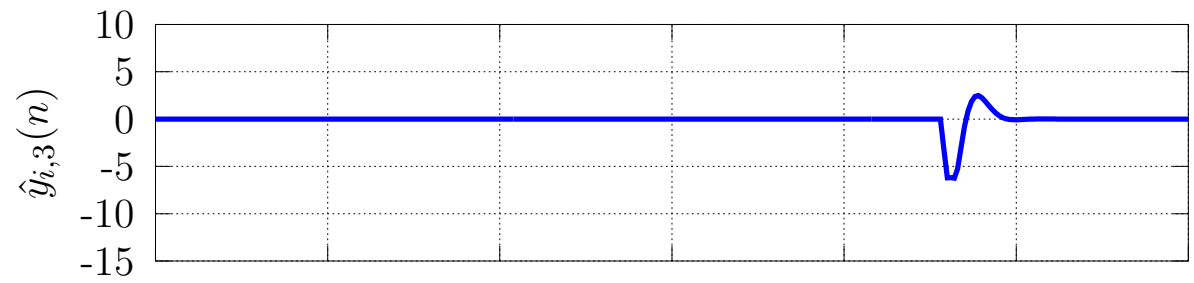

d)

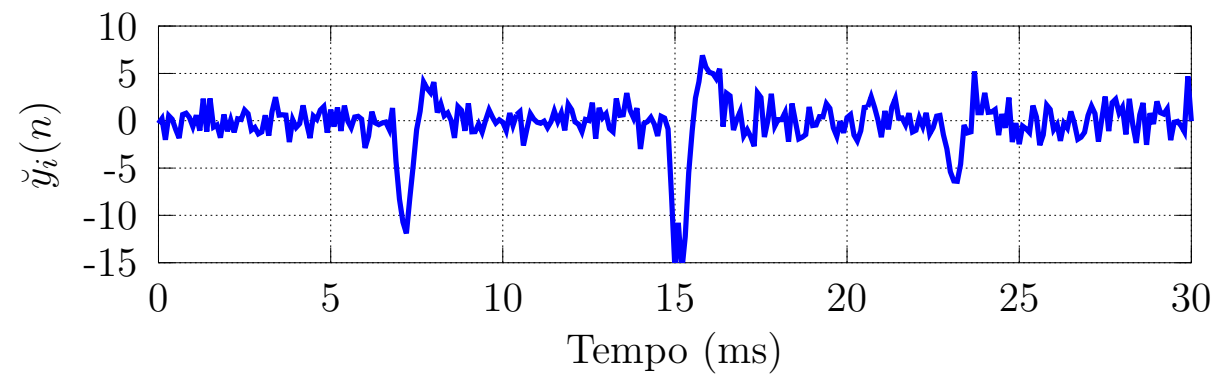

Figura 6.4: Geração de uma série artificial de spikes. a) saída do modelo original; b) saída do modelo com $\alpha_{2}=0.7$; c) saída do modelo com $\alpha_{3}=0.45$; d) mistura dos sinais com adição de ruído branco (SNR de $5 \mathrm{~dB}$ ).

\section{Simulação com filtro adaptativo}

Uma mistura de spikes gerada é utilizada na entrada do filtro adaptativo, e os sinais $x_{j}(n)$, com os impulsos unitários de cada célula, são utilizados como a resposta desejada. A configuração de modelagem inversa sobre a saída do sistema gerador de spikes é ilustrada na Figura 6.5, para o caso de 2 neurônios. Esta montagem permite simular a recuperação dos impulsos de cada célula a partir da série de spikes produzida por um modelo de múltiplos neurônios. Note que o modelo de múltiplas células segue a mesma estrutura apresentada na Figura 4.5, excluindo-se o efeito do ruído. 


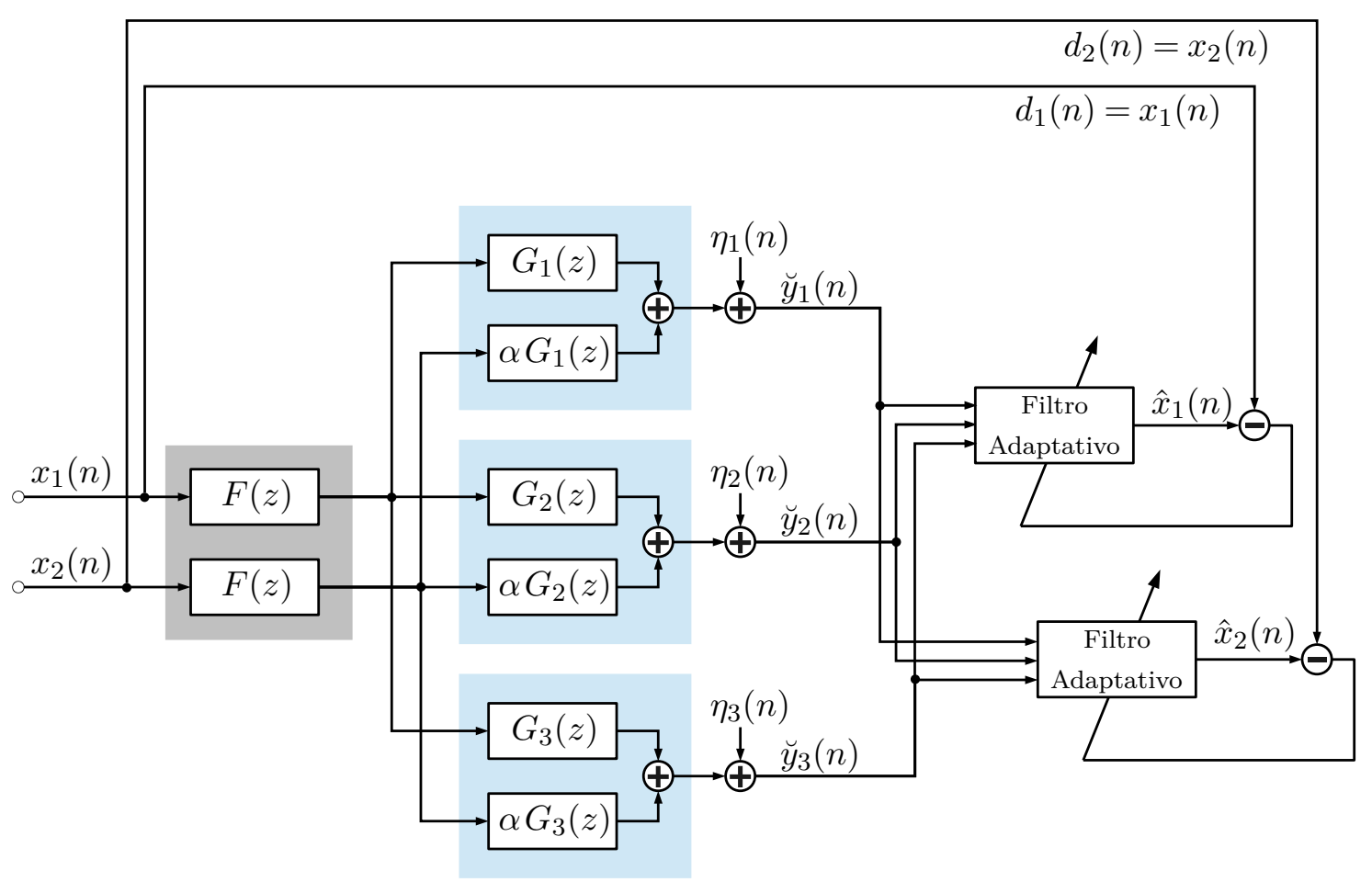

Figura 6.5: Configuração de modelagem inversa adaptativa usando uma sequência de spikes artificialmente gerada, para $L=2$ neurônios e $K=3$ eletrodos.

O resultado da simulação de uma configuração seguindo este esquema é apresentado na Figura 6.6, para um cenário contendo $L=3$ neurônios e $K=4$ eletrodos. Nesta simulação utilizou-se um filtro adaptativo para cada um dos sinais de resposta desejados, empregando o algoritmo NLMS. Os parâmetros utilizados deste algoritmo foram $\mu=0.5$ e $\delta=0.01$, e a saída de cada um deles passa por um decisor, da mesma forma que foi feito para o caso de um único neurônio, com $x_{\min }=0.5$. O filtro transversal adaptativo é simulado com $M=20$ coeficientes. Os valores dos coeficientes do modelo MIMO estão listados na Tabela 6.1 . 
a)

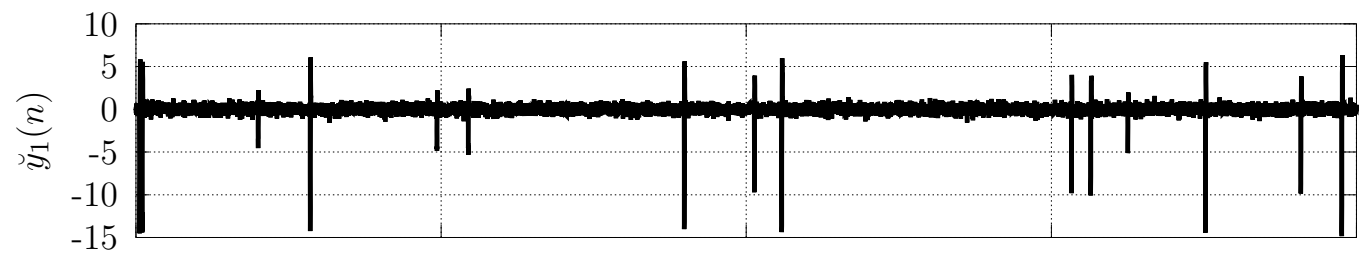

b)

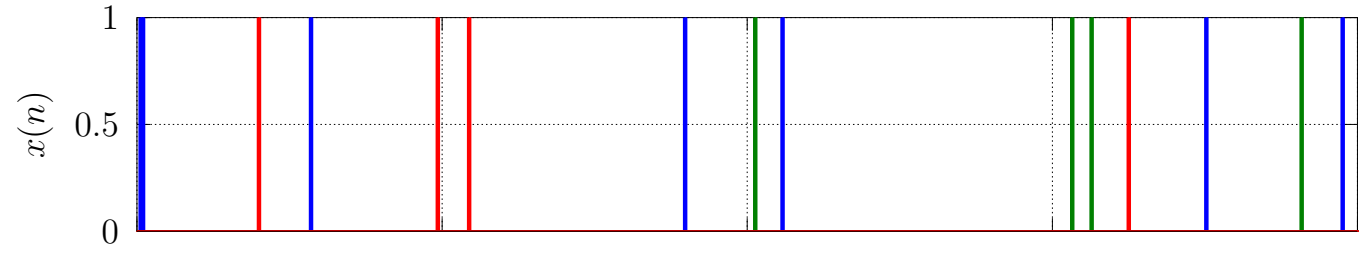

c)

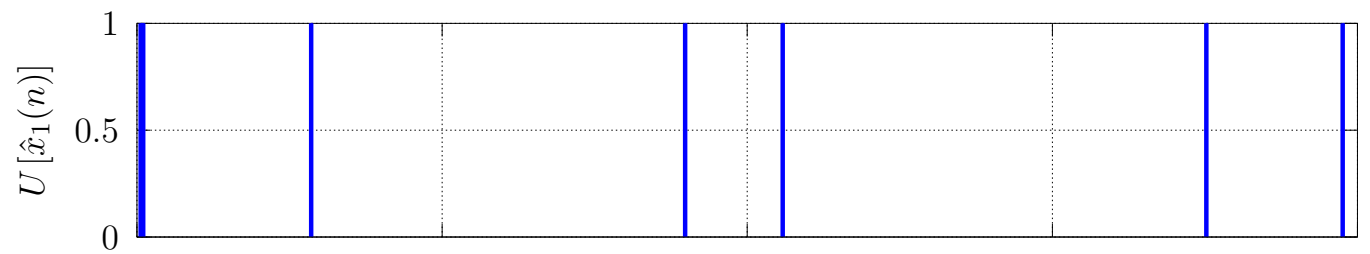

d)

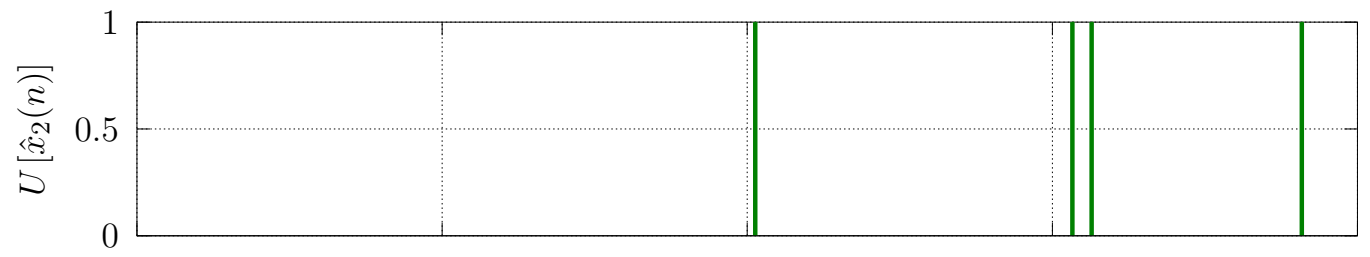

e)

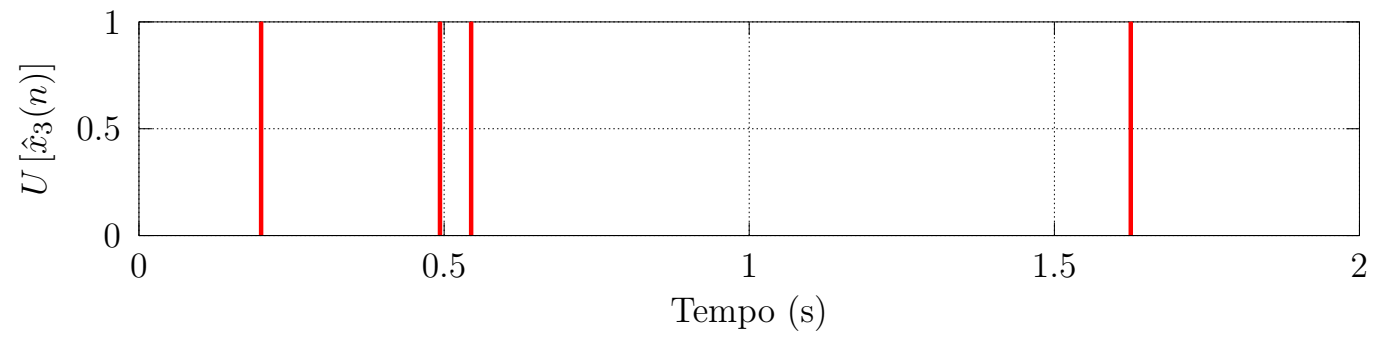

Figura 6.6: Resultados da simulação do algoritmo NLMS sobre saída do modelo MIMO, para $L=3$ neurônios e $K=4$ eletrodos. Em a) mistura de spikes em uma das saídas do modelo; b) impulsos unitários relativos a cada spike (cada célula é representada por uma cor diferente); c), d) e e) saídas recuperadas para cada neurônio, após passar por decisor. 
Tabela 6.1: Coeficientes do modelo gerador de spikes para simulação de modelagem inversa.

\begin{tabular}{rrrrrrr}
\hline & $F$ & $G_{1}$ & $G_{2}$ & $G_{3}$ & $G_{4}$ \\
\hline$g_{f}$ & 17.1440 & - & - & - & - \\
$a_{0}$ & 1.0000 & - & - & - & - \\
$a_{1}$ & 2.4230 & - & - & - & - \\
$a_{2}$ & -2.4711 & - & - & - & - \\
$a_{3}$ & 1.5514 & - & - & - & - \\
$a_{4}$ & -0.7650 & - & - & - & - \\
$a_{5}$ & 0.2597 & - & - & - & - \\
$a_{6}$ & -0.0343 & - & - & - & - \\
\hline$w_{0}$ & - & -0.3996 & -0.4888 & -0.4205 & -0.5475 \\
$w_{1}$ & - & 0.1415 & 0.2560 & 0.1503 & 0.3518 \\
$w_{2}$ & - & 0.1975 & 0.1810 & 0.2126 & 0.1303 \\
$w_{3}$ & - & -0.2550 & -0.2854 & -0.2730 & -0.2835 \\
$w_{4}$ & - & 0.2432 & 0.2670 & 0.2461 & 0.2675
\end{tabular}

Fatores de escala para os demais sistemas: $\alpha_{2}=0.67$ e $\alpha_{3}=0.33$.

Os instantes de disparo são definidos aleatoriamente dentro do intervalo de $2 \mathrm{~s}$, por meio de uma distribuição binomial, com o intuito de que resulte em uma quantidade pré-definida de disparos para cada célula. Nesta simulação foi utilizado uma relação sinal-ruído de 5 dB. É possível constatar que o filtro adaptativo conseguiu separar os instantes de disparo de cada célula com precisão. A contagem de falsos negativos (spikes não detectados), para diferentes valores de SNR, é apresentada na Figura 6.7, sob as mesmas condições de parâmetros do caso anterior. Nota-se que a detecção passa a apresentar erros com o aumento da potência do sinal de ruído. 


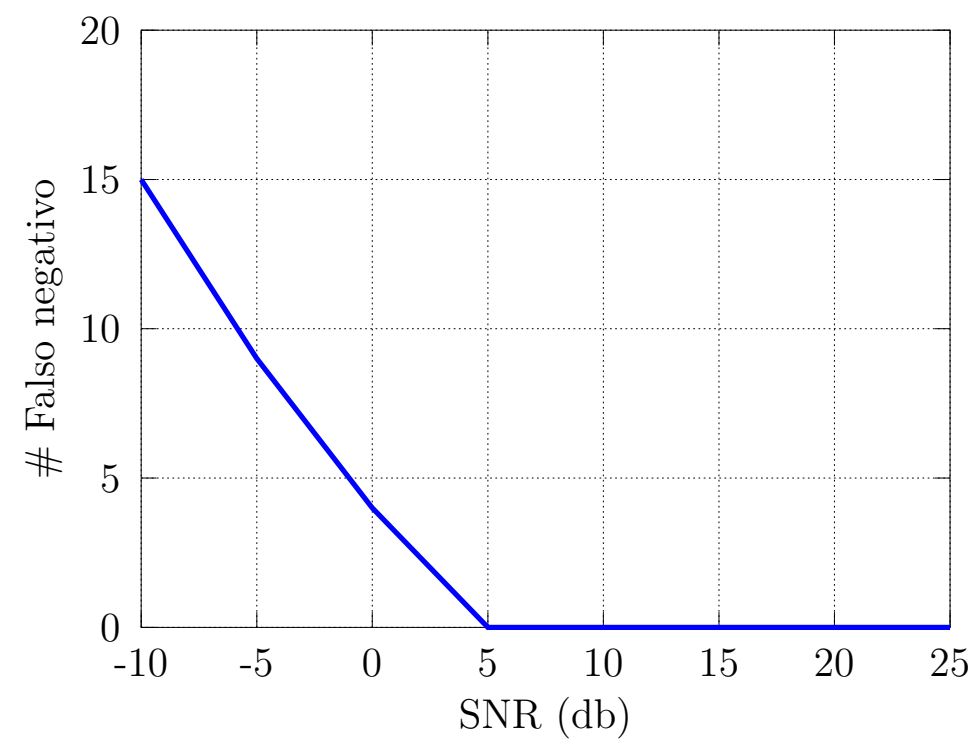

Figura 6.7: Erros de identificação vs. SNR para modelagem inversa.

Novamente, essa análise procura estabelecer um ponto de partida para soluções mais aprofundadas, porém apresenta resultados interessantes. Condições diversas de simulação podem ser exploradas para aprofundar esse estudo, incluindo parâmetros diferentes para o algoritmo adaptativo, valores dos coeficientes do modelo, quantidade de células e frequências de disparo. O próximo passo neste sentido é investigar outros algoritmos adaptativos, com o objetivo final de encontrar soluções que operem de forma não-supervisionada, idealmente sobre dados reais, ao invés de uma mistura artificialmente gerada para o sinal desejado.

\subsection{Discussão}

Neste capítulo foram introduzidas duas abordagens para a concepção do sistema inverso. Estas abordagens baseiam-se na estrutura linear do modelo proposto ao longo do trabalho, explorando soluções análogas a casos comumente encontrados em processamento de sinais. O objetivo aqui é exercitar a aplicação de técnicas que possam aproveitar os resultados obtidos com a modelagem do sinal neuronal. Uma solução para o sistema inverso que funcione nas condições de uma leitura em tempo real do sinal extracelular é de grande interesse para o problema do spike sorting, conforme exposto no Capítulo 1.

A tarefa de encontrar um sistema inverso foi discutida inicialmente como um problema de separação de fontes contendo uma mistura convolutiva. A solução neste tipo de abordagem, no entanto, não é imediata: em geral o número de neurônios observados em uma série temporal é maior que o número de sensores, resultando em um caso de 
separação submodelada (COMON; JUTTEN, 2010). Buscou-se apresentar uma primeira formulação matemática para o modelo inverso sob este ponto de vista, baseando-se no modelo obtido para o sinal neuronal. Futuros trabalhos que sigam esta abordagem podem explorar a estrutura da matriz de sistema do modelo, e do fato de que os sinais de entrada são definidos exclusivamente como impulsos unitários deslocados no tempo.

Uma segunda abordagem segue a relação natural da separação de fontes com o problema de equalização multiusuário. A utilização de um algoritmo adaptativo em uma configuração de modelagem inversa mostrou resultados positivos em dois cenários avaliados. Utilizando leituras extracelulares reais como entrada de um filtro adaptativo, foi possível recuperar os instantes de disparo de um dos neurônios ativos na mistura de spikes contida no sinal. Para testar essa abordagem no caso de múltiplas células, foi utilizada uma mistura de spikes artificialmente gerada por um modelo do tipo MIMO com adição de ruído. Com a mistura gerada foi possível simular a utilização de um filtro adaptativo multiusuário de forma a recuperar os instantes de disparo originais de mais de uma célula ao mesmo tempo. Em ambos os casos testados, a modelagem inversa foi realizada de forma supervisionada.

Apesar de estes cenários representarem uma simplificação da situação real em que o modelo inverso é de interesse, os testes aqui realizados contribuem para construir uma abordagem para o problema por meio de técnicas que estejam relacionadas com o problema de equalização de canais. Outros cenários podem ser avaliados, considerando os parâmetros do modelo e da configuração de filtragem adaptativa utilizada. Neste sentido, a pesquisa futura de ferramentas para complementar esta abordagem passa por definir mais precisamente as condições necessárias para a modelagem inversa não-supervisionada. 


\section{Conclusões e perspectivas}

Este trabalho apresentou o desenvolvimento de um modelo matemático para o sinal produzido pelo neurônio durante o disparo, utilizando técnicas de modelagem e identificação de sistemas. Tal modelo tem como propósito servir de base para a obtenção de um sistema inverso, com a função de separar spikes de diferentes neurônios em uma mistura de sinais. Dessa forma, buscou-se manter um foco maior sobre a parametrização da forma de onda observada em sinais experimentais reais, em detrimento de representar a dinâmica fisiológica da célula.

O Capítulo 2 apresentou uma introdução aos processos biológicos envolvidos na geração do sinal neuronal, fornecendo subsídio para a compreensão do funcionamento do neurônio, além de expor alguns aspectos importantes da aquisição de leituras do sinal em laboratório. Essa introdução também serviu para melhor compreender alguns dos modelos encontrados na literatura, e entender as diferenças entre modelos com variados níveis de abstração em relação aos fenômenos físico-químicos envolvidos, dando um contexto necessário à proposta deste trabalho.

No Capítulo 3 foi feita uma revisão da teoria de identificação de sistemas, com ênfase em modelos lineares de tempo discreto. Esse capítulo permitiu construir uma visão geral do processo de identificação, bem como o entendimento das ferramentas matemáticas utilizadas ao longo do trabalho. As estruturas dos modelos e algumas técnicas de estimação de parâmetros foram apresentadas com vistas à aplicação no caso do sinal neuronal.

O desenvolvimento da abordagem proposta para a construção do modelo foi apresentado no Capítulo 4. Nesse capítulo, a modelagem é realizada em etapas, a partir de um caso simplificado de um sistema para um único neurônio. Esse caso é por sua vez dividido em dois subsistemas: intracelular e extracelular. Isso permitiu utilizar os dados de ambos os sinais para obter parâmetros de modelos isolados, mas que ao serem concatenados em série são capazes de reproduzir o spike neuronal. A partir do caso simplificado, são construídos modelos para múltiplas saídas, e para o caso geral, representativo da atividade de múltiplas células de uma região. Este último é de especial interesse, uma vez que sugere 
uma estrutura linear para representar o sinal extracelular como uma mistura de sinais de diversas células.

A validação dessa proposta é feita no Capítulo 5. Esta tarefa inicia-se com o entendimento do sinal experimental utilizado, de forma a aplicar transformações que permitiram torná-lo mais apropriado ao processo de modelagem. As técnicas de estimação de parâmetros foram então aplicadas com sucesso, seguindo-se da validação do modelo por meio da comparação das saídas de cada subsistema com os seus respectivos sinais de referência.

O processo de validação é feito inicialmente para um disparo isolado do neurônio. Replicando o mesmo processo para uma sequência de disparos, foi possível visualizar a variação dos coeficientes ao longo do tempo, e compreendê-los como valores estatísticos que representam o comportamento altamente dinâmico de um neurônio. Esta interpretação é também exercitada com a aplicação de filtros adaptativos, que ao longo da sequência de amostras atualizam automaticamente os coeficientes, mantendo a capacidade de reproduzir o sinal com precisão. Apesar de nesse caso ter sido empregado um algoritmo supervisionado, o resultado obtido abre a perspectiva de investigar técnicas cegas que operem sobre a estrutura de filtros lineares que compõem o modelo.

O Capítulo 6 busca algumas alternativas para a tarefa de construir um sistema que realize a operação inversa à do modelo, transformando uma mistura de spikes extracelulares em sequências de impulsos separadas para cada célula. Aqui a grande motivação foi buscar uma solução que eventualmente contribua para o problema do spike sorting. As sugestões de tratamento para este problema baseiam-se no resultado positivo do modelo direto, e puderam ser exercitadas para alguns casos restritos. No entanto, devido às limitações de dados existentes e às características do sinal neuronal, muito ainda permanece em aberto para ser investigado com relação a este problema.

O trabalho como um todo apresenta algumas importantes conclusões gerais que devem ser ressaltadas. Em primeiro lugar, foi possível concluir que o sinal intracelular possui predominantemente características de um sistema autoregressivo, ao passo que o sinal extracelular possui características de um sistema média-móvel. Essa distinção surge como uma consequência natural do processo de modelagem empregado, e reflete indiretamente os fenômenos envolvidos em cada etapa de geração e propagação do sinal. Também importante é o fato de que uma mistura extracelular de spikes possa ser representada de forma aproximada por um sistema matricial $\mathbf{H}(z)$ cujos elementos são funções racionais, formando um sistema MIMO. O conhecimento da estrutura dessa matriz de sistema abre caminho para desenvolvimentos interessantes tanto do ponto de vista de modelagem de 
redes neuronais quanto no problema de identificação de spikes.

Esse resultado foi importante para iniciar a formulação do modelo inverso e investigar a aplicação de técnicas apropriadas. Mostrou-se que este problema é análogo ao spike sorting, e resume-se a encontrar os instantes em que ocorrem os impulsos unitários geradores dos disparos da célula. Nota-se que todo esse desenvolvimento é feito sem a necessidade de levar em consideração qualquer fator bioquímico da célula, baseando-se nas premissas estabelecidas pelo modelo direto. De forma mais pragmática, simulações com o modelo como gerador de misturas de spikes para modelagem inversa adaptativa mostraram resultados interessantes, sugerindo maior investigação para aplicações próximas de cenários reais.

\subsection{Trabalhos futuros}

Considerando os resultados obtidos com este trabalho, podemos vislumbrar algumas opções a serem investigadas para dar continuidade ao tema:

i Aplicações alternativas da parametrização. O trabalho pode ser aprofundado no sentido de explorar os resultados obtidos para outras aplicações que possam desfrutar da parametrização do sinal neuronal por meio dos coeficientes dos filtros lineares, além do caso aqui discutido de separação dos spikes. Além disso, a validação apresentada baseou-se exclusivamente em dados de uma mesma região cerebral, constituída por células neuronal com características próprias. Sabe-se no entanto, que neurônios apresentam-se em uma grande variedade de formas, de modo que o processo eventualmente pode apresentar resultados diferentes em outras regiões cerebrais ou outras condições de aquisição do sinal neuronal. Uma investigação alternativa pode considerar por exemplo os sinais de neurônios motores, ou sensoriais.

\section{ii Técnicas adaptativas não supervisionadas e que suportem o tipo de ruído} encontrado nos sinais observados. Idealmente, o processo de adaptação utilizado deverá ser capaz de funcionar sem um sinal de treinamento, o que torna a técnica útil para casos reais de separação de spikes. No entanto, os métodos mais comuns de equalização cega não necessariamente se aplicam neste caso. As características estatísticas do sinal neuronal são diferentes das encontradas em sinais de comunicações. Dessa forma, existe a necessidade de se entender quais as condições necessárias para que uma solução adaptativa cega seja viável e adaptar as técnicas mais adequadas a esse caso. Um exemplo pode ser encontrado em Mboup e Miranda 
(2002). Esse ponto se aplica tanto a modelagem direta quanto a modelagem inversa discutidas neste trabalho.

iii Métodos de separação de fontes mais adequados para sinais neuronais. Algumas propostas utilizando técnicas de separação de fontes podem ser encontradas na literatura, como por exemplo em Mamlouk et al. (2005). A formulação apresentada neste trabalho, no entanto, permite testar aplicações de ICA em conjunto com demais abordagens que explorem a estrutura do modelo, de forma a obter uma matriz mais bem condicionada para a mistura resultante. Um processo de equalização cega que permita remover apenas algumas fontes da mistura, por exemplo, pode ser complementado com uma solução via separação de fontes para separar os sinais restantes.

iv Outras técnicas que possam auxiliar o processamento do sistema inverso. Além das abordagens de modelagem inversa (equalização multiusuário) e de separação de fontes, podem ser pesquisadas outras técnicas alternativas que tirem proveito do modelo aqui desenvolvido. Como vimos, a estrutura do modelo possui a forma de um canal de comunicações do tipo MIMO, que por sua vez é a abstração de um cenário em que um arranjo de antenas recebe sinais de diferentes transmissores simultaneamente. Neste sentido, além das técnicas já citadas, podemos sugerir por exemplo o estudo de métodos baseados em ângulo de chegada dos sinais. Alternativas deste tipo devem ser investigadas para servir como parte de uma possível solução para o modelo inverso. 


\section{Referências Bibliográficas}

AGUIRRE, L. A. Introdução à identificação de sistemas: técnicas lineares e não-lineares aplicadas a sistemas reais. 3. ed. Belo Horizonte: Editora UFMG, 2007.

AIHARA, K.; TAKABE, T.; TOYODA, M. Chaotic neural networks. Physics Letters A, v. 144, n. 6-7, p. 333-340, Mar. 1990.

ASSIS, A. de R. Análise da estacionariedade e gaussianidade da atividade elétrica neural, do ruído biológico e do ruído de instrumentação. Dissertação (Mestrado) - Universidade Federal de Uberlândia, Uberlândia, MG, 2011.

ASTER, R. C.; BORCHERS, B.; THURBER, C. H. Parameter estimation and inverse problems. 2nd. ed. Boston, MA: Academic Press, 2012.

ATTUX, R. et al. On the relationships between blind equalization and blind source separation - part I: foundations. Journal of Communication and Information Systems, v. 22 , n. 1, p. $41-52,2007$.

ATTUX, R. et al. On the relationships between blind equalization and blind source separation - part II: relationships. Journal of Communication and Information Systems, v. 22 , n. 1, p. 53-61, 2007.

BEAR, M. F.; CONNORS, B. W.; PARADISO, M. A. Neuroscience: exploring the brain. 3rd. ed. Philadelphia, PA: Lippincott Williams \& Wilkins, 2006.

BEHESHTI, S.; DAHLEH, M. A. LTI systems, additive noise, and order estimation. In: 42nd IEEE Conference on Decision and Control, 2003. [S.l.: s.n.], 2003. v. 6, p. 6491-6496.

BELLANGER, M. Analyse des signaux et filtrage numérique adaptatif. Paris: Masson, 1989.

BOX, G. E. P.; JENKINS, G. M.; REINSEL, G. C. Time series analysis: forecasting and control. 4th. ed. Hoboken, NJ: John Wiley \& Sons, 2008.

COLE, K. S. Dynamic electrical characteristics of the squid axon membrane. Archives des Sciences Physiologiques, n. 3, p. 253-258, 1949.

COMON, P.; JUTTEN, C. (Ed.). Handbook of blind source separation: independent component analysis and applications. Oxford: Academic Press, 2010.

DAYAN, P.; ABBOTT, L. F. Theoretical neuroscience: computational and mathematical modeling of neural systems. Cambridge, MA: MIT Press, 2005.

FITZHUGH, R. Impulses and physiological states in theoretical models of nerve membrane. Biophysical Journal, v. 1, n. 5, p. 445-466, July 1961. 
GAO, D. et al. Performance evaluation of multilayer perceptrons for discriminating and quantifying multiple kinds of odors with an electronic nose. Neural Networks, v. 33, p. 204-215, Sept. 2012.

GIBSON, S.; JUDY, J. W.; MARKOVIC, D. Comparison of spike-sorting algorithms for future hardware implementation. In: Annual International Conference of the IEEE Engineering in Medicine and Biology Society. [S.l.: s.n.], 2008. p. 5015-5020.

GIBSON, S.; JUDY, J. W.; MARKOVIC, D. Technology-aware algorithm design for neural spike detection, feature extraction, and dimensionality reduction. IEEE Transactions on Neural Systems and Rehabilitation Engineering, v. 18, n. 5, p. 469-478, Oct. 2010.

GIBSON, S.; JUDY, J. W.; MARKOVIC, D. Spike sorting: the first step in decoding the brain. IEEE Signal Processing Magazine, v. 29, n. 1, p. 124-143, Jan. 2012.

GIRARDI-SCHAPPO, M.; TRAGTENBERG, M. H. R.; KINOUCHI, O. A brief history of excitable map-based neurons and neural networks. Journal of Neuroscience Methods, v. 220, n. 2, p. 116-130, Nov. 2013.

GOLD, C.; HENZE, D. A.; KOCH, C. Using extracellular action potential recordings to constrain compartmental models. Journal of Computational Neuroscience, v. 23, n. 1, p. 39-58, Aug. 2007.

GOLD, C. et al. On the origin of the extracellular action potential waveform: a modeling study. Journal of Neurophysiology, v. 95, n. 5, p. 3113-3128, May 2006.

HAYES, M. H. Statistical digital signal processing and modeling. New York, NY: John Wiley \& Sons, 1996.

HAYKIN, S. Adaptive Filter Theory. 3rd. ed. Upper Saddle River, NJ: Prentice Hall, 1996.

HAYKIN, S. Neural networks: a comprehensive foundation. Upper Saddle River, NJ: Prentice Hall, 2009.

HAYKIN, S.; WIDROW, B. Least-Mean-Square Adaptive Filters. Hoboken, NJ: Wiley-Interscience, 2003.

HENZE, D. A. et al. Intracellular features predicted by extracellular recordings in the hippocampus in vivo. Journal of Neurophysiology, v. 84, n. 1, p. 390-400, July 2000.

HENZE, D. A. et al. Simultaneous intracellular and extracellular recordings from hippocampus region CA1 of anesthetized rats. CRCNS.org, 2000. Disponível em: <http://dx.doi.org/10.6080/K02Z13FP>. Acesso em: 10 jun. 2014.

HINDMARSH, J. L.; ROSE, R. M. A model of the nerve impulse using two first-order differential equations. Nature, v. 296, p. 162-164, Mar. 1982.

HINDMARSH, J. L.; ROSE, R. M. A model of neuronal bursting using three coupled first order differential equations. Proceedings of the Royal Society of London. Series B, Biological sciences, v. 221, n. 1222, p. 87-102, Mar. 1984. 
HODGKIN, A. L.; HUXLEY, A. F. Measurement of current-voltage relations in the membrane of the giant axon of Loligo. The Journal of Physiology, v. 116, n. 3, p. 424-448, Apr. 1952.

HODGKIN, A. L.; HUXLEY, A. F. A quantitative description of membrane current and its application to conduction and excitation in nerve. The Journal of Physiology, v. 117, n. 4, p. 500-544, Aug. 1952.

HSU, C. C. et al. Chaotic neuron models and their VLSI circuit implementations. IEEE Transactions on Neural Networks, v. 7, n. 6, p. 1339-1350, Nov. 1996.

HYVÄRINEN, A.; KARHUNEN, J.; OJA, E. Independent Component Analysis. [S.l.]: John Wiley \& Sons, 2001.

IBARZ, B.; CASADO, J. M.; SANJUÁN, M. A. F. Map-based models in neuronal dynamics. Physics Reports, v. 501, n. 1-2, p. 1-74, Apr. 2011.

IZHIKEVICH, E. M. Dynamical systems in neuroscience. Cambridge, MA: MIT Press, 2007.

KOCH, C.; SEGEV, I. (Ed.). Methods in neuronal modeling: from ions to networks. 2nd. ed. Cambridge, MA: MIT Press, 1998.

LEWICKI, M. S. A review of methods for spike sorting: the detection and classification of neural action potentials. Network: Computation in Neural Systems, v. 9, n. 4, p. 53-78, Nov. 1998.

LIU, Y.; WANG, D.; DING, F. Least squares based iterative algorithms for identifying Box-Jenkins models with finite measurement data. Digital Signal Processing, v. 20, n. 5, p. 1458-1467, Sept. 2010.

LJUNG, L. System identification: theory for the user. 2nd. ed. Upper Saddle River, NJ: Prentice Hall, 1999.

MADISETTI, V. The Digital Signal Processing Handbook. 2nd. ed. Boca Raton, FL: CRC Press, 2009.

MAMLOUK, A. M. et al. Unsupervised spike sorting with ICA and its evaluation using genesis simulations. Neurocomputing, v. 65-66, p. 275-282, June 2005.

MBOUP, M.; MIRANDA, M. D. A polynomial approach to the blind multichannel deconvolution problem. In: Proceedings of International Telecommunications Symposium. Natal, RN: [s.n.], 2002.

MCCULLOCH, W. S.; PITTS, W. A logical calculus of the ideas immanent in nervous activity. Bulletin of Mathematical Biology, v. 5, n. 4, p. 115-133, Dec. 1943.

MENEZES, R. A.; MONTEIRO, L. H. A. Synaptic compensation on Hopfield network: implications for memory rehabilitation. Neural Computing and Applications, v. 20, n. 5, p. 753-757, July 2011.

MESBAH, S. et al. One-dimensional map-based neuron model: a logistic modification. Chaos, Solitons $\&$ Fractals, v. 65, p. 20-29, Aug. 2014. 
MONTEIRO, L. H. A.; BUSSAB, M. A.; CHAUI-BERLINCK, J. G. Analytical results on a Wilson-Cowan neuronal network modified model. Journal of Theoretical Biology, v. 219, n. 1, p. 83-91, Nov. 2002.

MORRIS, C.; LECAR, H. Voltage oscillations in the barnacle giant muscle fiber. Biophysical Journal, v. 35, n. 1, p. 192-213, July 1981.

NAGUMO, J.; ARIMOTO, S.; YOSHISAWA, S. An active pulse transmission line simulating nerve axon. Proceedings of the IRE, v. 50, n. 10, p. 2061-2070, Oct. 1962.

NEHER, E.; SAKMANN, B.; STEINBACH, J. H. The extracellular patch clamp: A method for resolving currents through individual open channels in biological membranes. Pflügers Archiv, v. 375, n. 2, p. 219-228, 1978.

NETO, P. L. d. O. C. Estatística. São Paulo: Edgard Blücher, 1977.

NIEDERMEYER, E.; SILVA, F. Lopes da. Electroencephalography: basic principles, clinical applications, and relatedfields. 4th. ed. Baltimore: Williams \& Wilkins, 1998.

OPPENHEIM, A. V.; SCHAFER, R. W. Discrete-time signal processing. 3rd. ed. Upper Saddle River, NJ: Prentice Hall, 2009.

PALMIERI, I.; MONTEIRO, L. H. A.; MIRANDA, M. D. The transfer function of neuron spike. Neural Networks, v. 68, p. 89-95, Aug. 2015.

PROAKIS, J. G.; MANOLAKIS, D. G. Digital signal processing: principles, algorithms, and applications. 3rd. ed. Upper Saddle River, NJ: Prentice Hall, 1996.

PURVES, D. et al. Neuroscience. 5th. ed. Sunderland, MA: Sinauer Associates, 2011.

QUIROGA, R. Q.; NÁDASDY, Z.; BEN-SHAUL, Y. Unsupervised spike detection and sorting with wavelets and superparamagnetic clustering. Neural Computation, v. 16, n. 8, p. 1661-1687, Aug. 2004.

ROSENBLATT, F. Principles of neurodynamics; perceptrons and the theory of brain mechanisms. Washington, DC: Spartan Books, 1962.

RULKOV, N. F. Regularization of synchronized chaotic bursts. Physical Review Letters, v. 86, n. 1, p. 182-186, Jan. 2001.

RULKOV, N. F. Modeling of spiking-bursting neural behavior using two-dimensional map. Physical Review E, v. 65, n. 4, p. 041922, Apr. 2002.

RUTISHAUSER, U.; SCHUMAN, E. M.; MAMELAK, A. N. Online detection and sorting of extracellularly recorded action potentials in human medial temporal lobe recordings, in vivo. Journal of Neuroscience Methods, v. 154, n. 1-2, p. 204-224, June 2006.

SAYED, A. H. Adaptive Filters. Hoboken, NJ: John Wiley \& Sons, 2008.

SCHERBERGER, H.; JARVIS, M. R.; ANDERSEN, R. A. Cortical local field potential encodes movement intentions in the posterior parietal cortex. Neuron, v. 46, n. 2, p. 347-354, Apr. 2005. 
SHILNIKOV, A. L.; RULKOV, N. F. Subthreshold oscillations in a map-based neuron model. Physics Letters A, v. 328, n. 2-3, p. 177-184, June 2004.

STERRATT, D. et al. Principles of computational modelling in neuroscience. Cambridge, UK: Cambridge University Press, 2011.

STEUBER, V.; JAEGER, D. Modeling the generation of output by the cerebellar nuclei. Neural Networks, v. 47, p. 112-119, Nov. 2013.

STOICA, P.; SELÉN, Y. Model-order selection: a review of information criterion rules. IEEE Signal Processing Magazine, v. 21, n. 4, p. 36-47, July 2004.

TABAK, J.; MURPHEY, C. R.; MOORE, L. Parameter estimation methods for single neuron models. Journal of Computational Neuroscience, v. 9, n. 3, p. 215-236, Nov. 2000.

TSUMOTO, K. et al. Bifurcations in Morris-Lecar neuron model. Neurocomputing, v. 69, n. 4-6, p. 293-316, Jan. 2006.

WILLMS, A. R. et al. An improved parameter estimation method for Hodgkin-Huxley models. Journal of Computational Neuroscience, v. 6, n. 2, p. 145-168, Mar. 1999. 


\section{APÊNDICE A - Função custo para a estimação só-polo}

A solução para o problema de estimação dos coeficientes de um modelo só-polo passa por definir a função custo a partir do critério dos mínimos quadrados. Este apêndice tem como objetivo demonstrar que a função custo neste caso pode ser considerada a partir do erro de estimação progressiva do sinal a ser modelado. O resultado é especialmente útil para o desenvolvimento do método de Prony para o caso do modelo só-polo no Capítulo 3.

A partir da Equação 3.11, podemos escrever a saída de um modelo autoregressivo só-polo como sendo

$$
y(n)=g_{f} x(n)+\sum_{k=1}^{K_{i}-1} a_{k} y(n-k)
$$

em que $x(n)$ representa a entrada do sistema, $a_{k}$ os coeficientes do modelo e $y(n)$ o sinal de saída. Para que o modelo siga esta relação, vamos definir o erro de estimação como

$$
\hat{e}(n)=y(n)-\sum_{k=1}^{K_{i}-1} a_{k} y(n-k)-g_{f} x(n) .
$$

Se o sinal modelado permitir exatamente uma representação por um sistema só-polo, teremos que $\hat{e}(n)=0$, e a Relação A.1 é válida. Podemos também escrever esta equação em termos do erro de predição progressiva:

$$
\hat{e}(n)=e(n)-g_{f} x(n)
$$

sendo $e(n)$ o erro de predição progressiva, dado por:

$$
e(n)=y(n)-\sum_{k=1}^{K_{i}-1} a_{k} y(n-k) .
$$

Dessa forma, a função custo a ser minimizada em um intervalo com $N$ amostras será a 
energia do erro de estimação, dada por

$$
J=\sum_{n=0}^{N-1}|\hat{e}(n)|^{2}=\sum_{n=0}^{N-1}\left|e(n)-g_{f} x(n)\right|^{2} .
$$

Expandindo o termo da direita, temos

$$
J=\sum_{n=0}^{N-1}\left[e^{2}(n)-2 g_{f} e(n) x(n)+g_{f}^{2} x^{2}(n)\right] .
$$

O mínimo desta função em termos dos coeficientes é dado pelo ponto em que a sua derivada é zero:

$$
\begin{aligned}
\frac{\partial J}{\partial a_{k}} & =\frac{\partial}{\partial a_{k}} \sum_{n=0}^{N-1}\left[e^{2}(n)-2 g_{f} e(n) x(n)+g_{f}^{2} x^{2}(n)\right] \\
& =\frac{\partial}{\partial a_{k}} \sum_{n=0}^{N-1} e^{2}(n)-2 g_{f} \frac{\partial}{\partial a_{k}} \sum_{n=0}^{N-1} e(n) x(n)+g_{f}^{2} \frac{\partial}{\partial a_{k}} \sum_{n=0}^{N-1} x^{2}(n) .
\end{aligned}
$$

O valor da entrada não depende de nenhum coeficiente, portanto:

$$
\frac{\partial}{\partial a_{k}} \sum_{n=0}^{N-1} x^{2}(n)=0
$$

Além disso, no modelo que estamos buscando, o sinal de entrada é composto apenas por um impulso unitário aplicado no instante $n=0$. Dessa forma

$$
\frac{\partial}{\partial a_{k}} \sum_{n=0}^{N-1} e(n) x(n)=\frac{\partial}{\partial a_{k}} \sum_{n=0}^{N-1} e(n) \delta(n)=\frac{\partial y(0)}{\partial a_{k}}=0 .
$$

Portanto, minimizar o erro de estimação é equivalente a minimizar o erro de predição do sinal procurado, e podemos escolher a função de custo como sendo

$$
J=\sum_{n=0}^{N-1}|e(n)|^{2}
$$

A partir desta função, iremos encontrar os coeficientes que produzem um preditor ótimo para o sinal, e que serão portanto os mesmos coeficientes do sistema só-polo. 


\section{APÊNDICE B - Solução do problema de estimação linear}

Este apêndice tem como objetivo apresentar o desenvolvimento da solução para a estimativa de coeficientes ótimos, considerando a função custo como sendo a minimização da energia do erro. Essa solução é a base das técnicas de estimação discutidas nos Capítulos 3 e 4, e é discutida com maiores detalhes em Sayed (2008) e Haykin (1996).

Supondo um sinal desejado $d(n)$ que se queira modelar, a partir de uma entrada $u(n)$ utilizando um filtro transversal com $K$ coeficientes. O erro de estimação será dado por

$$
\begin{aligned}
e(n) & =d(n)-\hat{d}(n) \\
& =d(n)-\mathbf{u}^{T}(n) \mathbf{w}
\end{aligned}
$$

sendo $\mathbf{u}(n)$ o vetor com $K$ amostras do sinal $u(n)$ defasadas no tempo, e w o vetor de coeficientes procurado. A função custo a ser minimizada será dada por:

$$
J=\sum_{n=0}^{N-1}|e(n)|^{2} .
$$

Derivando em relação ao vetor de coeficientes podemos encontrar o ponto de mínimo da função, temos então

$$
\begin{aligned}
\frac{\partial J}{\partial \mathbf{a}} & =\frac{\partial}{\partial \mathbf{w}} \sum_{n=0}^{N-1}\left[d(n)-\mathbf{u}^{T}(n) \mathbf{w}\right]^{2}=\mathbf{0} \\
& =2 \sum_{n=0}^{N-1}\left[d(n)-\mathbf{u}^{T}(n) \mathbf{w}\right] \mathbf{u}(n) .
\end{aligned}
$$

Logo,

$$
\sum_{n=0}^{N-1}\left[\mathbf{u}(n) \mathbf{u}^{T}(n)\right] \mathbf{w}=\sum_{n=0}^{N-1} d(n) \mathbf{u}(n) .
$$

Então, podemos escrever

$$
\mathbf{R}_{u u} \mathbf{w}=\mathbf{p}_{u d}
$$


o que nos leva a solução das equações normais para o problema de estimação:

$$
\mathbf{w}=\mathbf{R}_{u u}^{-1} \mathbf{p}_{u d}
$$

A matriz $\mathbf{R}$ é a matriz de autocorrelação do sinal $u(n)$ e o vetor $\mathbf{p}$ é o vetor de autocorrelação cruzada com o sinal desejado $d(n)$.

No caso da predição linear de um sinal $y(n)$, basta substituir na relação encontrada:

$$
\begin{aligned}
\mathbf{u}(n) & =\mathbf{y}(n-1) \\
d(n) & =y(n) \\
\mathbf{a} & =\mathbf{w} .
\end{aligned}
$$

De forma que a solução será dada por

$$
\mathbf{a}=\mathbf{R}_{y y}^{-1} \mathbf{r}_{y y}
$$

seguindo a mesma estrutura da Equação B.8, com $\mathbf{r}_{y y}$ sendo o vetor de correlação cruzada do vetor $\mathbf{y}(n-1)$ com o sinal $y(n)$. 


\section{APÊNDICE C - Algoritmo RLS (Recursive Least Squares)}

O algoritmo RLS é utilizado no Capítulo 5 para a modelagem dinâmica adaptativa do sinal neuronal, onde apresentou resultados positivos. Detalhes sobre o funcionamento e formulação teórica deste algoritmo podem ser encontrados em Haykin (1996).

Inicialização:

$$
\begin{aligned}
& \mathbf{P}(0)=\delta^{-1} \mathbf{I} \\
& \mathbf{w}(0)=\mathbf{0} \\
& u(n)=0 \quad \forall n<0
\end{aligned}
$$

Para cada instante de tempo $n=0,1, \ldots, N-1$, calcular:

$$
\begin{aligned}
\mathbf{k}_{t}(n) & =\mathbf{P}(n) \mathbf{u}(n) \\
g_{t}(n) & =\left[\lambda+\mathbf{u}^{T}(n) \mathbf{k}_{t}(n)\right]^{-1} \\
\mathbf{k}(n) & =g_{t}(n) \mathbf{k}_{t}(n) \\
y(n) & =\mathbf{u}^{T}(n) \mathbf{w}(n) \\
e(n) & =d(n)-y(n) ; \\
\mathbf{w}(n+1) & =\mathbf{w}(n)+e(n) \mathbf{k}(n) ; \\
\mathbf{P}(n+1) & =\lambda^{-1}\left[\mathbf{P}(n)-g_{t}(n) \mathbf{k}_{t}(n) \mathbf{k}_{t}(n)^{T}\right]
\end{aligned}
$$

Os valores de $y(n), e(n)$ e $\mathbf{w}(n)$ representam a saída do filtro, o erro de estimação, e o vetor de coeficientes, respectivamente. $\mathrm{O}$ vetor $\mathbf{u}(n)$ representa o vetor contendo as $M+1$ amostras do sinal de entrada atrasadas no tempo, sendo $M$ a ordem do filtro. A resposta desejada é representada por $d(n)$. 


\section{APÊNDICE D - Algoritmo NLMS (Normalized Least Mean Squares)}

Este algoritmo foi empregado com sucesso nas simulações da configuração de modelagem inversa apresentadas no Capítulo 6. O NLMS é um algoritmo bastante utilizado em filtragem adaptativa, e discutido com maior profundidade em Sayed (2008).

Inicialização:

$$
\begin{aligned}
& \mathbf{w}(0)=\mathbf{0} \\
& u(n)=0 \quad \forall n<0
\end{aligned}
$$

Para cada instante de tempo $n=0,1, \ldots, N-1$, calcular:

$$
\begin{aligned}
\mathbf{u}(n) & =\left[\begin{array}{llll}
u(n) & u(n-1) & \ldots & u(n-M+1)
\end{array}\right]^{T} \\
y(n) & =\mathbf{u}^{T}(n) \mathbf{w}(n) \\
e(n) & =d(n)-y(n) \\
\mathbf{w}(n+1) & =\mathbf{w}(n)+\mu e(n) \mathbf{u}(n) /\left(\delta+\mathbf{u}^{T} \mathbf{u}\right)
\end{aligned}
$$

Os valores de $y(n), e(n)$ e $\mathbf{w}(n)$ representam a saída do filtro, o erro de estimação, e o vetor de coeficientes, respectivamente. $\mathrm{O}$ vetor $\mathbf{u}(n)$ representa o vetor contendo as $M+1$ amostras do sinal de entrada atrasadas no tempo, sendo $M$ a ordem do filtro. A resposta desejada é representada por $d(n)$. Os parâmetros específicos do algoritmo são $\mu$, passo de adaptação, e $\delta$, um valor suficientemente pequeno para evitar divisão por zero quando a entrada for nula. 